\title{
Growth equilibrium modeling of urban sprawl on agricultural lands in West Virginia
}

Yohannes G. Hailu

West Virginia University

Follow this and additional works at: https://researchrepository.wvu.edu/etd

\section{Recommended Citation}

Hailu, Yohannes G., "Growth equilibrium modeling of urban sprawl on agricultural lands in West Virginia" (2002). Graduate Theses, Dissertations, and Problem Reports. 1547.

https://researchrepository.wvu.edu/etd/1547

This Thesis is protected by copyright and/or related rights. It has been brought to you by the The Research Repository @ WVU with permission from the rights-holder(s). You are free to use this Thesis in any way that is permitted by the copyright and related rights legislation that applies to your use. For other uses you must obtain permission from the rights-holder(s) directly, unless additional rights are indicated by a Creative Commons license in the record and/ or on the work itself. This Thesis has been accepted for inclusion in WVU Graduate Theses, Dissertations, and Problem Reports collection by an authorized administrator of The Research Repository @ WVU. For more information, please contact researchrepository@mail.wvu.edu. 


\title{
Growth Equilibrium Modeling of Urban Sprawl on Agricultural Lands in West Virginia
}

\author{
Yohannes G. Hailu
}

Thesis submitted to the

College of Agriculture, Forestry, and Consumer Sciences

at West Virginia University

in partial fulfillment of the requirements

for the degree of

\section{Master of Science}

in

Agricultural and Resource Economics

Randall S. Rosenberger, Ph.D., Chair

Tesfa G. Gebremedhin, Ph.D.

Timothy T. Phipps, Ph.D.

Department of Agricultural and Resource Economics

Morgantown, West Virginia

2002

Key words: Growth Equilibrium, Model, Land Use, Agricultural Land, Urban Fringe, Land Conversion, Development, Employment, Population.

Copyright 2002 Yohannes G. Hailu 


\title{
ABSTRACT \\ Growth Equilibrium Modeling of Urban Sprawl on Agricultural Lands in West Virginia
}

\author{
Yohannes G. Hailu
}

With dynamic economic and social changes, increasing pressure is exerted on natural resources management. Agricultural land resources particularly face growing pressure of conversion to non-agricultural uses from population and development demands for land. The continual conversion of agricultural land may have implications in terms of the loss of prime farmland, irreversible landscape changes, deteriorating environmental quality, and interference with rural lifestyles. This study models urban sprawl on agricultural land in a growth equilibrium modeling approach where the population-employment simultaneous equations system is estimated using two-stages-least-squares while changes in agricultural land is estimated using OLS on West Virginia data. Results of the study indicate that population and employment growth induce reallocation of agricultural lands, with population accounting for a significant pressure on agricultural land conversion. Poor agricultural performance and urban adjacency significantly induces conversion and facilitates sprawl at urban fringes. Results also indicate that Federal and NGOs land conservation programs significantly reduce changes in agricultural land density. 
With great honor to my role model Gebremeskel Gebremariam Habteyonas ... 


\section{ACKNOWLEDGEMENT}

This research work would have never been highly enhanced if it were not for the assistance and encouragement of people who vested their time and effort for its completion.

I would like first to extend my sincere appreciation and recognition to my chair advisor, Randall S. Rosenberger (Ph.D.), for his remarkable guidance, vital criticism, sheer professionalism, intellectual ideas, painstaking and critical review, and for creating a warm and friendly working atmosphere. I am also indebted for his effort to expose me to the professional world of research and excellence.

I am also grateful to my committee members, Tesfa G. Gebremedhin (Ph.D.) and Timothy T. Phipps (Ph.D.), for their critical comments, intellectual discussions, and for creating a friendly working atmosphere. I am also indebted for their encouragement and professional guidance that assisted me in staying throughout the program.

I would like also to extend my appreciation to colleagues and friends for their suggestions and advices that contributed to the improvement of the research work.

I thank you all.

The Researcher. 


\section{TABLE OF CONTENTS}

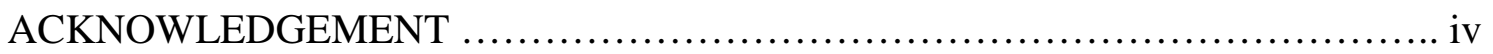

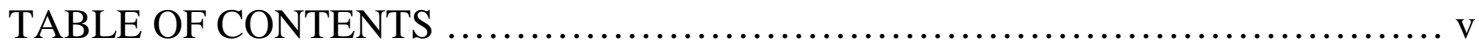

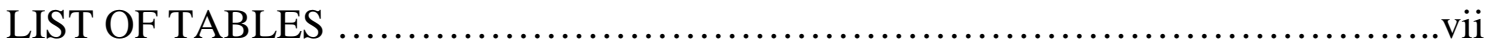

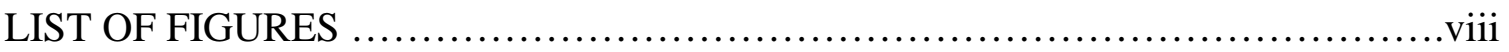

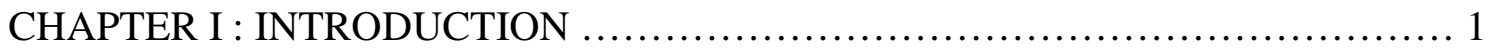

1.1. Problem Statement ..............................................

1.2. General Review of Previous Works .............................. 9

1.3. Objective of the Study ........................................11

1.4. Methods of Analysis ..........................................11

1.5. Organization of the Study .................................... 12

CHAPTER II: ECONOMIC THEORY OF LAND RESOURCE ALLOCATION, USE, AND CONVERSION .....................................

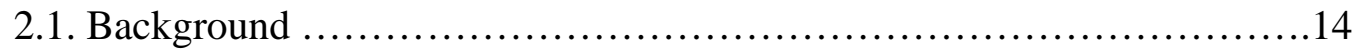

2.2. General Review of Early Land Rent, Use, and Allocation

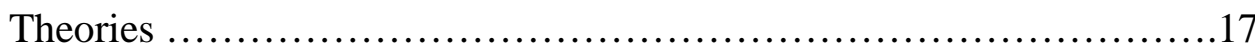

2.3. Development of Early Bid-Rent Functions and Land Allocation .........21

2.4. Economics of Land Use, Allocation, and Conversion ..................25

2.5. Mathematical Analysis of Land Use Decisions and Allocation

in a Microeconomics Framework ....................................31

2.5.1. Mathematical Consideration of Land-Use and

Location Decisions by Businesses ......................32

2.5.2. Mathematical Consideration of Land-Use and

Location Decisions for Personal Consumption

Purposes (Consumers) ................................ 38 


\section{CHAPTER III: MODELING AGRICULTURAL LAND CONVERSION}

IN A REGIONAL GROWTH FRAMEWORK ....................45

3.1. General Modeling Overview ....................................45

3.2. Empirical Model ................................................ 51

3.3. Sources of Data and Statistical Summary of Variables ...................61

CHAPTER IV: EMPIRICAL RESULTS AND ANALYSIS ......................67

4.1. Empirical Results Presentation ....................................67

4.2. Analysis of Results .......................................... 73

4.2.1. Analysis of the Population Density Model ...................74

4.2.2. Analysis of the Employment Density Model .................83

4.2.3. Analysis of the Agricultural Land Density Model .............90

CHAPTER V: SUMMARY AND CONCLUSION ..............................97

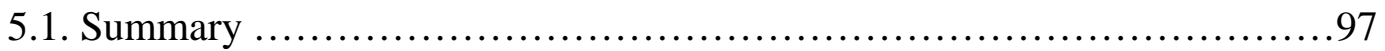

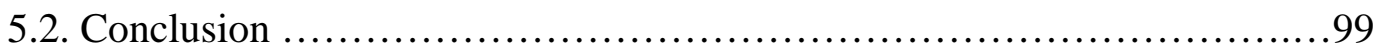

5.3. Policy Recommendations .................................... 102

5.4. Limitations of the Study and Areas of Further Study ..................... 104

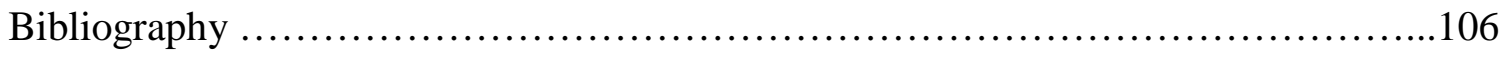




\section{LIST OF TABLES}

Table 1: Definition of Specified Variables

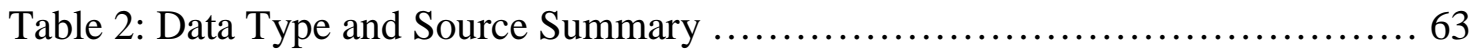

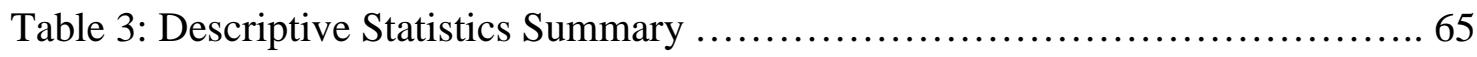

Table 4. Empirical Result for the Population Density Structural Model (1990-1999) .............................................. 71

Table 5. Empirical Result for the Employment Density Structural

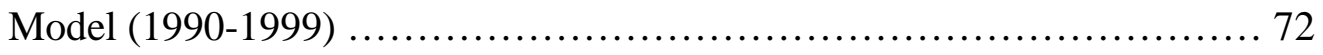

Table 6. Empirical Result for the Agricultural Land Density Change

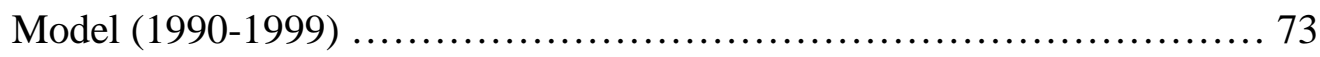




\section{LIST OF FIGURES}

Fig. 1. US Population Growth (in millions): 1900-2050 .............................

Fig. 2. Farm Land in US: $1940-1992$.......................................6

Fig. 3. Land Use Changes in United States: 1982 - 1992 .........................

Fig. 4. Bid Rent Function for Land situated at a certain distance ....................23

Fig 5. Bid Rent functions of Three Agricultural Activities and Land

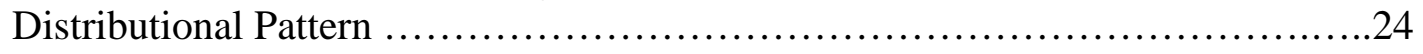

Fig 6. Bid Rent Functions of Three Sectors and Resulting Land

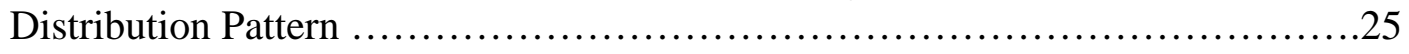

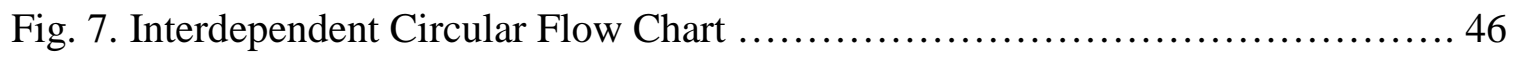

Fig. 8. Reduced Form Specialized Two Sectors Circular Flow Chart ................ 48

Fig. 9. New Acres of Developed Land in Non-Metropolitan Areas,

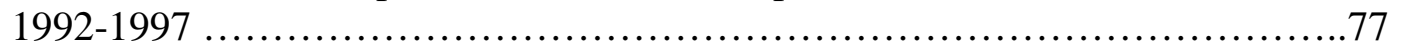

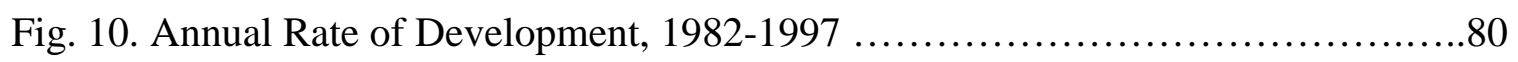

Fig. 11. Percentage Change in Population: 1990 - 1999 ............................81

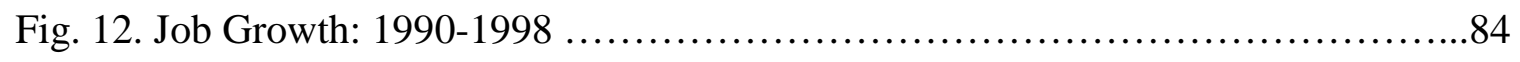

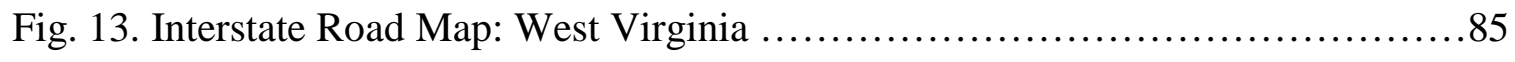

Fig. 14. Crop Land Converted to Developed Land by NRCS Region,

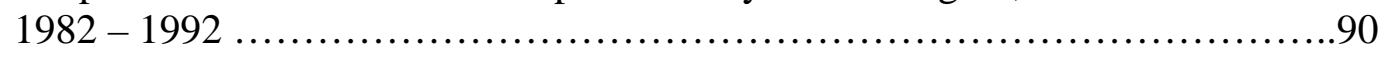

Fig. 15. Acres of Non-Federal Developed Land, 1997 ..............................

Fig. 16. Population Changes: 1990-2000, West Virginia ..........................93 


\section{CHAPTER I}

\section{INTRODUCTION}

\subsection{PROBLEM STATEMENT}

Throughout history, there has been an intricate relationship between mankind, natural resources and the environment. In a prolonged timeframe, this intricate relationship has been changing as a response to varying natural, social, political, technological and economic forces.

In the past centuries, total world population was relatively small and consequent consumption pressure on resources was limited. The archaic technological know-how on resource control and use has limited pressure on resources. This particularly contributed to maintaining a natural balance between ecosystems and human populations around the world.

Different sources indicate that world population was about 190 million by 200AD, about 360 million by 1300AD, 813 million by 1800 AD, 2.07 billion by 1930 AD, 4.456 billion by $1980 \mathrm{AD}$, and about 6.08 billion by $2000 \mathrm{AD}^{1}$. This global trend in population growth has resulted in increasing pressures on resources, which demanded critical emphasis on the allocation of the scarce global natural resources.

Recent exponential population growth and dynamically changing economic activities over space and time resulted in concern about the nature and health of our relationship with the natural world. Heated debates on issues of land use systems, land degradation, environmental pollution, energy supply, wildlife extinction, and reduced natural resource stocks on the one hand and land use planning, environmental management, alternative renewable energy planning, wildlife protection, and natural resource management policy issues on the other are all indications of the urgency of reconsideration on (and

\footnotetext{
${ }^{1}$ For more detail refer http://futuresedge.org/World_Population_Issues/Historical_World_Population.html.
} 
precautious approaches to) the relationship between economic agents and natural resources. Of special importance is human dependence on natural systems for the provision of food and fiber.

One of the natural resources facing demographic, economic and technological pressures is agricultural land. Consequently, today there are growing concerns and issues around land use systems and preservation. Historically, land has been a critical input defining economic and social life in almost all parts of the world. Its significance ranged from defining community identity and political territory to the very basic provision of a way of life for agrarian societies and transformed economies.

This study focuses on conversion of agricultural land to development and urban uses. Agricultural land has faced pressures from two dimensions, from population pressure and alternative economic activities competing for land and from growing global demand to meet food and fiber requirements. Although the growing global demand for food and fiber has been met through improved agricultural technologies and agro-genetics, in many instances, the competition for land between different economic activities has resulted in conflict of interest and consequent government intervention through land use policies and different incentive schemes.

Currently, the conversion of agricultural land for urban and development uses worldwide is an important issue. The World Resource Institute, in its 1996-97 land conversion assessment, reported that "although the amount of land converted to urban uses may be small globally, a trend is emerging in both developed and developing countries; cities from Los Angeles to Jakarta, Indonesia, are rapidly expanding outward, consuming ever greater quantities of land. This urban sprawl, characterized by low-density development and vacant and derelict land, leads to the wasteful use of land resources, higher infrastructure costs, and excessive energy consumption and air pollution because of the greater use of motorized transport.",2

\footnotetext{
${ }^{2}$ For detailed account of the issue refer http://www.wri.org/wri/wr-96-97/ee txt2.html.
} 
In the policy arena, the United Nations is concerned about the land conversion trend and its implication to global food security and sustainable development. In its Millennium Summit under the name New Century, New Challenges, the UN set policy and implementation priorities for this century. The UN's concern about land conversion issues is evident in its policy statement "Defending the soil: the best hope of feeding a growing world population from shrinking agricultural land may lie in biotechnology, but its safety and environmental impact are hotly debated."3

Similarly, population growth and a changing economy away from agricultural and manufacturing to services and technology in the United States has created pressure on agricultural land through development demands and competition for other land uses. Trends in land management issues indicate that there is growing concern about the conversion of agricultural lands to other uses as cities and towns expand and demand more land.

Estimates of population growth in the US indicate that starting with WWII, population pressure has intensified and may continue to grow at a steady pace.

Fig. 1. US Population Growth (in millions): 1900-2050

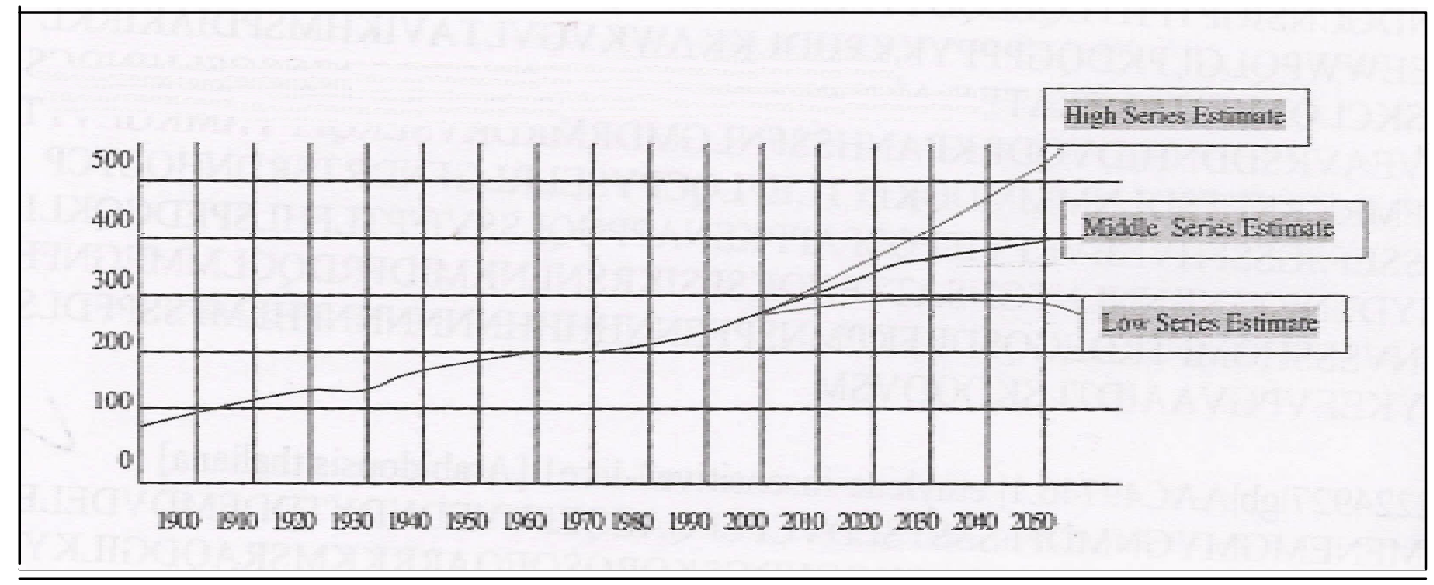

Source: U.S. Bureau of the Census, Current Population Reports, adopted in Diamond, Henry L. \& Patrick F. Noonan, (forwarded by Laurance S. Rockefeller), Land Use in America, 1996.p. 86.

\footnotetext{
${ }^{3}$ Refer UN millennium challenges and policies at $h \mathrm{ttp}: / / \mathrm{www}$.un.org/millennium/sg/report/summ.htm.
} 
Figure 1 shows that US population has recently been growing at relatively high rates. The impact on agricultural land has come, among other factors, through increased demand for housing and development. With growing income and purchasing power in the US, a significant proportion of farmland has been converted to urban, housing, recreational, and other development uses. In fact, the World Resource Institute reports, "urban population growth [in US] has slowed to 1.3 percent per year, yet urban development continues to encroach on surrounding lands as residents abandon inner cities and move to the suburbs. The total amount of land dedicated to urban uses increased from 21 million hectares in 1982 to 26 million hectares in 1992. In one decade, 2,085,945 hectares of forestland, 1,525,314 hectares of cultivated cropland, 943,598 hectares of pastureland, and 774,029 hectares of rangeland were converted to urban uses."4

Rapid population growth in cities and towns can have a dual effect on agriculture. It can lead to urban encroachment on agricultural lands and facilitate the conversion process as well as result in increased demand for food and fiber. Even though technology in agricultural production can play a big role in increasing output, this may not mean that the United States could not become a deficit producer of some major crops in the future. Because of constantly increasing prices and shortages of food across the world, some observers expect that the continued loss of farmland to urban uses may interfere with the US's long-run ability to produce food and fiber for its increasing population and for the rest of the world (Vesterby, Heimlich and Krupa, 1994; Plaut, 1980).

Farmland has been continually declining because of complex economic interactions and demographic factors. Figure 2 shows the trend in farmland in the US, which indicates the state of the problem.

\footnotetext{
${ }^{4}$ Refer detailed report at http://www.wri.org/wri/wr-96-97/ee txt2.html.
} 


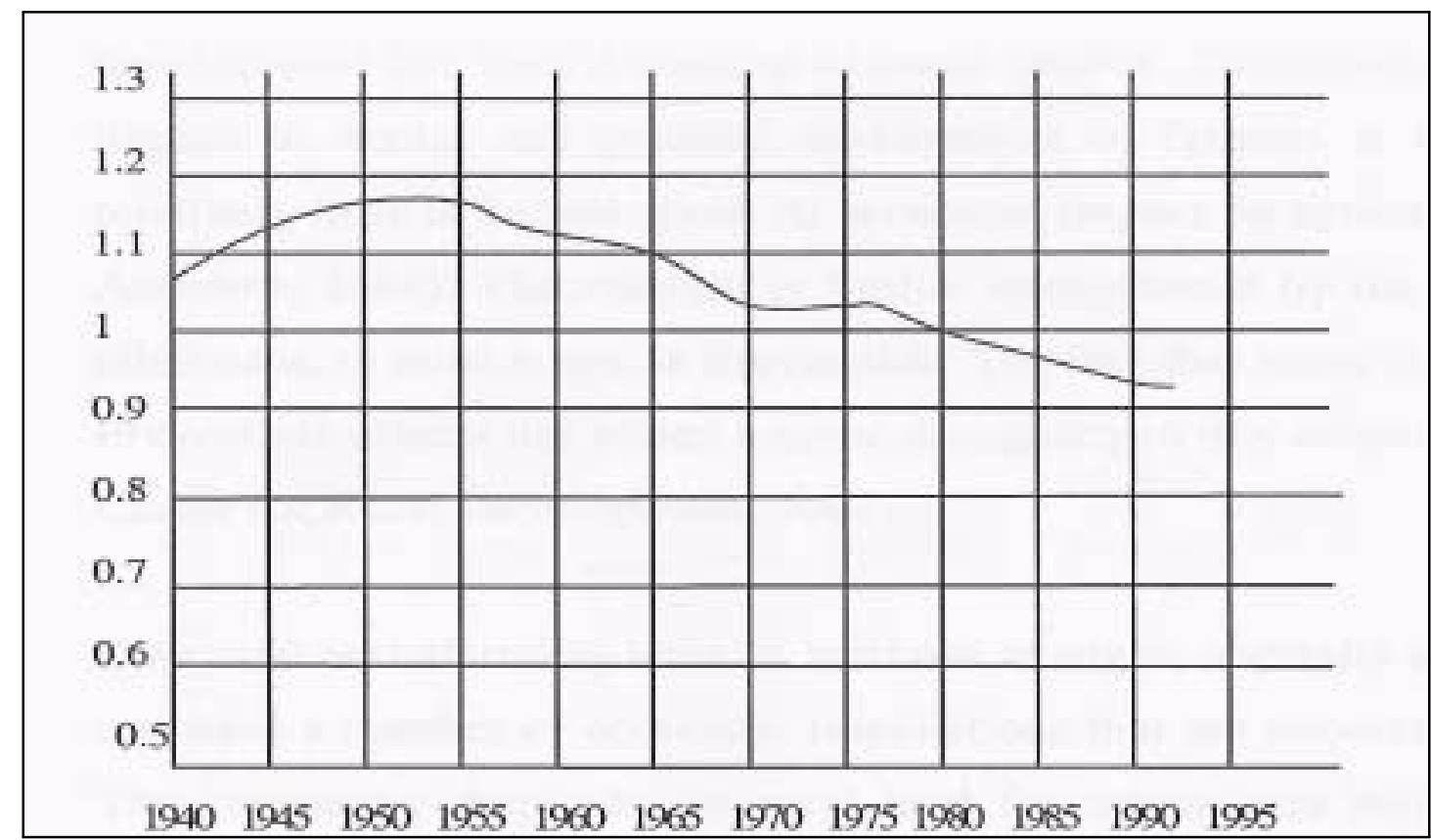

Source: U.S. Bureau of the Census, Census of Agriculture, adopted in Diamond, Henry L. \& Patrick F.

Noonan, (forwarded by Laurance S. Rockefeller), Land Use in America, 1996. p. 86.

Population and economic well being in the US has dramatically changed since WWII. This created pressures on farmland starting in the mid-1950s as indicated by figure 2 .

USDA's report in 1990 concerning the extent of agricultural land conversion indicates that, "in the United States, at least, productive agricultural land surrounding cities, which they expand into greater than $60 \%$ of the land removed from agriculture comes from cropland." It adds further emphasis by stating that "... and $90 \%$ of the croplands likely to be converted to other uses in 50 years is expected to be prime farmland." (USDA, 1990). The Natural Resource Conservation Service also reports that for the 5-year periods of 1982-87, 1987-92, and 1992-97, prime farmland conversion accounted for about 30 percent of the newly developed land (NRCS, 2001).

The impact of this land conversion trend away from agricultural production to development has been a focus of research. Suburbanization has had a significant impact on the social and political environments of farmers at the urban fringe; however, 
relatively little is known about its economic impact on agriculture (Lopez, Adelaja, and Andrews, 1988). The concern is further strengthened by the fact that land converted to other uses, in most cases, is irreversible. The fact that many current land use choices have irreversible effects has added a sense of urgency to this subject (The North East Regional Center for Rural Development, 2002).

Continual and alarming rates of land use changes, especially away from agricultural uses can have a number of economic implications that are important for policy consideration. The competing demands for rural land for urban uses lead to a gradual diminishing supply of prime agricultural land. As a result, land brought into production to compensate for farmland losses is often of lower quality, and is marginal in agricultural productivity (Ramsey and Corty, 1982).

\section{Fig. 3. Land Use Changes in United States: 1982 - 1992}

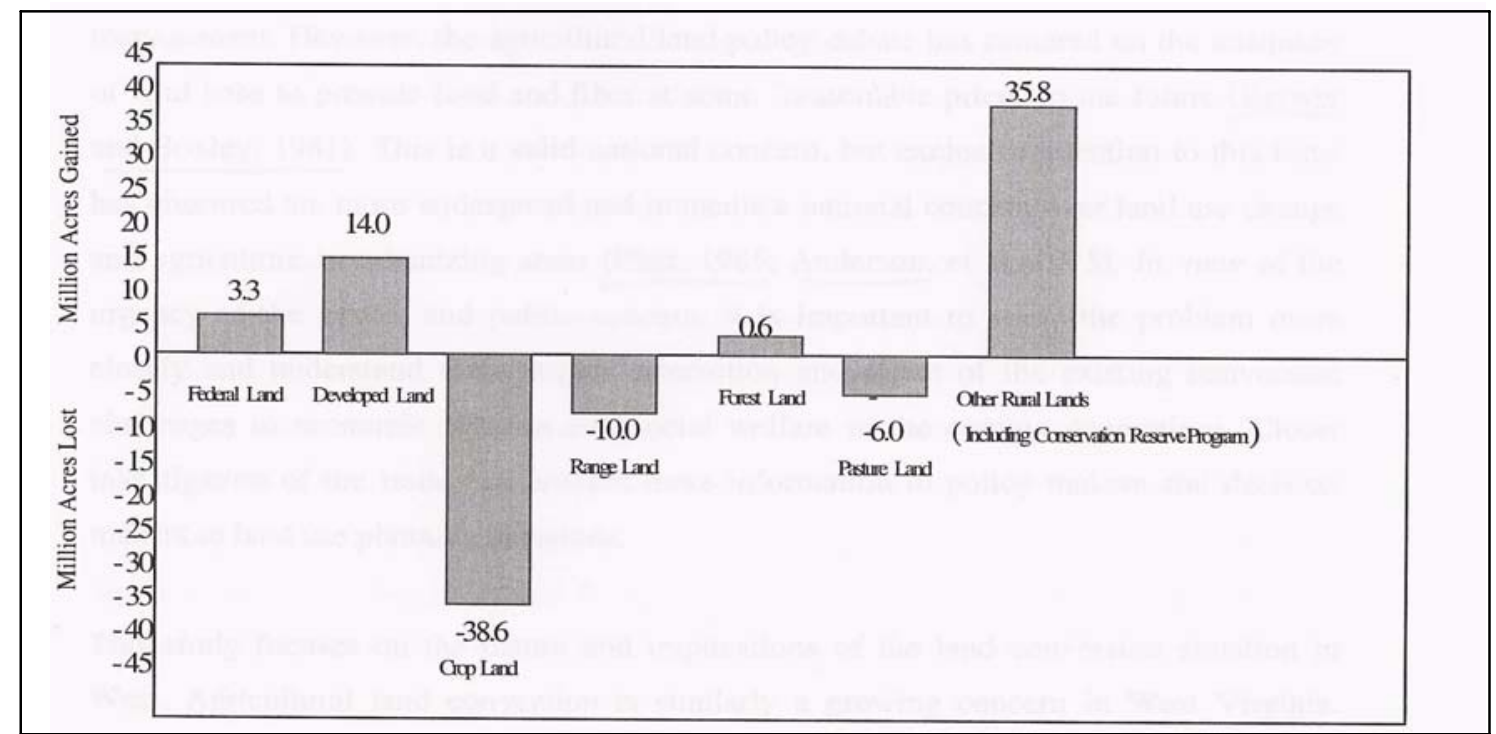

Source: U.S. Soil Conservation Service, National Resource Inventory, 1992,, adopted in Diamond, Henry L. \& Patrick F. Noonan, (forwarded by LauranceS. Rockefeller), Land Use in America, 1996.p. 86.

The National Resource Inventory similarly reports particular concern on the effect of agricultural land conversion on croplands. Figure 3 shows the change in land use in one decade (1980-1990) in the United States and shows the relative change in agricultural land use in the stated period. 
Although agricultural land preservation policies increased the total quantity of agricultural land in the period, development pressures impacted the state of agricultural land, particularly cropland, which by their very nature are typically prime farm lands.

Development of adjacent agricultural lands can also interfere with the efficiency of farming practices. With increasing rural land development, consequent demand for public facilities arises and claims even more land. Regulation of farming practices and increased property taxes as well as speculation on land can reduce farming practices and their efficiency. As prime farm land shrinks and the need of land for non-agricultural uses accelerates over time, the quality of farm family life disappears and the values that spring from living close to that land is diminished. The quality and rate of conversion of rural land affects not only the productive capacity of food and fiber, but it also affects the rural economies, environmental quality, and other socio-economic activities.

The trend of agricultural land development has triggered public policy debate on land use management. However, the agricultural land policy debate has centered on the adequacy of the land base to provide food and fiber at some "reasonable price" in the future (Brewer and Boxley, 1981). This is a valid national concern, but exclusive attention to this issue has obscured the more widespread and immediate national concern over land use change and agriculture in urbanizing areas (Platt, 1985; Anderson, et al, 1975). In view of the urgency of the matter and public concern, it is important to study the problem more closely and understand the complex interaction and effect of the existing conversion challenges to economic systems and social welfare in the coming generations. Closer investigation of the issue can provide more information to policy makers and decision makers in land use planning decisions.

This study focuses on the nature and implications of the land conversion situation in West Virginia. Development of rural lands to other uses indicates a permanent loss of scenic views, open space, wildlife habitat and rural life style. Some studies indicated increased use of land for residential, commercial, industrial, extractive, and recreational uses and for transportation, public utilities, community facilities, and government installations 
(State MRP Land Use Committee, 1976; Tall and Colyer, 1989). The Census of Agriculture 1992 also reported that the total number of farm acres in West Virginia declined by over three percent from 3.37 million acres in 1987 to 3.27 million acres in 1992.

A substantial amount of land in and around the small towns and their constituting counties located near large centers, particularly in the eastern Panhandle, is being used for second or retirement homes, campground and weekend recreational use, or has been purchased for profitable investments. Most of these developments seek flat, well-drained land. However, the quantities of such land, which are usually used for farming, are severely limited in most West Virginia communities. As a result, such losses of land make it difficult or impossible to maintain rural land for agricultural uses because returns to land in agriculture are low relative to other uses in West Virginia (MRP, 1976).

Agricultural technologies compensated in many other states by increasing yields and lessening the impact of conversion of land from being noticed. However, the revolution in agricultural production techniques creates a disadvantage for areas such as West Virginia. A large proportion of the land is steeply sloped, with the most productive land being converted to housing, commercial, or industrial uses. Since returns on land in agriculture are low relative to other land uses, specific policies are needed to protect the remaining agricultural areas.

From the economic perspective, a major criticism of agricultural preservation measures is that they are based on limited information about the impacts of sub-urbanization on agricultural production and income (Gardner, 1977). Hence, a study of the conversion of agricultural land in West Virginia is an important task and may shed light as to the extent of the problem and alternative land management schemes in the state.

It is finally appropriate to comment that understanding the balance between humans and nature with all the complex interactions is a timely and wise endeavor, as Donald Worster (1993) beautifully suggests that: "the way we use the land reflects our understanding of 
nature and our perception of ourselves. If widespread degradation is an indication that our understanding of nature is narrow, it also suggests that so too is our perception of our own role in the functioning of natural system." (quoted in Diamond and Noonan, 1996).

\subsection{GENERAL REVIEW OF PREVIOUS WORKS}

Conversion of agricultural land to urban uses is a phenomenon currently affecting countries as population growth, existing agricultural practices and shifts in economic activity interact dynamically. Suburbanization, which is characteristic of many regions of the US, has been accelerated in the post war period by federal tax policies that subsidized single family housing and state and local highway construction. As a result, housing and their infrastructural development have occurred in predominantly agricultural areas (Lopez, et al, 1988).

More recently, urban land has increased by 2.4 million acres from 1970 to 1980. Defined metropolitan land areas increased by 60 percent between 1970 and 1985 and recently encompassed 16 percent of U.S. land (Heimlich and Reining, 1989). Barkley and Wunderlich (1989) added that a 1988 survey showed that 3.5 percent of rural land transferred each year, of which 88.4 percent is agricultural land. Likewise, the Census of Agriculture (1992) reported that areas in the United States increased by 30 million acres from 25.5 million acres in 1960 to 55.9 million acres in 1990. According to Pimentel and Giampietro (1994), over the next 60 years urbanization will diminish the U.S. arable land base of 470 million acres.

Public facilities encouraged by a growing population also claim a significant proportion of agricultural land. Over the past 200 years, for instance, the expansion of these systems has covered 260 million acres, approximately half of which was arable land (Berry, 1978).

There are different theories explaining what forces drive land conversion. One factor focuses on the difference in rates of return from land due to its use and its relative location as explained by Von Thuenen location theory. The conversion process presented 
by R.F. Muth based on this theory suggests that land use patterns and the market price of land are established by relative rental gradients for urban and agricultural uses. Conversion of land to urban uses proceeds in concentric circles around a central city; then, at the equilibrium boundary between urban and agricultural uses, relative rents of competing uses are equal. Policy changes that favor suburbanization and growing housing demand associated with population growth shift the urban and rural rent gradient so that the equilibrium boundary moves away from the city center. Land speculation can cause the market value of agricultural land to rise above the agricultural use value before conversion if the expected urban rent at the conversion date over the planning horizon exceeds the current agricultural rent (Lopez, et al, 1988).

The implications of this theory of land conversion have resulted in diverse analyses and understanding among different concerned scholars and policy analysts. For instance, Krupa and Vesterby (ERS) concluded that "contrary to popular opinion, urbanization does not necessarily mark the end of agriculture in rapidly growing counties. Farmland does tend to decrease in counties where rapid population growth is sustained over several decades. But changes in crops to high value fruit and nut; vegetables; and nursery and green house products more than compensate for losses of other crops in real market value. These changes can be attributed in part to the adaptive nature of agriculture..." (Krupa \& Vesterby, 2001, p.11).

However, many still insist that there are a number of direct and indirect implications that are not fully compensated during the conversion process. Vesterby, et al. (1994) raise issues revolving around the value of land that may fail to be accounted for in the valuation process. Aside from issues of productivity of the agricultural sector impacted by conversion processes, urbanization of rural land does raise issues at the State and local levels with regard to protecting watersheds, maintaining air quality, providing open space, preserving rural life styles, preventing urban sprawl, and preserving local economies. These values are usually not internalized in the market price of farmland. 
Many studies also measure the direct effects of the loss of farmland to urban uses in terms of output reduction and income losses. Indirect impacts on the farming community could also include regulatory restrictions on farming practices with sub urbanization, technical impacts, and speculative influences. When farmers become uncertain about the future viability of agriculture in their area, farmland production falls, as does farming income. Ultimately, the critical mass of farming production needed to sustain the local farming economy collapses (Berry 1976; Daniels and Nelson 1986; Daniels 1986; Lapping and Fitzsimmon 1982).

Farmers can also face insecurity in their future operation that may lead them to reduce investments in farming. They may also await conversion of their land to other nonagricultural uses - an effect called the impermanence syndrome. Land use policies, therefore, should address the impermanence impact on the agricultural sector vis-à-vis land management schemes.

Hence, understanding the full impacts of alternative land management policies and the existing relationships between urban and rural agricultural land allocations is key to addressing the land use challenge.

\subsection{OBJECTIVES OF THE STUDY}

The general objective of this study is to measure the direct and indirect effects of migration on farmland conversion in West Virginia. Specifically, the objectives are to:

1. Model the effect of population changes on agricultural land conversion.

2. Model the effect of employment changes on agricultural land conversion.

3. Model other factors associated with population and employment changes and agricultural land conversion.

\subsection{METHODS OF ANALYSIS}

This study will use extensive descriptive and qualitative analysis. To facilitate the understanding of descriptive relationships in land use processes, extensive secondary data 
is collected. This will provide an initial understanding of the extent of the problem in West Virginia and possible trends.

Secondary data is collected from different sources including the US Census of Agriculture, County and City Data Books, REIS, and on-line sources.

The database will also provide a base to undertake econometric analysis to understand the effects of suburbanization on agricultural lands. Particularly changes in population, income, employment, land in farming and other competing uses, and geographical location aspects and accessibility information will be relied upon for econometric evaluation of the problem.

This study will typically employ an econometric model following the Carlino-Mills Growth Model with relevant adjustments to address the objective of this study. This model was initially used to explore the determinants of population and employment densities inter-regionally. The model uses changes in employment and population with other relevant exogenous variables to explain county growth by estimating a system of equations model using two-stage least-squares method (TSLS) (Carlino \& Mills, 1987). This general growth model has been applied in different studies for different purposes by making adjustments to the original model. For instance, Deller et al. (2001) employed the Carlino-Mills model to study the role of amenities and quality of life in rural economic growth, and in Duffy-Deno (1997) to study the economic effect of endangered species preservation in the non-metropolitan west.

\subsection{ORGANIZATION OF THE STUDY}

This thesis consists of five distinct chapters. Chapter One provides a general introduction to the statement of the research problem, the objectives, methods of analysis and a general review of the land use literature. It also introduces the research ideas and direction. Chapter Two provides an overview of the land use theories development and a microeconomic theoretical framework for land use decision processes and optimal location and land size considerations by economic agents. It provides the necessary 
theoretical intuition for the specified model. Chapter Three builds the empirical model with detailed specification of the variables of the model. It specifies a system of equations growth model to estimate the change in economic and demographic factors on agricultural lands. Chapter Four focuses on the presentation and analysis of the empirical results generated from the specified model. Finally, Chapter Five will provide a summary of the research. 


\section{CHAPTER II}

\section{ECONOMIC THEORY OF LAND RESOURCE ALLOCATION, USE, AND CONVERSION}

\subsection{BACKGROUND}

Economics, as a formally organized and scientific field, has been expanding and encompassing numerous areas of interest since the time of Adam Smith. Though basic questions of what to produce, how to produce and for whom to produce are general concerns of every society from the earliest times history can record, a concise and more scientific approach to address such general and numerous specific societal questions has grown in the past few centuries.

As a particular field, economics has been dealing with resource use and allocation problems. Economic resources bounded by the natural, physical, and technical growth constraints on the one hand, and growing human insatiable needs on the other has created pressure on the use and allocation of scarce resources.

Knowledge in the understanding and management of natural environments and all endowed resources has increased throughout human history. However, global population increases, unwise and unsustainable resource utilization practices, distorted allocation policies, and alarmingly growing new human needs and the justifiable desire to maintain an already achieved economic status have all engendered further pressure on the use of scarce economic resources.

Economic resources have different characteristics requiring different methods of management and distribution. It is generally true that resources are bound to economic forces of demand and supply in determining their value and distribution once they are made accessible to the market. However, specific behavior of resources and their relative 
abundance will also play a significant role in determining the value and distribution of those resources.

Of the four factors of production, the land resource has a peculiar characteristic of zero price elasticity in physical supply and a high opportunity cost in economic supply. Among other reasons, this coupled with physical immobility make the determination of its value and distribution different from other factors.

Labor mobility within and across nations, some degree of capital mobility, and the freedom of entrepreneurs to locate in areas of high incentive and productivity have all played roles in price adjustments and value convergence among economic resources across space. Land, however, is constrained by its physical immobility or spatial fixity in alternative economic use which consequently limits value adjustments across space in its wider dimension. Hence, it is no wonder that land resources have captured the interest of many economists since the pre-Classical economics period.

In Neo-classical microeconomics, though it is possible to subject land to a general frame of marginalist analysis, its specific physical behavior and high opportunity costs of conversion to alternative uses by themselves deserved a cautious approach. This is one fundamental reason why policies related with land reform, reallocations as well as free market distribution, permit the coordination and redirection of trends in land use practices through regulations and/or different incentive schemes.

More recently, the sustainable use of land between different competing economic activities along with an understanding of implications for coming generations is receiving growing attention. As land use changes affect not only land, per se, but also on the environment and other natural amenities, its analysis within a comprehensive sustainable economic framework is a definite requirement.

Though markets are an ambiguously efficient means of resource distribution under certain assumptions, failure of markets to address the crucial issues of externalities and 
sustainability in natural resource allocation can result in adverse long-term consequences; as Theodore Roosevelt, 26th President of the United States, beautifully puts it:

To waste, to destroy our natural resources, to skin and exhaust the land instead of using it so as to increase its usefulness, will result in undermining in the days of our children the very prosperity which we ought by right to hand down to them amplified and developed ${ }^{5}$.

This chapter generally deals with the genesis of economic theory of land value and allocation from the pre-Classical period to the Neo-Classical marginalist approach to understand the root and further developments in land use and allocation economics. It also includes an application of a neo-classical framework for the determination of goal maximizing location preferences. This will provide a sound theoretical foundation for the econometric analysis in this thesis.

Through time, land has been converted to different uses for different economic, technological, institutional, legal, and policy reasons. The conversion of land across sectors, however, is not without implications to environmental quality, income growth, and welfare changes across sectors. Of particular interest for this study is the conversion of agricultural lands to nonagricultural uses. This conversion process through time could have implications on quality of life, preservation of environmental and other natural amenities, farm income, sustainable agricultural production, as well as on public interests of open space, farming tradition, and landscape preservation standards.

\footnotetext{
${ }^{5}$ Quotation adopted from http://www.stthomas.edu/recycle/land.htm
} 


\subsection{GENERAL REVIEW OF EARLY LAND RENT, USE, AND ALLOCATION THEORIES}

Land rent and use issues have been focal points for theoretical development in the early pre-classical, classical, and neoclassical periods of economics. Although the nature of land issues change from period to period and from generation to generation, some fundamental attributes of land value and use were investigated at some depth. Most earlier studies in the area starting in the $17^{\text {th }}$ century focused on agrarian land uses. Recently, with societal transformation to more industrial and service economies, differential land rents and competing uses has gained more attention.

Though limited in depth and focus of analysis, pre-classical analysts had devoted time to investigating the value and use of land. Some even consider that land-rent first became area of vigorous theoretical interest for the works of the seventeenth-century mercantilists (Keiper, et al., 1961).

This period revealed early theoretical interest in the theory of value, particularly in the development of an early rent concept in land and labor. Generally, land use theories in this period can be inferred from the works of prominent contributors of the period.

William Petty, one such contributor, states that the extrinsic value of land may be derived by taking the average of all bargains undertaken at a definite given time period (Wilson, 1894). He summarizes value as one that is generated from a net return on the use value of land and the other aspect depending on average bargaining value which could be influenced by the market condition. On the relationship between land value and population, Petty argues that rent of land near places of high population increases due to the honor and satisfaction of having land there (Keiper, et al., 1961).

Cantilon demonstrates that the allocation and use of land depends on the return different activities promise to bring to that land (Cantilon, 1755). Similarly, Turgot addresses the same question in his argument that competition sets the price of leases of land (Turgot, 1770). 
Classical Period economists generally measured value in terms of labor cost which entered extensively in international trade analysis based on comparative labor cost advantages and production and distribution issues. Extensive writings have also been made in land rent theories and allocations.

One of the contributors to classical land rent theory is Adam Smith, whose work greatly shaped economic thinking of his period and laid a foundation for the later development of economics. Smith treats the rent of land as a monopoly price, "it is not at all proportioned to what the landlord may have laid out upon the improvement of the land, or to what he can afford to take; but to what the farmer can afford to give." (Smith, 1776). His classical land use theory takes into account the influence of competition between different economic activities on land use and allocation as well as the role of distance and transportation cost in land rent and use. The influence of distance from a particular city or populous area on land rent is that rent not only varies with fertility of land but it also varies with location. Land near a town gives a greater rent than land equally fertile in a distant location. Though the production cost may not be different, the produce costs more to bring it to the to the distant market (Ibid, 1776).

Smith argues that good transportation facilities like roads, canals, and navigable rivers will diminish transportation costs and makes distant places more accessible. This encourages the 'cultivation of the remote', which is the most expensive location of the country (Ibid, 1776). With regard to land conversion between different uses, Smith states that "an acre of land will produce a much smaller quantity of the one species of food than of the other, the inferiority of the quantity must be compensated by the superiority of the price. If it was more than compensated, more corn land would be turned into pasture; and if it was not compensated, part of what was in pasture would be brought back into corn.”(Ibid, 1776).

Another significant contributor to the theory of land rent in the classical period is David Ricardo. His rent theory recognizes that there is an upward trend in human demography and location friction, and competition for resources will create rent. In describing the 
behavior of rents for fertile and surrounding marginal lands, Ricardian theory develops a concentric circle type of analysis. With three types of land arranged according to their fertility with 1 being the most fertile, the theory states that as the competition for marginal lands increases, the rent for the more fertile ones will increase. As land of lesser quality, say third quality, is put into use rent rises on the second by the difference of their productivity. Similarly, the rent for first quality land will also increase since its rent is greater than that of the second quality. As population grows, which shall force a country to depend on worse quality land, rent on all fertile land rises (Ricardo, 1817).

An extension in Classical land theory is introduced by John Stuart Mill who brought the concept of opportunity costs into the theory. Mill views land rent as the rent which any land yields in excess of its produce "beyond what would be returned to the same capital if employed on the worst land in cultivation'(Mill, 1848). This addition to rent theory involves an element of opportunity cost as the rent of a given land is compared to whatever is in excess "if that capital is invested" in poor land. Mill argues that the value of goods that are scarce is entirely determined by demand and supply (Ibid, 1848).

Therefore, it can generally be concluded about the rent theories of classical economists that the period reflected a tendency of rent theory genesis from Smith's and Ricardian labour value based interpretations to a more complex and extended concept of Mill with the introduction of opportunity cost.

As a break away from pure classical thinking of economic value and exchange, the neoclassical period evidences a new paradigm of economic thinking. Bringing into the core of economics the philosophical ideas of utilitarianism, it approaches consumer behavior from a utility point of view and profit maximization motives from a business point of view and generates a whole set of microeconomic behavioral analysis from that angle.

By 1866, one of the founders of the neo-classical thinking, William Javons, stated his view of utilitarian economics that "a true theory of economy can only be attained by going back to the great springs of human action - the feelings of pleasure and pain." 
(Javons, 1866). Under this micro-economic framework, exchange of goods and services can occur to the extent where utility is successively created until a point where the diminishing marginal utility will remove all utility incentives for a given price.

In contrast to classical theory of labor value, another founder of neo-classical economics, Carl Menger, argues that value is not embodied in goods but rather on the satisfaction of human needs (Menger, 1871). Neo-classical economics treats land as a commodity subject to the forces of demand and supply. For instance, Menger argues that the treatment of the value of land is not exceptional among goods. Menger argues that whenever a question arises as to the determination of the value of land, it is subject to the general laws of value determination (Ibid, 1871).

Similarly, Alfred Marshal argues "the rent of land is no unique fact, but simply the chief species of a larger genus of economic phenomena; and that the theory of the rent of land is no isolated economic doctrine but merely one of the chief applications of a particular corollary from the general theory of demand and supply..." (Marshall, 1890).

On the study of land conversion to different uses, Henderson developed the concept of 'margin of transference.' This concept states that land is at the margin of transference if its rent is just sufficient to protect its being converted to other alternative uses (Keiper, et al., 1961).

Today, with the transformation of the American economy from agrarian to industrial and now services, as well as the improvement of communication technology and resulting lower accessibility costs, the competition over a given convenient space is intense. Business and residential location decisions expand to greater distances from the center of the city or administrative centers. Though the allocation of land at a particular space and with given natural features among different economic activities will follow the same basic economic principles, the process, however, is by no means trivial. 
The consideration of buying a piece of land for residence for instance can be treated the same way as a consideration for the purchase decision of a common commodity in terms of economic behavior. As Robert M. Haig argues in selecting a residence, one can be thought as buying accessibility precisely as one buys consumer goods. One hence compares location and resulting costs of friction, rent, time and commuting costs which are matched with derived satisfaction and resources to place the consumption decision (Haig, 1926).

Finally, households decide their location based on their utility maximization derive and resources; producers make similar decisions of location based on their maximization tendency. The point where these two forces balance determines location (Losch, 1954).

The trend in value and allocation theories indicate the transformation of economic thinking from Classical labor value based approach to the marginal value based approach of Neo-Classical Economics.

\subsection{DEVELOPMENT OF EARLY BID-RENT FUNCTIONS AND LAND ALLOCATION}

Development of early bid rent functions and its early mathematical treatment is associated with the work of von Thunen. Different economic historians and writers attribute his work as an early sign of departure from classical thinking to neo-classical thought, especially in the theory of distribution and application of marginalist analysis.

Von Thunen's land allocation theory gives a more complete picture of the allocation process by bringing competition and transportation savings in a mathematical bid-rent function. Von Thunen starts with certain assumptions that could be relaxed to meet reality. The assumptions ask to:

Consider a very large town in the center of a fertile plain which does not contain any navigable rivers or canals. The soil of the plain is assumed to be of uniform fertility which allows cultivation everywhere. At a great distance the plain ends in an uncultivated wilderness, by which this state is absolutely cut off from the rest of the world. This plane 
is assumed to contain no other cities but the central town and in this all manufacturing products must be produced; the city depends entirely on the surrounding country for its supply of agricultural products. All mines and mineral deposits are assumed to be located right next to the central town. (Brooks, 1987).

The main concern under such a case is to determine how distance from the city affects the efficient allocation of land for different economic activities. The model specifies that each economic activity (in agriculture) can bid a rent at a particular location per unit of land offering a bid the maximum of which is equal to the value of the product minus all the costs of production, including transportation cost. Competition among producers ensures that the actual rent bid will be the largest. Potential profit for any product diminishes with distance at a rate equal to the transportation cost (Ibid, 1987).

Following Von Thunen's argument, we can write the bid rent function in a simple mathematical form as: $R_{n}=p Q-w_{i} X_{i}-D_{t}$ where $R_{n}$ is the net revenue per unit of land from the products of that land situated at distance $t$ from the central market, $Q$ is output and $X_{i}$ is the set of all inputs needed to produce $Q$ per unit of land, $p$ and $w$ representing input and output prices per unit respectively and $\mathrm{D}_{t}$ denotes the cost of transporting $\mathrm{Q}$ to a unit of distance. $R_{n}$ can be viewed as the maximum any bidder can offer since it does not make any economic sense to offer for a specific parcel of land at a specific location a bid that is more than what that land is economically worth. Hence, it follows that any change in input and output prices as well as any improvement in transportation technology is going to affect the optimal allocation of land and effect the spatial feature of land uses. (see Brooks, 1987).

To graphically generate a bid-rent function from $R_{n}=p Q-w_{i} X_{i}-D_{t}$, we may identify net revenue (maximum bid) on the vertical axis and distance on the horizontal axis. Thus, by taking the intercepts we can draw the bid rent function (figure 4). 
Fig. 4. Bid Rent Function for Land situated at a certain distance.

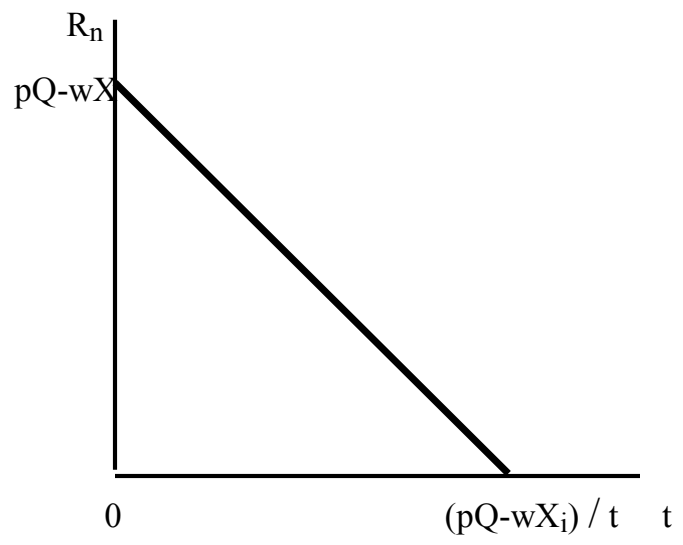

It can be noted from the bid rent function that changes in input and output prices as well as improvement in transportation technology can affect net revenue. This results in different bid rent functions for different economic activities and will result in different spatial land use distributions.

Following Von Thunen's concept of concentric circle analysis, it is possible now to see what happens if more than one activity on a parcel of land occurs under conditions of full competition. For a three-crop example in agriculture, Fig. 5 indicates the allocation pattern that can result. Assume three crops A, B , and C compete over a favorable location. Lets assume now that $R_{n} A>R_{n} B>R n C \forall Q_{i}>0$; where $R_{n}$ is net revenue (maximum bid). It is evident that with distance and constant transport technology and input and output prices, the net revenue of $\mathrm{A}, \mathrm{B}$, and $\mathrm{C}$ diminishes as distance from a market increases as transportation cost saving declines. Hence, the land will be allocated in such a way that A bids out locations near the center followed by $\mathrm{B}$ and $\mathrm{C}$ as shown in figure 5. The crop offering the highest net revenue at a given location will outbid other activities and the land will be put to that use. However, it is clear that relaxing the assumptions of a constant technology coefficient and constant input and output prices, the land use pattern will be varying and dynamic over space, although the same behavioral pattern can generally be captured. 
Fig 5. Bid Rent functions of Three Agricultural Activities and Land Distributional Pattern

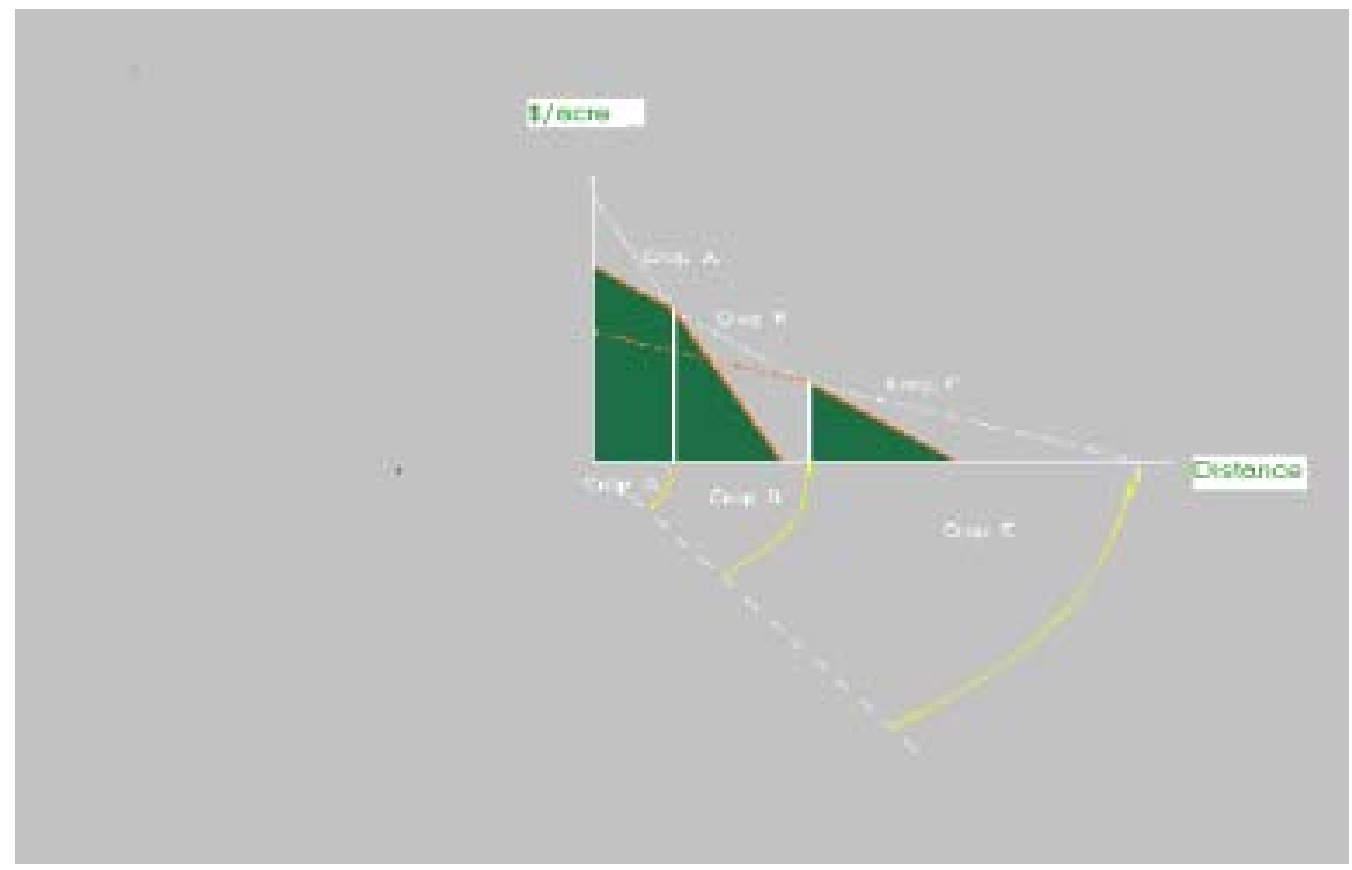

Source: Adopted from http://faculty.washington.edu/ krumme/450/exercises/landuse.gif

An interesting issue will arise when consideration is given to differential rents arising from spatial competition involving different sectors. Though the same principle applies, a general concentration of sectors across space may be observed for reasons of higher returns in certain sectors per given distance and agglomeration economies. Fig 6 demonstrates a hypothetical land use distribution across three sectors. It shows that retail activity will prevail over space up to a concentric circle with radius of $\mathrm{d} 1$ and manufacturing within a distance of $\mathrm{d}_{2}-\mathrm{d}_{1}$ from the central market and residential concentrations in the area $d_{3}-d_{2}$. For the whole distance $0 \rightarrow d_{3}$ the upper margins of the bid rent functions forms the rent gradient.

Viewing the allocation process dynamically, the market price for each product is simultaneously determined and depends not only on its supply and demand condition, but also on the prices of other goods and services associated with it. Thus, the supply and spatial location of agricultural industry depends on its price and prices of other goods (Ibid, 1987). 
Fig 6. Bid Rent Functions of Three Sectors and Resulting Land Distribution Pattern

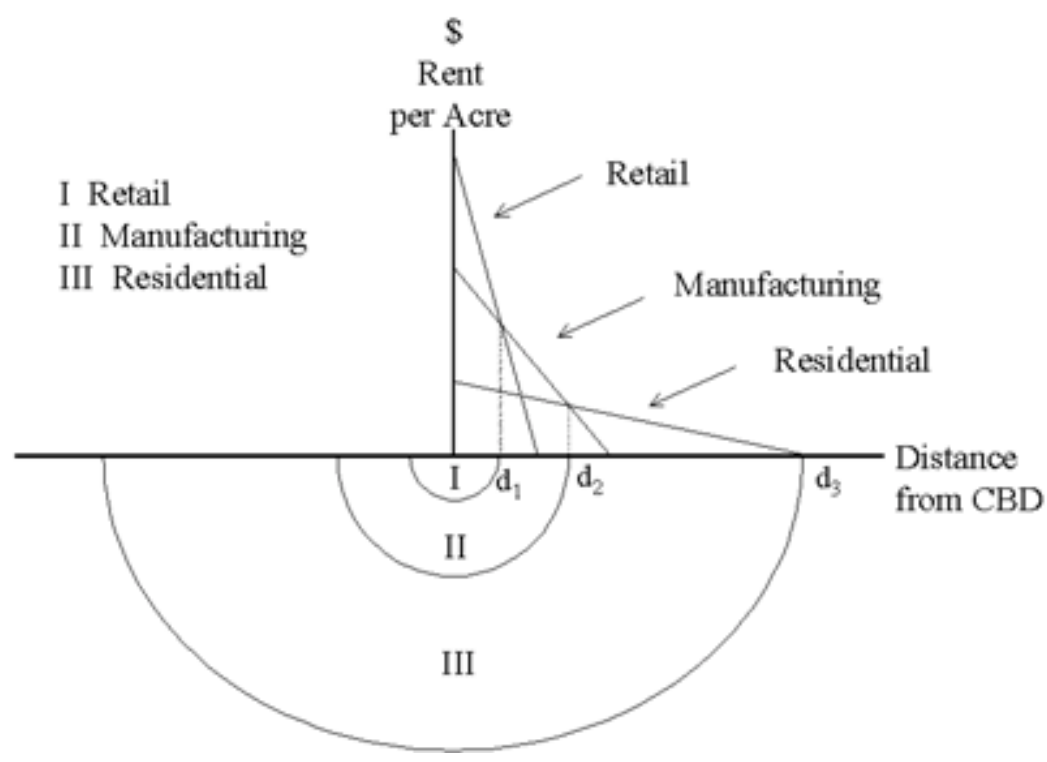

Source: http://www.uncc.edu/ hscampbe/landuse/b-models/C-bidrent.html

\subsection{ECONOMICS OF LAND USE, ALLOCATION, AND CONVERSION}

As discussed in section 2.2, the study and understanding of land rent, use, and allocation has been the concern of theoretical study for a long time. However, a deeper understanding of the land use process with changing individual and societal economic needs across space is still creating economics modeling and policy challenges.

This study deals with the conversion of agricultural lands to non-agricultural uses, especially at the urban fringe. Urban fringe is meant as the:

... underdeveloped space into which a town or city expand by circumferential or radial growth. It is a zone of mixed land-use elements and characteristics in which rural activities and modes of life are in rapid retreat, and into which not only residential, but also commercial, educational, recreational, public service and other largely extensive uses of land are intruding. In a land-use, and often in an administrative, sense too, the area is only partially assimilated into the growing urban complex. (Thomas, in Johnson, ed., 1974). 
Through time, the change in spatial features in the cities has received greater attention because the redevelopment of inner cities addresses difficult social problems and partly because new construction activities in the city pose architectural preservation questions. On the other hand, changes on the edge of the city are related with the conversion of land to urban uses. This could involve basically a greater alteration than other forms of land use changes taking place in urban areas. (Johnson, ed., 1974).

This new spatial feature definitely creates friction among economic sectors in their competition for land as well as on social and environmental interactions. This, however, increases societal costs in terms of increasing costs of amenities due to scattered and unplanned rural development, frictions in land use, deterioration of environmental quality, disruption of local production methods and farming practices, and transformation of rural landscapes into urban type developments. Suburban developments also affect the value of agricultural land and different use competitions can reduce the effectiveness of the agricultural sector. In many cases, conversion processes do not account for externalities associated with land conversion and as such their long-term implications to societal welfare should be properly gauged and understood.

Consequently, through the transformation of "pastoral farmland into often-unattractive suburbs, sprawl is thought to disrupt a natural balance between urban and non-urban land uses, leading to a deplorable degradation of the landscape" (Brueckner and Fansler, 1983, p. 479). In many cases, the positive externalities of the rural sector are not accounted for in the value of the converted land to other uses. Irwin and Bockstael suggest in their estimation of open space spillovers using a hedonic pricing model of residential property sales that the positive amenity value associated with open space may not be identified. (Irwin and Bockstael, 2001).

From a policy perspective, the conversion of agricultural lands to non-agricultural (development) uses has been a critical public issue. "In recent years, attention has focused on preserving local benefits from agricultural lands such as open space, environmental quality, and impediments to urban sprawl. Many of these benefits have 
public characteristics and, as a consequence, will tend to be undersupplied by private producers" (Plantinga and Miller, 2001, p. 56).

Understanding the forces behind land conversion to non-agricultural uses is particularly relevant in modeling and predicting land use changes. Pressure on agricultural land can generally be seen from the rural agricultural sector point of view as well as from city pressure points of view to explain the origin and effect of factors of conversion.

With increases in urban population and residential and employment preference towards the edge of cities, the conversion process becomes eminent unless interrupted by policy measures. Behind the forces of population and employment changes across time and space, however, are a number of theories trying to identify the possible sources of factors affecting the suburbanization process. One class of theoretical "explanation for suburbanization stresses fiscal and social problems of central cities: high taxes, low quality public schools and other government services, ..., crime, congestion and low environmental quality. These problems lead affluent central city residents to migrate to suburbs, which induces further out-migration" (Mieszkowski and Mills, 1993, p. 137).

In the context of the United States, different reasons are generally attributed as causing suburbanization pressures during different decades. During the 1950s, it was claimed that home mortgage insurance by the federal government was responsible for suburbanization. In the 1960s, the interstate highway system and racial tensions were popular explanations of decentralization. More recently, crime and schooling considerations have been prominent explanations of urban decentralization. (Ibid, 1993).

Although land development pressures can be seen from a different perspective, theoretically they can be generalized in a microeconomic framework of utility and profit maximization motives with location and land size being relevant decision factors. Land may be demanded for direct consumption needs as in housing or for manufacturing and other commercial purposes. 
In the case of private housing demand for land, "open space is often cited as a primary attractor of urban and suburban residents to exurban areas located just beyond the metropolitan fringe. Included in the rural amenities afforded by open space are scenic views, recreational opportunities, and an absence of the disamenities associated with development, such as traffic congestion and air pollution." (Irwin and Bockstael, 2001, p. $668)$.

Mills argues that that households endowed with "perfect knowledge of $\mathrm{P}(\mathrm{t})$, the vector of residential service prices at time $t$, select the residential service that maximizes their utility. This behavior may be summarized by household's compensated demand functions (defined by the level of utility achieved under prices $\mathrm{P}(\mathrm{t})$ ). Land not being used in the provision of residential services is taken up by some unspecified alternative use." (Mills, 1978, p. 228).

In the case of industrial and other commercial demand for land, generally locations that minimize costs and help maximize profits are desired. Miyao provides a general approach of the location problem. In a two industry analogy, arranging zones and industries can be arranged in an increasing distance from centers such that the $\mathrm{i}^{\text {th }}$ industry occupies zone $\mathrm{i}$ $(i=1, \ldots, m)$. In the long-run competitive equilibrium, satisfying the long-run zero profit condition, the $\mathrm{i}^{\text {th }}$ industry bid rent at distance $\mathrm{x}$ can be expressed as $\mathrm{r}_{\mathrm{i}}(\mathrm{x})$,

$$
\mathrm{C}_{\mathrm{i}}\left[\mathrm{r}_{\mathrm{i}}(\mathrm{x}), \mathrm{w}\right]=\mathrm{p}_{\mathrm{i}}-\mathrm{q}_{\mathrm{i}}(\mathrm{x})(\mathrm{i}=1, \ldots, \mathrm{m})
$$

where $\mathrm{C}_{\mathrm{i}}, \mathrm{p}_{\mathrm{i}}, \mathrm{q}_{\mathrm{i}}$, and $\mathrm{w}$ are the $\mathrm{i}^{\text {th }}$ industry's per unit production cost, output price and per unit transport cost, and the wage rate respectively. The wage rate is assumed uniform across the region. The equilibrium condition requires that for the $\mathrm{i}^{\text {th }}$ industry to occupy zone i, its bid rent must be one of the highest, i.e., the bid rent is required at least to be equal to other industries everywhere in the zone; $i$ : $r_{i}(x) \geq r_{j}(x)$ for all $j=1, \ldots, m$. (Miyao, 1977).

Within these general frameworks, a number of relevant factors of influence can be introduced into the system. Among other factors, population growth and employment 
expansion are relevant factors in influencing the land conversion process. They simultaneously interact to influence one another and the demand for land across different land uses.

Brueckner shows that "under certain simplifying assumptions about preferences and technology, population density is shown to have an exponential form (Brueckner, 1982), $D(\theta)=D_{0} e^{-\gamma \theta}$, where $\theta$ is the distance from the CBD (Central Business District), $D_{0}$ is the population density at the edge of the CBD, and $\gamma$ is the gradient or the constant percentage change in the population density per unit change in distance from the CBD." (Brueckner, in Mieszkowski and Mills, 1993, p. 138). However, with expanding population, greater distances from the city edge are brought under settlement consideration.

Barlowe argues that irrespective of the opinion one holds on the ambigeous question of population control, it need to be understood that the population growth pressure has a significant impact on the demand for land and its products (Barlowe, 1958). Consequent problems of land conversion from rural to urban uses have intensified concern among many persons. (Muth, 1961).

With increasing suburbanization, need arises in the suburban areas to develop sociopolitical and economic institutions, transport and public utility infrastructure, health and education services and other attendant social needs facilitating the conversion of land to more intensified suburban uses. (Fisher, 1956).

Simultaneously interacting, employment also plays a major role in affecting land use patterns over space and in affecting the conversion of land away from agriculture. Though direction of causation between employment or population is a debatable issue, the Natural Evolution Theory of cities and suburbs indicates that the decentralization of residential places from the central city is followed by the decentralization of employment. Hence, firms moved to the suburbs following the change in population location preferences, to provide services and to benefit from lower suburban land and labor costs. 
However, the movement of employers to suburban areas further stimulates a change in population across regions as employees followed them. (Mieszkowski and Mills, 1993).

Generally, in a competitive land market the price for land equals the present discounted value of the stream of future rents. Thus, if rents from development exceed agricultural rents in the future, the higher rents from future development will be capitalized into the current price of agricultural land. (Plantinga and Miller, 2001). Hence, as the development pressure intensifies following the out-migration of population and businesses to suburban areas, more land will be put into use for housing and development purposes as these economic activities might provide a better bid than competing agricultural and other rural economic activities.

From a theoretical perspective, establishing a sound relationship among factors that interact in the land conversion process is crucial. Understanding such interplay of locational (spatial) objective maximization decisions of households and businesses provides a microeconomics perspective of the land use issue.

Some studies provide a microeconomic approach to land use issues and establish relevant relationships between economic behaviors and location in a comparative static analysis. For example, Brueckner and Fansler provide comparative static emphasis of Wheaton (1974) indicating specific relationships between distance and other variables of interest represented as:

$$
\partial \mathrm{x} / \partial \mathrm{L}>0, \partial \mathrm{x} / \partial \mathrm{r}_{\mathrm{a}}<0, \partial \mathrm{x} / \partial \mathrm{y}>0, \partial \mathrm{x} / \partial \mathrm{t}<0
$$

where $\mathrm{x}$ is the distance to the urban-rural boundary, $\mathrm{L}$ is the urban population size, $\mathrm{r}_{\mathrm{a}}$ is agricultural land rent, $y$ is income and $t$ is per round-trip mile commuting cost. The result establishes that with the increase in the urban population, the edge of the city must expand as the need arises for more people to be housed. An increase in agricultural land rent raises the opportunity cost of urban land relative to agricultural land and results in a more compact city. An increase in income increases the demand for housing and results 
in an expanding city margin. Finally, a rise in per mile commuting cost lowers disposable income at any given location, and hence reduces housing demand which results in less pressure towards city edges. (Brueckner and Fansler, 1983).

Similarly, Plantinga and Miller provide a discussion of the competitive land market study of Capozza and Helsey (1989). The model provides equilibrium rents from developed land as:

$$
\mathrm{R}(\mathrm{t}, \mathrm{z})=\mathrm{A}+\mathrm{rC}+(\overline{\mathrm{T} / \mathrm{L})} \mathbf{-} \overline{\mathrm{z}}(\mathrm{t})-\mathrm{z}]
$$

where $\mathrm{A}$ is a constant annual agricultural rent, $\mathrm{T}$ is commuting cost, $\mathrm{L}$ is a fixed land requirement, $\mathrm{z}$ is distance to the city center, and $\mathrm{z}(\mathrm{t})$ is the distance from city boundary to a city center. The comparative static results establish that development rents are rising through time at a fixed location $(\partial \mathrm{R}(\mathrm{t}, \mathrm{z}) / \partial \mathrm{t}>0)$ resulting from population pressures. Population growth expands the city boundary $(\partial z(t) / \partial t>0)$ and confers location rents on existing developed land. With an increase in distance away from the central city, development rents decline $(\partial \mathrm{R}(\mathrm{t}, \mathrm{z}) / \partial \mathrm{t}<0)$ due to the falling of rents to offset increasing commuting costs. (Plantinga and Miller, 2001).

Therefore, though a microeconomic framework provides a general theoretical base to analyze land use changes, the inclusion of employment, population, commuting costs, distance from urban center, farm rents, developments prices, and many more variables of interest within the general microeconomics and regional growth realm are all relevant and can enrich the understanding of land use changes and allocation frictions.

\subsection{MATHEMATICAL ANALYSIS OF LAND USE DECISIONS AND ALLOCATION IN A MICROECONOMICS FRAMEWORK ${ }^{6}$}

So far, the general theoretical reasoning behind the guiding economic principles of land use and allocation has been discussed. Among other things, a decision to locate at a specific place can be affected by prices, transport technology, location preference, degree

\footnotetext{
${ }^{6}$ For detailed mathematical and graphical analysis refer to Alonso, (1964).
} 
of competition, legal systems, population pressures, degree of regional growth, government policies, and so forth.

Land can be allocated to lots of purposes starting from government institutional requirements to purely commercial ends. The decision to place government institutions and public facilities at a particular location rests on a lot of social and economic factors and in most cases can be viewed as exogenous. For the purpose of current analysis, we can limit the demand for land to commercial, residential and agricultural purposes and see how pressures like population and business and employment expansion affect the agricultural sector or land in agriculture.

\subsubsection{Mathematical Consideration of Land-Use and Location Decisions by \\ Businesses}

Lets assume that the objective of a given firm is to maximize profit by taking into account the effect of location on profit through transportation costs. In the case of agricultural businesses, to simplify the analysis, lets assume that fertility is constant over a given location so that the factor entering into the decision is the cost of transportation from the nearest market.

Then, following the theoretical microeconomic framework of Alonso, (1964), it is possible to characterize the behavior of a profit maximizing firm mathematically as:

(1) $\quad \operatorname{Max} \pi=\mathrm{R}-\mathrm{C}-\mathrm{L}$

Where $\pi=$ total profits

$\mathrm{R}=$ total revenue

$\mathrm{C}=$ total operating costs

$\mathrm{L}=$ land cost 
All of the right hand side variables are also some function of distance and land size. Substituting we can rewrite the relationship as:

$$
\begin{aligned}
& \operatorname{Max} \pi=R(t, q)-C(R, t, q)-L(t) q \\
& \text { Where } \mathrm{t}=\text { distance to location of market } \\
& \qquad \begin{aligned}
\mathrm{q} & =\text { land size in use } \\
L(t) \mathrm{q} & =\text { land rental cost }
\end{aligned}
\end{aligned}
$$

A profit-maximizing operator will achieve a maximum when the first derivative of the profit function is zero:

$$
\begin{aligned}
\mathrm{d} \pi= & (\partial \mathrm{R} / \partial \mathrm{t}) \mathrm{dt}+(\partial \mathrm{R} / \partial \mathrm{q}) \mathrm{dq}-(\partial \mathrm{C} / \partial \mathrm{R}) \mathrm{dR}-(\partial \mathrm{C} / \partial \mathrm{t}) \mathrm{dt}-(\partial \mathrm{C} / \partial \mathrm{q}) \mathrm{dq}-\mathrm{q}(\partial \mathrm{L} / \partial \mathrm{t}) \mathrm{dt}- \\
& \mathrm{L}(\mathrm{t}) \mathrm{dq}=0
\end{aligned}
$$

Substituting again for $\mathrm{dR}$ with its proper partial derivatives from equation (2) we can rewrite equation (3) as:

$$
\begin{aligned}
\mathrm{d} \pi= & \partial \mathrm{R} / \partial \mathrm{t} d \mathrm{t}+\partial \mathrm{R} / \partial \mathrm{qdq}-\partial \mathrm{C} / \partial \mathrm{R}(\partial \mathrm{R} / \partial \mathrm{t} \mathrm{dt}+\partial \mathrm{R} / \partial \mathrm{q} \mathrm{dq})-\partial \mathrm{C} / \partial \mathrm{t} \mathrm{dt}-\partial \mathrm{C} / \partial \mathrm{qdq}- \\
& \mathrm{q}(\partial \mathrm{L} / \partial \mathrm{t}) \mathrm{dt}-\mathrm{L}(\mathrm{t}) \mathrm{dq}=0 \\
\mathrm{~d} \pi= & \partial \mathrm{R} / \partial \mathrm{t} \mathrm{dt}+\partial \mathrm{R} / \partial \mathrm{qdq}-\partial \mathrm{C} / \partial \mathrm{R} . \partial \mathrm{R} / \partial \mathrm{t} \mathrm{dt}-\partial \mathrm{C} / \partial \mathrm{R} . \partial \mathrm{R} / \partial \mathrm{qdq}-\partial \mathrm{C} / \partial \mathrm{t} \mathrm{dt}-\partial \mathrm{C} / \partial \mathrm{q} \\
& \mathrm{dq}-\mathrm{q}(\partial \mathrm{L} / \partial \mathrm{t}) \mathrm{dt}-\mathrm{L}(\mathrm{t}) \mathrm{dq}=0
\end{aligned}
$$

$$
\begin{aligned}
0= & \mathrm{dt}(\partial \mathrm{R} / \partial \mathrm{t}-\partial \mathrm{C} / \partial \mathrm{R} . \partial \mathrm{R} / \partial \mathrm{t}-\partial \mathrm{C} / \partial \mathrm{t}-\mathrm{q}(\partial \mathrm{L} / \partial \mathrm{t})+\mathrm{dq}(\partial \mathrm{R} / \partial \mathrm{q}-\partial \mathrm{C} / \partial \mathrm{R} . \partial \mathrm{R} / \partial \mathrm{q}- \\
& \partial \mathrm{C} / \partial \mathrm{q}-\mathrm{L}(\mathrm{t}))
\end{aligned}
$$

Now holding $\mathrm{dt}$ and dq equal to zero (remaining at some constant level) we can get two expressions that can be simultaneously solved. Holding $\mathrm{dt}$ constant $(\mathrm{dt}=0)$, the right hand side of equation 4 can be rewritten as:

$$
\mathrm{dq}(\partial \mathrm{R} / \partial \mathrm{q}-\partial \mathrm{C} / \partial \mathrm{R} . \partial \mathrm{R} / \partial \mathrm{q}-\partial \mathrm{C} / \partial \mathrm{q}-\mathrm{L}(\mathrm{t}))=0
$$$$
(\partial \mathrm{R} / \partial \mathrm{q}-\partial \mathrm{C} / \partial \mathrm{R} . \partial \mathrm{R} / \partial \mathrm{q}-\partial \mathrm{C} / \partial \mathrm{q}-\mathrm{L}(\mathrm{t}))=0
$$ 
Setting dq constant $(\mathrm{dq}=0)$,

$$
\begin{aligned}
& \mathrm{dt}(\partial \mathrm{R} / \partial \mathrm{t}-\partial \mathrm{C} / \partial \mathrm{R} . \partial \mathrm{R} / \partial \mathrm{t}-\partial \mathrm{C} / \partial \mathrm{t}-\mathrm{q}(\partial \mathrm{L} / \partial \mathrm{t})=0 \\
& (\partial \mathrm{R} / \partial \mathrm{t}-\partial \mathrm{C} / \partial \mathrm{R} \cdot \partial \mathrm{R} / \partial \mathrm{t}-\partial \mathrm{C} / \partial \mathrm{t}-\mathrm{q}(\partial \mathrm{L} / \partial \mathrm{t})=0
\end{aligned}
$$

Simultaneously solving equations 5 and 6 , the values for $t$ (distance to location of market) and $\mathrm{q}$ (land size in use) can be determined.

$$
\mathrm{t}^{*}=\mathrm{t}^{*}(\mathrm{R}, \mathrm{C}, \mathrm{L}), \mathrm{q}^{*}=\mathrm{q}^{*}(\mathrm{R}, \mathrm{C}, \mathrm{L})
$$

Once the solution for $\mathrm{q}$ and $\mathrm{t}$ is determined from the system, the values for $\pi^{*}, \mathrm{R}^{*}(\mathrm{t}, \mathrm{q})$, $\mathrm{C}^{*}(\mathrm{t}, \mathrm{q})$, and $\mathrm{L}^{*}(\mathrm{t})$ can be solved by inserting the optimal values of $\mathrm{q}$ and $\mathrm{t}$ into the explicit objective function.

The above mathematical relationships contain key information concerning location and land size decisions. From equation 6 we have,

$$
(\partial \mathrm{R} / \partial \mathrm{t}-\partial \mathrm{C} / \partial \mathrm{R} . \partial \mathrm{R} / \partial \mathrm{t}-\partial \mathrm{C} / \partial \mathrm{t}-\mathrm{q}(\partial \mathrm{L} / \partial \mathrm{t})=0
$$

$\partial \mathrm{R} / \partial \mathrm{t}: \quad$ is generally negative and indicates the marginal revenue lost due to moving a unit of additional distance $\mathrm{dt}$ from a given center.

$\partial \mathrm{C} / \partial \mathrm{R} . \partial \mathrm{R} / \partial \mathrm{t}$ : indicates the marginal operating cost incurred due to a change in revenue which is indirectly affected by distance. It can also be viewed as the indirect effect of distance on operating costs.

$\partial \mathrm{C} / \partial \mathrm{t}: \quad$ measures the rise in marginal operating costs resulting from a change in distance from a given location. It can optionally be conceived also as a direct influence of distance on operating costs.

$q(\partial \mathrm{L} / \partial \mathrm{t}): \quad$ captures the general decline in land rents resulting from a change in distance from a central market location.

Note that equation 6 simply explains the maximizing economic condition in which the net gain in terms of revenue resulting from a selection of a particular land location should equal the marginal cost of that particular site selected. Otherwise, the location is not optimally selected and will not satisfy the profit-maximizing objective. 
Information concerning the plot size decision can similarly be generated from equation 5 . It holds general information about the influence of land size on revenue and cost both directly and indirectly. This can explicitly be noted from each expression in equation 5 . From equation 5 we have,

$(\partial \mathrm{R} / \partial \mathrm{q}-\partial \mathrm{C} / \partial \mathrm{R} . \partial \mathrm{R} / \partial \mathrm{q}-\partial \mathrm{C} / \partial \mathrm{q}-\mathrm{L}(\mathrm{t}))=0$

$\partial \mathrm{R} / \partial \mathrm{q} \quad$ Captures the change in revenue due to a unit change in plot size

$\partial \mathrm{C} / \partial \mathrm{R} . \partial \mathrm{R} / \partial \mathrm{q}$ Measures the effect of a change in revenue from a change in the size of operation which is cause by the increase in land size. In a sense this measures the indirect effect of land size on the cost of production.

$\partial \mathrm{C} / \partial \mathrm{q} \quad$ Captures the change in cost caused by a unit change in the size of land put under operation which is generally positive. It is the direct effect of land size decision on cost.

$\mathrm{L}(\mathrm{t}) \quad$ Measures the marginal cost of land.

Similarly, equation 5 reiterates the economic condition that the benefit obtained from determining land size to put in use should equate the costs associated with it at the margin. Otherwise, a selected land size will not be optimal and hence will not satisfy the profit maximization goal.

\section{Comparative Statics Considerations}

In the previous mathematical setup, distance and land size variables were solved for given levels of revenue, cost and land price. In a way the solution can be regarded as a snapshot picture of an equilibrium given the mentioned variables at some level. However, technology and markets as well as a number of regulatory and institutional factors can affect the cost and revenue structures as well as the value of land. This will dynamically affect the spatial feature of economic activities. Though dynamics is beyond the intent of this research work, particular mathematical comparative statics are developed and discussed below to shed light on the effect of exogenous variables on decisions of location and land use. 
Restating the profit maximization mathematical expression and solving for first order conditions gives:

$$
\begin{aligned}
& \operatorname{Max} \pi=\mathrm{R}(\mathrm{t}, \mathrm{q})-\mathrm{C}(\mathrm{R}, \mathrm{t}, \mathrm{q})-\mathrm{L}(\mathrm{t}) \mathrm{q} \\
& \partial \pi / \partial \mathrm{t}=\partial \mathrm{R} / \partial \mathrm{t}-(\partial \mathrm{C} / \partial \mathrm{R})(\partial \mathrm{R} / \partial \mathrm{t})-\partial \mathrm{C} / \partial \mathrm{t}-\mathrm{q}(\partial \mathrm{L} / \partial \mathrm{t})=0 \\
& \partial \pi / \partial \mathrm{q}=\partial \mathrm{R} / \partial \mathrm{q}-(\partial \mathrm{C} / \partial \mathrm{R})(\partial \mathrm{R} / \partial \mathrm{q})-\partial \mathrm{C} / \partial \mathrm{q}-\mathrm{L}(\mathrm{t})=0
\end{aligned}
$$

Hence, $\partial \pi / \partial t=\partial \pi / \partial t(R, C, L, t, q)$

$$
\partial \pi / \partial q=\partial \pi / \partial q(R, C, L, t, q)
$$

Totally differentiating 3 and 4 gives:

$$
\begin{aligned}
& \mathrm{d}(\partial \pi / \partial \mathrm{t})=[\partial(\partial \pi / \partial \mathrm{t}) / \partial \mathrm{R}] \mathrm{dR}+[\partial(\partial \pi / \partial \mathrm{t}) / \partial \mathrm{C}] \mathrm{dC}+[\partial(\partial \pi / \partial \mathrm{t}) / \partial \mathrm{L}] \mathrm{dL}+[\partial(\partial \pi / \partial \mathrm{t}) / \partial \mathrm{t}] \mathrm{dt} \\
& +[\partial(\partial \pi / \partial \mathrm{t}) / \partial \mathrm{q}] \mathrm{dq}=0 \\
& \mathrm{~d}(\partial \pi / \partial \mathrm{q})=[\partial(\partial \pi / \partial \mathrm{q}) / \partial \mathrm{R}] \mathrm{dR}+[\partial(\partial \pi / \partial \mathrm{q}) / \partial \mathrm{C}] \mathrm{dC}+[\partial(\partial \pi / \partial \mathrm{q}) / \partial \mathrm{L}] \mathrm{dL}+ \\
& {[\partial(\partial \pi / \partial \mathrm{q}) / \partial \mathrm{t}] \mathrm{dt}+[\partial(\partial \pi / \partial \mathrm{q}) / \partial \mathrm{q}] \mathrm{dq}=0}
\end{aligned}
$$

With alternative notations the above differentiations can be restated for convenience as:

$$
\begin{aligned}
& \mathrm{d} \pi_{\mathrm{t}}=\pi_{\mathrm{tR}} \mathrm{dR}+\pi_{\mathrm{tC}} \mathrm{dC}+\pi_{\mathrm{tL}} \mathrm{dL}+\pi_{\mathrm{tt}} \mathrm{dt}+\pi_{\mathrm{tq}} \mathrm{dq}=0 \\
& \mathrm{~d} \pi_{\mathrm{q}}=\pi_{\mathrm{qR}} \mathrm{dR}+\pi_{\mathrm{qC}} \mathrm{dC}+\pi_{\mathrm{qL}} \mathrm{dL}+\pi_{\mathrm{qt}} \mathrm{dt}+\pi_{\mathrm{qq}} \mathrm{dq}=0
\end{aligned}
$$

Separating endogenous and exogenous variables (or decision variables from the others) results in:

$$
\begin{aligned}
& \pi_{\mathrm{tt}} \mathrm{dt}+\pi_{\mathrm{tq}} \mathrm{dq}=-\pi_{\mathrm{tR}} \mathrm{dR}-\pi_{\mathrm{tC}} \mathrm{dC}-\pi_{\mathrm{tL}} \mathrm{dL} \\
& \pi_{\mathrm{qt}} \mathrm{dt}+\pi_{\mathrm{qq}} \mathrm{dq}=-\pi_{\mathrm{qR}} \mathrm{dR}-\pi_{\mathrm{qC}} \mathrm{dC}-\pi_{\mathrm{qL}} \mathrm{dL}
\end{aligned}
$$

Restating in a matrix form:

$$
\left(\begin{array}{cc}
\pi_{\mathrm{tt}} & \pi_{\mathrm{tq}} \\
\pi_{\mathrm{qt}} & \pi_{\mathrm{qq}}
\end{array}\right)\left(\begin{array}{l}
\mathrm{dt} \\
\mathrm{dq}
\end{array}\right)=\left(\begin{array}{l}
-\pi_{\mathrm{tR}} \mathrm{dR}-\pi_{\mathrm{tC}} \mathrm{dC}-\pi_{\mathrm{tL}} \mathrm{dL} \\
-\pi_{\mathrm{qR}} \mathrm{dR}-\pi_{\mathrm{qC}} \mathrm{dC}-\pi_{\mathrm{qL}} \mathrm{dL}
\end{array}\right)
$$




$$
\begin{gathered}
\mathrm{dt}=\frac{\left(\begin{array}{cc}
-\pi_{\mathrm{tR}} \mathrm{dR}-\pi_{\mathrm{tC}} \mathrm{dC}-\pi_{\mathrm{tL}} \mathrm{dL} & \pi_{\mathrm{tq}} \\
-\pi_{\mathrm{qR}} \mathrm{dR}-\pi_{\mathrm{qC}} \mathrm{dC}-\pi_{\mathrm{qL}} \mathrm{dL} & \pi_{\mathrm{qq}}
\end{array}\right)}{\left(\begin{array}{cc}
\pi_{\mathrm{tt}} & \pi_{\mathrm{tq}} \\
\pi_{\mathrm{qt}} & \pi_{\mathrm{qq}}
\end{array}\right)} \\
\text { (12) } \mathrm{dt}=\frac{-\pi_{\mathrm{qq}}\left(\pi_{\mathrm{tR}} \mathrm{dR}+\pi_{\mathrm{tC}} \mathrm{dC}+\pi_{\mathrm{tL}} \mathrm{dL}\right)+\pi_{\mathrm{tq}}\left(\pi_{\mathrm{qR}} \mathrm{dR}-\pi_{\mathrm{qC}} \mathrm{dC}-\pi_{\mathrm{qL}} \mathrm{dL}\right)}{\pi_{\mathrm{tt}} \pi_{\mathrm{qq}}-\left(\pi_{\mathrm{tq}}\right)^{2}}
\end{gathered}
$$

Assuming that the second order conditions for unconstrained optimum is satisfied with $\pi_{\mathrm{tt}}<0$ and $\pi_{\mathrm{tt}} \pi_{\mathrm{qq}}-\left(\pi_{\mathrm{tq}}\right)^{2}>0^{7}$, comparative statics with respect to $\mathrm{dt} / \mathrm{dR}, \mathrm{dt} / \mathrm{dC}, \mathrm{dC} / \mathrm{dL}$ can be analyzed by alternately setting any other two exogenous variables to zero. For instance, $\mathrm{dt} / \mathrm{dR}$ (letting $\mathrm{dC}=\mathrm{dL}=0$ ) equals:

$$
\mathrm{dt} / \mathrm{dR}=\frac{\left(\pi_{\mathrm{tq}}\right)\left(\pi_{\mathrm{qR}}\right)-\left(\pi_{\mathrm{qq}}\right)\left(\pi_{\mathrm{tR}}\right)}{\pi_{\mathrm{tt}} \pi_{\mathrm{qq}}-\left(\pi_{\mathrm{tq}}\right)^{2}}
$$

From this relationship it can be seen that not only does location determine revenue, but revenue also determines the location of the firm. Thus, relaxing the analysis of location and land use decisions in a given cost, revenue and land cost environments will lead to a dynamic analysis of the issue. This is one reason why some variables still need to be held constant in the comparative statics analysis. The comparative static results will indicate the influence of an exogenous variable on the location decision.

Similarly,

$$
\mathrm{dq}=\frac{\left(\begin{array}{cc}
\pi_{\mathrm{tt}} & -\pi_{\mathrm{tR}} \mathrm{dR}-\pi_{\mathrm{tC}} \mathrm{dC}-\pi_{\mathrm{tL}} \mathrm{dL} \\
\pi_{\mathrm{qt}} & -\pi_{\mathrm{qR}} \mathrm{dR}-\pi_{\mathrm{qC}} \mathrm{dC}-\pi_{\mathrm{qL}} \mathrm{dL}
\end{array}\right)}{\left(\begin{array}{ll}
\pi_{\mathrm{tt}} & \pi_{\mathrm{tq}} \\
\pi_{\mathrm{qt}} & \pi_{\mathrm{qq}}
\end{array}\right)}
$$

\footnotetext{
${ }^{7}$ From Young's Theorem $\pi \mathrm{tq}=\pi \mathrm{qt}$. Since the order of differentiation does not matter, $(\pi \mathrm{tq})(\pi \mathrm{qt})$ can be written as $(\pi \mathrm{tq})^{2}$.
} 


$$
\mathrm{dq}=\frac{-\pi_{\mathrm{tt}}\left(\pi_{\mathrm{qR}} \mathrm{dR}+\pi_{\mathrm{qC}} \mathrm{dC}+\pi_{\mathrm{qL}} \mathrm{dL}\right)+\pi_{\mathrm{qt}}\left(\pi_{\mathrm{tR}} \mathrm{dR}+\pi_{\mathrm{tC}} \mathrm{dC}+\pi_{\mathrm{tL}} \mathrm{dL}\right)}{\pi_{\mathrm{tt}} \pi_{\mathrm{qq}}-\left(\pi_{\mathrm{tq}}\right)^{2}}
$$

Comparative static results can be generated for $\mathrm{dq} / \mathrm{dR}, \mathrm{dq} / \mathrm{dC}$, and $\mathrm{dq} / \mathrm{dL}$. For instance, $\mathrm{dq} / \mathrm{dL}$ (by letting $\mathrm{dR}=\mathrm{dC}=0$ ) provides:

$$
\mathrm{dq} / \mathrm{dL}=\frac{\left(\pi_{\mathrm{qt}}\right)\left(\pi_{\mathrm{tL}}\right)-\left(\pi_{\mathrm{tt}}\right)\left(\pi_{\mathrm{qL}}\right)}{\left(\pi_{\mathrm{tt}}\right)\left(\pi_{\mathrm{qq}}\right)-\left(\pi_{\mathrm{tq}}\right)^{2}}
$$

The comparative static results from the consideration of the optimal land size decision and exogenous variable of interest can provide relevant information on the sensitivity of optimal land size considerations with respect to changes in those exogenous variables.

\subsubsection{Mathematical Consideration of Land-Use and Location Decisions for Personal Consumption Purposes (Consumers)}

Yet another spatial pressure on the use of land comes from consumers for purposes of residence and related personal uses, or as usually referred to as "direct consumption." Mathematically, following Alonso, (1964), the economic behavior of consumers with regard to location and plot size use can be characterized as follows.

$$
\begin{aligned}
& \operatorname{Max} U=U(h, q, t) \\
& \begin{aligned}
\text { Where } U= & \text { Utility } \\
h= & \text { a bundle of all other goods and services the consumer may prefer to } \\
& \text { consume } \\
\mathrm{q}= & \text { the quantity of land preferred for direct uses } \\
& t=\text { the location/distance from a given population center }
\end{aligned}
\end{aligned}
$$

The consumer's goal is to maximize the level of attainable utility arising from a decision to consume a given combination of $\mathrm{h}, \mathrm{q}$, and t. Location $(\mathrm{t})$ could be viewed as a consumable commodity as it generates its own utility, including scenic values and safe 
neighborhoods. h can be viewed as a Hicksian bundle or a composite good the consumer may prefer to consume.

However, the choice of a maximum level of utility by the consumer is limited by a budget constraint. It can generally be stated that given the utility maximization objective of the consumer, the budget of the consumer (income) can be fully allocated among consumption options of $\mathrm{h}, \mathrm{t}$ and $\mathrm{q}$. From this it can be stated that the price of these options times the quantity of each that the consumer may prefer to consume cannot exceed the available resource of the consumer - the budget constraint. Mathematically, it can be expressed as:

$$
\begin{aligned}
& \mathrm{Y}=\mathrm{P}_{\mathrm{h}} \mathrm{h}+\mathrm{P}(\mathrm{t}) \mathrm{q}+\mathrm{C}_{\mathrm{k}}(\mathrm{t})^{8} \\
& \text { where } \mathrm{Y}=\text { income } \\
& \mathrm{P}_{\mathrm{h}}=\text { price of the composite good/commodity bundle } \\
& \mathrm{h}=\mathrm{a} \text { basket of preffered consumption goods/commodity bundle } \\
& \mathrm{P}(\mathrm{t})=\text { the price of land at a given location } \mathrm{t} \\
& q=\text { the quantity of land for private consumptive uses } \\
& C_{k}(t)=\text { the cost of commuting to a center from location/distance } t
\end{aligned}
$$

The decision problem to the consumer here is, given prices and income, what level of $\mathrm{h}$ (a consumption bundle), q (land size to use for private purposes), and $\mathrm{t}$ (at what distance from the center of activity) will satisfy maximum utility within the existing budget constraint. The utility function, $\mathrm{U}=\mathrm{U}(\mathrm{h}, \mathrm{q}, \mathrm{t})$, is at maximum when $\mathrm{dU}=0$. Totally differentiating $U$ we get:

$$
\mathrm{dU}=(\partial \mathrm{U} / \partial \mathrm{h}) \mathrm{dh}+(\partial \mathrm{U} / \partial \mathrm{q}) \mathrm{dq}+(\partial \mathrm{U} / \partial \mathrm{t}) \mathrm{dt}=0
$$

Holding $\mathrm{t}$ constant at some given distance $(\mathrm{dt}=0)$ we have:

\footnotetext{
${ }^{8}$ The setup of the budget constraint implicitly suppresses possible savings. Consequently, it disregards utility associated with savings. This topic is not critically relevant to the present case, however, Y can be viewed as discretionary income (total income less obligatory payments - for example, taxes and savings) for allocation among goods to attain maximum utility associated with that level of resource.
} 


$$
\begin{aligned}
& \mathrm{dU}=(\partial \mathrm{U} / \partial \mathrm{h}) \mathrm{dh}+(\partial \mathrm{U} / \partial \mathrm{q}) \mathrm{dq}=0 \\
& (\partial \mathrm{U} / \partial \mathrm{h}) \mathrm{dh}=(-\partial \mathrm{U} / \partial \mathrm{q}) \mathrm{dq}
\end{aligned}
$$

$$
-\mathrm{dh} / \mathrm{dq}=(\partial \mathrm{U} / \partial \mathrm{q}) /(\partial \mathrm{U} / \partial \mathrm{h})
$$

Now holding q constant at some size $(\mathrm{dq}=0)$ we have:

$$
\begin{aligned}
& \mathrm{dU}=(\partial \mathrm{U} / \partial \mathrm{h}) \mathrm{dh}+(\partial \mathrm{U} / \partial \mathrm{t}) \mathrm{dt}=0 \\
& (\partial \mathrm{U} / \partial \mathrm{h}) \mathrm{dh}=(-\partial \mathrm{U} / \partial \mathrm{t}) \mathrm{dt} \\
& -\mathrm{dh} / \mathrm{dt}=(\partial \mathrm{U} / \partial \mathrm{t}) /(\partial \mathrm{U} / \partial \mathrm{h})
\end{aligned}
$$

Important information can also be captured by totally differentiating the budget constraint. From equation 15 we can see that a change in income affects h, q, k and p. This means as income changes, the amount of $\mathrm{h}$ one can afford changes. Similarly, the amount of land preferred and the amount we can afford to spend on commuting changes (implicitly affecting location since $\mathrm{C}_{\mathrm{k}}(\mathrm{t})$ ). The price of land also changes as it depends on where it is located. However, assuming perfect competition in all markets, the prices remain unaffected by a change in income since a given consumer has limited influence over market prices, as there are many buyers and sellers. Therefore, $\mathrm{dY}$ can be expressed as:

$$
d \mathrm{Y}=(\partial \mathrm{Y} / \partial \mathrm{h}) \mathrm{dh}+(\partial \mathrm{Y} / \partial \mathrm{q}) \mathrm{dq}+\left(\partial \mathrm{Y} / \partial \mathrm{C}_{\mathrm{k}}(\mathrm{t})\right)\left(\partial \mathrm{C}_{\mathrm{k}}(\mathrm{t}) / \partial \mathrm{t}\right) \mathrm{dt}+(\partial \mathrm{Y} / \partial \mathrm{p}(\mathrm{t}))(\partial \mathrm{p}(\mathrm{t}) / \partial \mathrm{t}) \mathrm{dt}=0
$$

Substituting the relevant partial derivatives from equation 2 we get:

$$
\begin{aligned}
& d Y=P_{h} d h+P(t) d q+\left(d C_{k}(t) / d t\right) d t+q(d p(t) / d t) d t=0 \\
& P_{h} d h+P(t) d q+\left[\left(d C_{k}(t) / d t\right)+q(d p(t) / d t)\right] d t=0
\end{aligned}
$$

Since the problem deals with a three-dimensional surface, a cross section at a constant $Y$ can be evaluated by holding $\mathrm{t}$ and $\mathrm{q}$ variables constant separately. The cross sectional representation when $t$ is held constant is: 


$$
\begin{aligned}
& \mathrm{P}_{\mathrm{h}} \mathrm{dh}+\mathrm{P}(\mathrm{t}) \mathrm{dq}=0 \\
& \mathrm{P}_{\mathrm{h}} \mathrm{dh}=-\mathrm{P}(\mathrm{t}) \mathrm{dq} \\
\text { (21) } \quad & -\mathrm{dh} / \mathrm{dq}=\mathrm{P}(\mathrm{t}) / \mathrm{P}_{\mathrm{h}}
\end{aligned}
$$

Letting $\mathrm{t}$ vary and holding $\mathrm{q}$ constant, the cross sectional representation yields:

$$
\begin{aligned}
& P_{h} d h+\left[\left(d C_{k}(t) / d t\right)+q(d p(t) / d t)\right] d t=0 \\
& P_{h} d h=-\left[\left(d C_{k}(t) / d t\right)+q(d p(t) / d t)\right] d t \\
& -d h / d t=\left[\left(d C_{k}(t) / d t\right)+q(d p(t) / d t)\right] / P_{h}
\end{aligned}
$$

Equating equations 17 and 21:

$$
-\mathrm{dh} / \mathrm{dq}=\mathrm{P}(\mathrm{t}) / \mathrm{P}_{\mathrm{h}}=-\mathrm{dh} / \mathrm{dq}=(\partial \mathrm{U} / \partial \mathrm{q}) /(\partial \mathrm{U} / \partial \mathrm{h}
$$

$$
\mathrm{P}(\mathrm{t}) / \mathrm{P}_{\mathrm{h}}=(\partial \mathrm{U} / \partial \mathrm{q}) /(\partial \mathrm{U} / \partial \mathrm{h})
$$

Equating equations 18 and 22:

$-\mathrm{dh} / \mathrm{dt}=(\partial \mathrm{U} / \partial \mathrm{t}) /(\partial \mathrm{U} / \partial \mathrm{h})=-\mathrm{dh} / \mathrm{dt}=\left[\left(\mathrm{dC}_{\mathrm{k}}(\mathrm{t}) / \mathrm{dt}\right)+\mathrm{q}(\mathrm{dp}(\mathrm{t}) / \mathrm{dt})\right] / \mathrm{P}_{\mathrm{h}}$

$$
(\partial \mathrm{U} / \partial \mathrm{t}) /(\partial \mathrm{U} / \partial \mathrm{h})=\left[\left(\mathrm{dC}_{\mathrm{k}}(\mathrm{t}) / \mathrm{dt}\right)+\mathrm{q}(\mathrm{dp}(\mathrm{t}) / \mathrm{dt})\right] / \mathrm{P}_{\mathrm{h}}
$$

Therefore, solving for the utility maximization and the budget constraint conditions, the consumer will optimally decide on the allocation of the budget between $\mathrm{h}^{*}, \mathrm{q}^{*}$, and $\mathrm{t}^{*}$.

Equations 23 and 24 hold key information about the utility maximization condition. Equation 23 dictates that at optimal the Marginal Rate of Substitution of land and the composite goods should equal their price ratios. Similarly, equation 24 dictates that the Marginal Rate of Substitution between distance and the bundle of goods should equal their price/marginal cost ratio. Though $\mathrm{P}_{\mathrm{h}}$ is easily understood as price of the composite goods, $\left[\left(\mathrm{dC}_{\mathrm{k}}(\mathrm{t}) / \mathrm{dt}\right)+\mathrm{q}(\mathrm{dp}(\mathrm{t}) / \mathrm{dt})\right]$ associated with $(\partial \mathrm{U} / \partial \mathrm{t})$ deserves some explanation. $\left(\mathrm{dC}_{\mathrm{k}}(\mathrm{t}) / \mathrm{dt}\right)$ captures the change in commuting cost with a change in distance and $\mathrm{q}(\mathrm{dp}(\mathrm{t}) / \mathrm{dt})$ captures a resulting change in land prices with a change in distance. 
From equation 24, we can extract one more vital piece of information. One can easily argue that $\mathrm{P}_{\mathrm{h}}, \partial \mathrm{U} / \partial \mathrm{h}, \mathrm{q} \geq 0$. Prices and quantities are typically positive. ${ }^{9}$ Utility increases as a person gets more and more consumable commodities hence $\partial \mathrm{U} / \partial \mathrm{h}>0$. However, $\partial \mathrm{U} / \partial \mathrm{t}<0$ since the further one is located from the center of activity, the more discomfort and disutility may arise through spending more time and resources on commuting. $\mathrm{dC}_{\mathrm{k}}(\mathrm{t}) / \mathrm{dt}>0$ as commuting costs increase with distance. Therefore, it is possible to isolate $\mathrm{dp}(\mathrm{t}) / \mathrm{dt}<0$ for the whole relationship to hold. Thus, it can be concluded that the individual will commute so long as $|\mathrm{dp}(\mathrm{t}) / \mathrm{dt}| \geq \mathrm{dC}_{\mathrm{k}}(\mathrm{t}) / \mathrm{dt}$, i.e, so long as the savings in land associated with distance from a center exceeds the marginal cost of transportation to the center. The person avoids locations where $\mathrm{dC}_{\mathrm{k}}(\mathrm{t}) / \mathrm{dt}>|\mathrm{dp}(\mathrm{t}) / \mathrm{dt}|$, ceteris paribus.

An interesting argument can be raised that though the commuting cost is greater than the savings from land, such locations may be preferred if they have high quality natural amenities that are not reflected in the market. In this case, it is assumed here that all other variables that interact in the system are assumed constant. The inclusion of such variables will not alter the microeconomic foundation if amenity values are translated in the market or if such considerations directly enter the utility function of individuals.

\section{Comparative Static Considerations}

As in the case of firms, similar comparative statics analysis can be developed for the utility maximization problem. Setting up and solving the system for first order conditions yields:

$$
\begin{aligned}
& \text { Max } U=U(h, q, t) \\
& \text { s.t. } Y=P_{h} h+P(t) q+C_{k}(t)
\end{aligned}
$$

Setting up the Lagrangian expression and solving for first order conditions yields:

\footnotetext{
${ }^{9}$ Under rare analytical circumstances prices can assume negative values when resources are received with a per unit payment for receiving them. Poultry litter could be an example. Litter can be used as an input in a farm while the chicken producer may pay per unit price for disposing his litter off his plant to the farm. Hence the farmer can get the litter at a negative price. This discussion is irrelevant for most economic analysis since it is a rare economic phenomenon.
} 


$$
\begin{aligned}
\mathrm{L}=\mathrm{U}(\mathrm{h}, \mathrm{q}, \mathrm{t}) & +\lambda\left[\mathrm{Y}-\mathrm{P}_{\mathrm{h}} \mathrm{h}-\mathrm{P}(\mathrm{t}) \mathrm{q}-\mathrm{C}_{\mathrm{k}}(\mathrm{t})\right] \\
\partial \mathrm{L} / \partial \mathrm{h} & =\partial \mathrm{U} / \partial \mathrm{h}-\lambda \mathrm{P}_{\mathrm{h}}=0 \\
\partial \mathrm{L} / \partial \mathrm{q} & =\partial \mathrm{U} / \partial \mathrm{q}-\lambda \mathrm{P}(\mathrm{t})=0 \\
\partial \mathrm{L} / \partial \mathrm{t} & =\partial \mathrm{U} / \partial \mathrm{t}-\lambda\left[\mathrm{q}(\partial \mathrm{P} / \partial \mathrm{t})-\partial \mathrm{C}_{\mathrm{k}} / \partial \mathrm{t}\right]=0 \\
\partial \mathrm{L} / \partial \lambda & =\mathrm{Y}-\mathrm{P}_{\mathrm{h}} \mathrm{h}-\mathrm{P}(\mathrm{t}) \mathrm{q}-\mathrm{C}_{\mathrm{k}}(\mathrm{t})=0
\end{aligned}
$$

The first order conditions can be expressed in a function as:

$\partial \mathrm{L} / \partial \mathrm{h}=\partial \mathrm{L} / \partial \mathrm{h}\left(\lambda, \mathrm{h}, \mathrm{q}, \mathrm{t}, \mathrm{P}_{\mathrm{h}}\right)$

$\partial \mathrm{L} / \partial \mathrm{q}=\partial \mathrm{L} / \partial \mathrm{q}(\lambda, \mathrm{h}, \mathrm{q}, \mathrm{t}, \mathrm{P}(\mathrm{t}))$

$\partial \mathrm{L} / \partial \mathrm{t}=\partial \mathrm{L} / \partial \mathrm{t}\left(\lambda, \mathrm{h}, \mathrm{q}, \mathrm{t}, \mathrm{P}(\mathrm{t}), \mathrm{C}_{\mathrm{k}}(\mathrm{t})\right)$

$\partial \mathrm{L} / \partial \lambda=\partial \mathrm{L} / \partial \lambda\left(\lambda, \mathrm{h}, \mathrm{q}, \mathrm{t}, \mathrm{Y}, \mathrm{P}_{\mathrm{h}}, \mathrm{P}(\mathrm{t}), \mathrm{C}_{\mathrm{k}}(\mathrm{t})\right)$

Totally differentiating the functional expressions yields:

$$
\begin{aligned}
\mathrm{d}(\partial \mathrm{L} / \partial \mathrm{h})= & {[\partial(\partial \mathrm{L} / \partial \mathrm{h}) / \partial \lambda] \mathrm{d} \lambda+[\partial(\partial \mathrm{L} / \partial \mathrm{h}) / \partial \mathrm{h}] \mathrm{dh}+[\partial(\partial \mathrm{L} / \partial \mathrm{h}) / \partial \mathrm{q}] \mathrm{dq}+} \\
& {[\partial(\partial \mathrm{L} / \partial \mathrm{h}) / \partial \mathrm{t}] \mathrm{dt}+\left[\partial(\partial \mathrm{L} / \partial \mathrm{h}) / \partial \mathrm{P}_{\mathrm{h}}\right] \mathrm{dP}_{\mathrm{h}}=0 } \\
\mathrm{~d}(\partial \mathrm{L} / \partial \mathrm{q})= & {[\partial(\partial \mathrm{L} / \partial \mathrm{q}) / \partial \lambda] \mathrm{d} \lambda+[\partial(\partial \mathrm{L} / \partial \mathrm{q}) / \partial \mathrm{h}] \mathrm{dh}+[\partial(\partial \mathrm{L} / \partial \mathrm{q}) / \partial \mathrm{q}] \mathrm{dq}+} \\
& {[\partial(\partial \mathrm{L} / \partial \mathrm{q}) / \partial \mathrm{t}] \mathrm{dt}+[(\partial(\partial \mathrm{L} / \partial \mathrm{q}) / \partial \mathrm{P}(\mathrm{t}))] \mathrm{dP}(\mathrm{t})=0 } \\
\mathrm{~d}(\partial \mathrm{L} / \partial \mathrm{t})= & {[\partial(\partial \mathrm{L} / \partial \mathrm{t}) / \partial \lambda] \mathrm{d} \lambda+[\partial(\partial \mathrm{L} / \partial \mathrm{t}) / \partial \mathrm{h}] \mathrm{dh}+[\partial(\partial \mathrm{L} / \partial \mathrm{t}) / \partial \mathrm{q}] \mathrm{dq}+[\partial(\partial \mathrm{L} / \partial \mathrm{t}) / \partial \mathrm{t}] \mathrm{dt}+} \\
& {[(\partial(\partial \mathrm{L} / \partial \mathrm{t}) / \partial \mathrm{P}(\mathrm{t}))] \mathrm{dP}(\mathrm{t})+\left[\left(\partial(\partial \mathrm{L} / \partial \mathrm{t}) / \partial \mathrm{C}_{\mathrm{k}}(\mathrm{t})\right)\right] \mathrm{d} \mathrm{C}_{\mathrm{k}}(\mathrm{t})=0 } \\
\mathrm{~d}(\partial \mathrm{L} / \partial \lambda)= & {[\partial(\partial \mathrm{L} / \partial \mathrm{\lambda}) / \partial \lambda] \mathrm{d} \lambda+[\partial(\partial \mathrm{L} / \partial \lambda) / \partial \mathrm{h}] \mathrm{dh}+[\partial(\partial \mathrm{L} / \partial \lambda) / \partial \mathrm{q}] \mathrm{dq}+} \\
& {[\partial(\partial \mathrm{L} / \partial \lambda) / \partial \mathrm{t}] \mathrm{dt}+[\partial(\partial \mathrm{L} / \partial \lambda) / \partial \mathrm{Y})] \mathrm{dY}+\left[\partial(\partial \mathrm{L} / \partial \lambda) / \partial \mathrm{P}_{\mathrm{h}}\right] \mathrm{dP}_{\mathrm{h}}+} \\
& {[(\partial(\partial \mathrm{L} / \partial \lambda) / \partial \mathrm{P}(\mathrm{t}))] \mathrm{dP}(\mathrm{t})+\left[\left(\partial(\partial \mathrm{L} / \partial \lambda) / \partial \mathrm{C}_{\mathrm{k}}(\mathrm{t})\right)\right] \mathrm{dC}_{\mathrm{k}}(\mathrm{t})=0 }
\end{aligned}
$$

For convenience, this can alternatively be expressed in a different notation as:

$$
\begin{aligned}
d L h= & L_{h \lambda} d \lambda+L_{h h} d h+L_{h q} d q+L_{h t} d t+L_{h P_{h}} d P_{h}=0 \\
d L q= & L_{q \lambda} d \lambda+L_{q h} d h+L_{q q} d q+L_{q t} d t+L_{q}(t) d P(t)=0 \\
d L t= & L_{t \lambda} d \lambda+L_{t h} d h+L_{t q} d q+L_{t t} d t+L_{t P(t)} d P(t)+{ }_{L t C k(t)} d C_{k}(t)=0 \\
d L \lambda= & L_{\lambda \lambda} d \lambda+L_{\lambda h} d h+L_{\lambda q} d q+L_{\lambda t} d t+L_{\lambda Y} d Y+L_{\lambda P h} d_{h}+L_{\lambda P(t)} d P(t)+ \\
& L_{\lambda C k(t)} d C_{k}(t)=0
\end{aligned}
$$




\section{Rearranging:}

$$
\begin{aligned}
& L_{h \lambda} d \lambda+L_{h h} d h+L_{h q} d q+L_{h t} d t=-L_{h P h} d P_{h} \\
& L_{q \lambda} d \lambda+L_{q h} d h+L_{q q} d q+L_{q t} d t=-L_{q P(t)} d P(t) \\
& L_{t \lambda} d \lambda+L_{t h} d h+L_{t q} d q+L_{t t} d t=-L_{t P(t)} d P(t)-\left(L_{t C k(t)} d C_{k}(t)\right. \\
& L_{\lambda \lambda} d \lambda+L_{\lambda h} d h+L_{\lambda q} d q+L_{\lambda t} d t=-L_{\lambda P(t)} d P(t)-L_{\lambda C k(t)} d C_{k}(t)-L_{\lambda Y} d Y-L_{\lambda P h d} P_{h}
\end{aligned}
$$

$$
\left(\begin{array}{cccc}
\mathrm{L}_{\lambda \lambda} & \mathrm{L}_{\lambda h} & \mathrm{~L}_{\lambda \mathrm{q}} & \mathrm{L}_{\lambda t} \\
\mathrm{~L}_{\mathrm{h} \lambda} & \mathrm{L}_{\mathrm{hh}} & \mathrm{L}_{\mathrm{hq}} & \mathrm{L}_{\mathrm{ht}} \\
\mathrm{L}_{\mathrm{q} \lambda} & \mathrm{L}_{\mathrm{qh}} & \mathrm{L}_{\mathrm{qq}} & \mathrm{L}_{\mathrm{qt}} \\
\mathrm{L}_{\mathrm{t} \lambda} & \mathrm{L}_{\mathrm{th}} & \mathrm{L}_{\mathrm{tq}} & \mathrm{L}_{\mathrm{tt}}
\end{array}\right)\left(\begin{array}{c}
\mathrm{d} \lambda \\
\mathrm{dh} \\
\mathrm{dq} \\
\mathrm{dt}
\end{array}\right)=\left(\begin{array}{c}
-\mathrm{L}_{\lambda \mathrm{P}(\mathrm{t})} \mathrm{dP}(\mathrm{t})-\mathrm{L}_{\lambda C k(t)} \mathrm{dC}_{\mathrm{k}}(\mathrm{t})-\mathrm{L}_{\lambda Y} \mathrm{dY}-\mathrm{L}_{\lambda \mathrm{Ph}} \mathrm{dP}_{\mathrm{h}} \\
-\mathrm{L}_{\mathrm{hPh}} \mathrm{dP}_{\mathrm{h}} \\
-\mathrm{L}_{\mathrm{qP}(\mathrm{t})} \mathrm{dP}(\mathrm{t}) \\
-\mathrm{L}_{\mathrm{tP}(\mathrm{t})} \mathrm{dP}(\mathrm{t})-\mathrm{L}_{\mathrm{tCk}(\mathrm{t})} \mathrm{dC}_{\mathrm{k}}(\mathrm{t})
\end{array}\right)
$$

Solutions for $\mathrm{d} \lambda$, $\mathrm{dh}$, $\mathrm{dq}$ and $\mathrm{dt}$ can be generated by applying Cramer's Rule to the matrices. Comparative statics can be carried out on dh/dp, dh/dy, dh/ $\mathrm{P}_{\mathrm{h}} \ldots$ etc and any other relationship of interest provided that the bordered Hessian matrix is negative definite.

To conclude, economic agents operate to maximize gains given different constraints. The allocation of land at a given location thus depends on which economic agent promises the payment of the highest bid rent depending on the relative benefit of the location (land) to any particular economic agent. The final spatial feature, thus, will be determined by the dynamics of economic interests and competition. 


\section{CHAPTER III}

\section{MODELING AGRICULTURAL LAND CONVERSION IN A REGIONAL GROWTH FRAMEWORK}

\subsection{GENERAL MODELING OVERVIEW}

The analysis and modeling of land use across different sectors of an economy and among different competing economic agents have been a concern for different disciplines. Numerous analyses have focused on this challenging issue from quite diverse perspective and approaches.

As outlined in the previous chapter, economic agents behave in maximizing behavioral interests. Consumers generally maximize utility given the consumption of different goods and services available in their endowment basket, which is subject to the individual's income. For the present topic of interest, land is one consumable good (for housing, recreation, open space, ...) that provides utility to consumers. Similarly, producers generally behave to maximize profits by efficiently utilizing factors to supply goods and/or services. Land, as a significant factor input, determines the cost as well as the revenue structure of business enterprises. Hence, an efficient location decision, as well as

efficient land size determination are criteria in the profit maximization endeavor. The competition for land results in spatial frictions that are evident across a given landscape through time.

Understanding the underlying economic motives of economic agents and capturing behavioral friction across space is a complex undertaking and a critical requirement in the modeling process of land use. A change in economic activity across space and gradual conversion of land to different uses can be captured accordingly.

Generally, the competing demands for a fixed physical supply of land for different uses can be treated as a special case of the overall determination of the flow of resources 
(factors), products and services in an economy. Broadly viewed, this process can be represented by the circular flow chart in figure 7 .

Fig. 7. Interdependent Circular Flow Chart

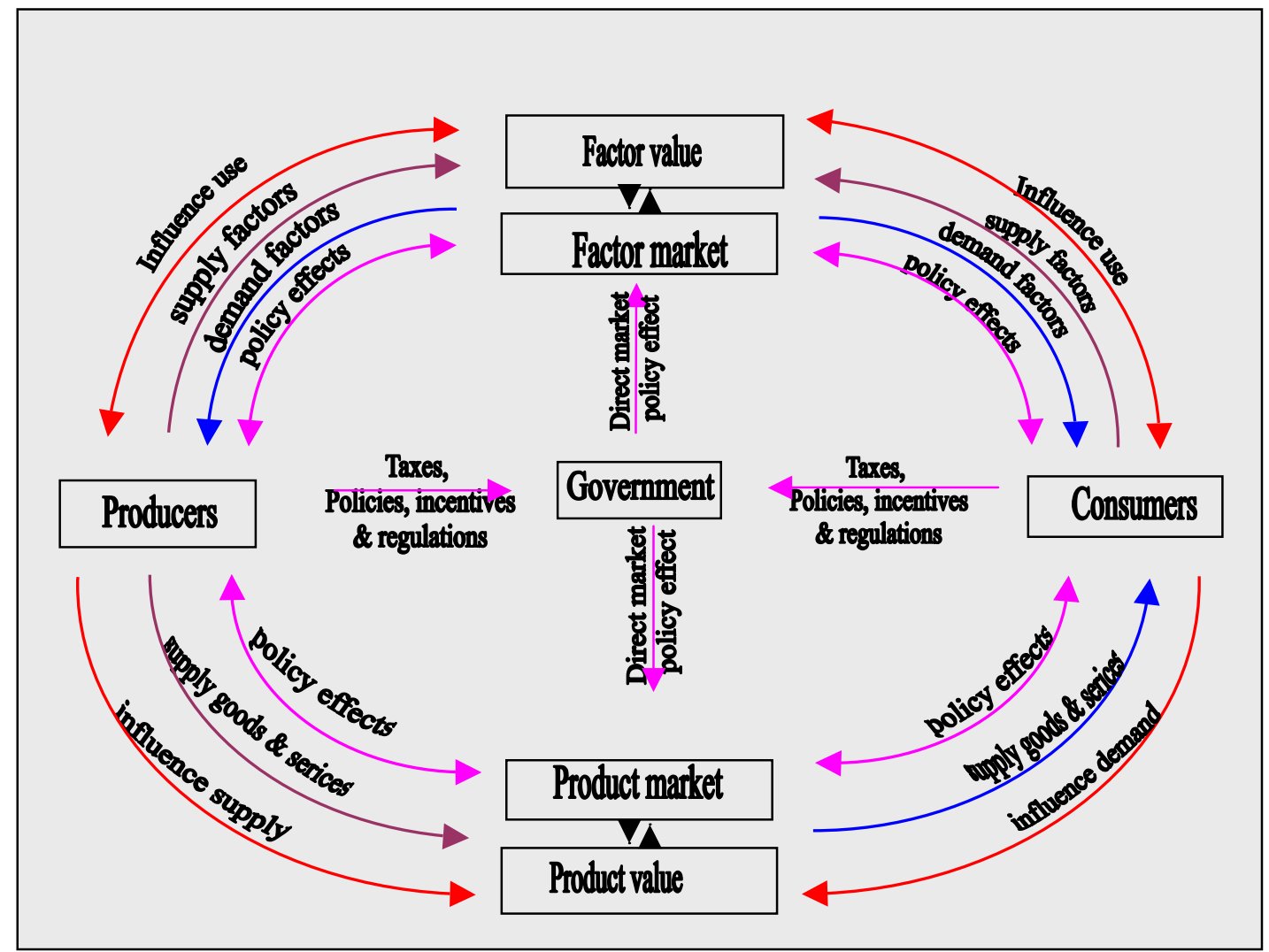

Traditionally, consumers (households) are treated as suppliers of factors (labor; capital) to producers through the factor market and earn factor compensation and income. Producers use these factor supplies in the production process to supply goods and services to consumers through the product market to generate profits. Government operates as providing the required market infrastructure, legal settings, and policies to coordinate producers and consumers. This emphasizes a unidirectional flow of resources and products across the economy.

However, as indicated in figure 7, the flow of resources is multidirectional involving use friction. Consumers (households) do not only supply factors but can also demand them from the factor market and producers not only demand factor inputs, they can decide to 
supply those factors in the factor market. Taking land as a significant input exchanged in the factor market, households (landlords) can supply land to the market for sale or rent the resource to generate a flow of financial endowments. However, households can also demand land to maintain higher utility from the flow of services of land to consumers. Similarly, businesses demand land as an input of production (both farm and non-farm businesses) to produce profit-generating outputs as well as to maintain locational cost and revenue advantages emanating from a given parcel at a particular location. However, as industry cost structures, technology, taste of consumers, government policies, environmental requirements, etc change, they may find it cost effective to relocate, hence supplying the present land holding back to the factor market. This is consistent with the assumption that firms are spatially mobile to maintain location equilibrium.

It should be noted, however, that though land can be shifted from one sector to the other with varying economic conditions and resulting changes in spatial feasibility, the return of non-agricultural sector land to agricultural uses seems less likely. Reverting land from non-agricultural sectors back to agriculture involves prohibitive costs of reclamation or cost that may not be sufficiently low to reclaim the land for agricultural use. However, agricultural lands, especially farmland, can be used at lower reclamation costs to other sectors. Thus, the ease of capital mobility across sectors is different.

It can be noted from the circular flow chart that there is immense interdependence among sectors. The simultaneous decisions of consumers and producers both in the product and factor markets affect the value of products and resources and their consequent distributional structure. Any change in the factor or product market by an exogenous event or endogenous decision factor affects the decision by different sectors in the economy, which in turn affects the efficiency and distribution of resource use.

Abstracting from the general framework, specific analogous representation can be established by focusing only on two sectors in the economy and narrowing resource consideration only to land. This intentional departure facilitates the framework for modeling land use changes across economic agents. 
Suburban and rural land, as indicated earlier, can be demanded for direct use by consumers and by agricultural and non-agricultural producers. Consumers' demand for land can be motivated by a number of factors. As indicated in figure 8 , consumers (households) tend to demand more sub-urban and rural land as population pressure and urban congestion intensifies and as the quality of life including natural amenities tend to be valued higher by households for housing and recreational purposes. Households can also be attracted to suburban areas for employment as there are growing small business enterprises across the urban fringe and emerging rural economies.

Fig. 8. Reduced Form Specialized Two Sectors Circular Flow Chart.

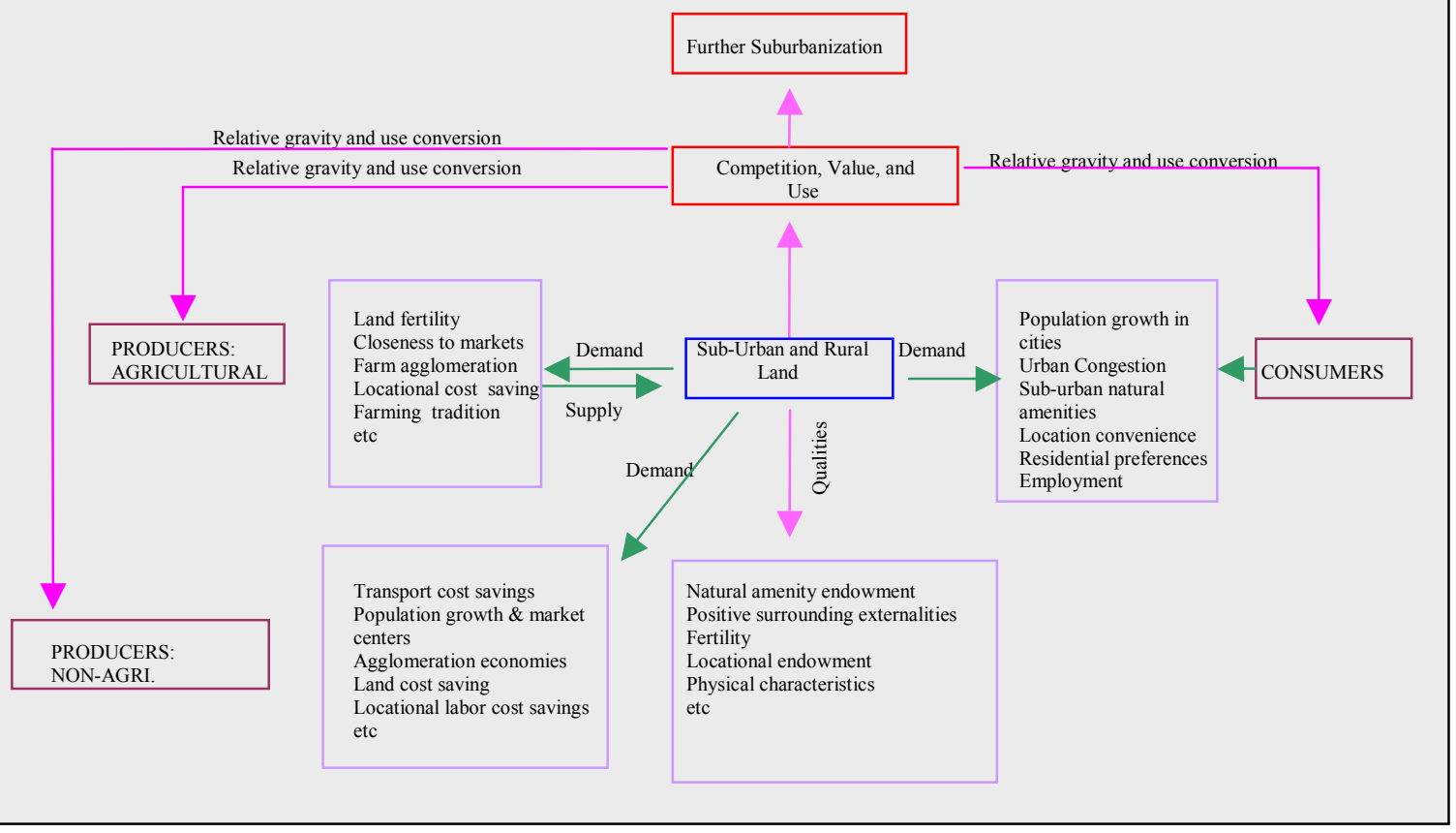

The demand of rural and suburban land for agricultural land purposes is motivated by fertility and location factors affecting the profit of farmers, the agglomeration of farms in the farm environment, and the farming tradition maintained for generations. However, with intensified competition over suburban land on the one hand and lesser per acre return of agricultural enterprises on the other has led to the conversion of land to other non-agricultural uses. This implies that the agricultural sector is not only a source of demand for land, but is also a net supplier of rural land for other competing uses. 
Non-agricultural producers are similarly motivated by locational convenience to maximize profits. Transportation costs and agglomeration economies can attract firms to a given location that generates better locational returns. Non-agricultural firms consider regional labor cost savings and market size in their location decision. Growing suburban population, transport savings and labor advantages can motivate firms to relocate to locations where such advantages are prevalent. This exerts pressure on the suburban land markets and increases the price of land.

In most cases, land demanded for different purposes in the suburban area satisfies certain qualities. Starting from locational convenience and nearness to big markets, it could provide positive environmental externalities and physical characteristics that could be of interest to developers. As the gravity over land intensifies, the value increases in the factor markets enabling one sector to outbid competing sectors. This gravity can enhance the conversion of agricultural lands to urban uses and contributes to further suburbanization. Though it is theoretically relevant to view firms as being mobile over space, the mobility of resources back to certain sectors is ambiguous. Though the relative strength of sectors in terms of bidding power can determine the flow of land resources, land taken away from agriculture is often irreversible.

From the established general framework, specific relationships in a regional growth frame can be generated for the modeling purpose. Generally, the changes in spatial land use features can be partially captured by aggregate changes in population and employment. The growth of population in suburban areas and metropolitan cities as well as the spread of small businesses and recreational and administrative land requirements can exert pressure on the current use of land.

Steinnes and Fisher (1974) introduced a model to simultaneously determine population and employment growth in an intraurban model. Similarly, Carlino \& Mills (1987) explored the determinants of population and employment densities interregionally in a theoretical framework that simultaneously determines employment and population densities. 
In the Carlino-Mills model, a general equilibrium approach addresses that both households and producers are geographically mobile. Consumers maximize utility, which depends on purchased goods and services, on locations relative to work places, and on spatially varying nonmarket amenities. A conventional budget constraint equates income to the sum of spending on goods and services. Profit-maximizing firms' production costs vary by location because of regional comparative advantages, including transport cost differentials, regional variation in labor supply, agglomeration economies, and state and local taxes. They assume that firms and households adjust to disequilibrium by distributed-lag adjustment equations. In such a model, equilibrium population and employment are simultaneously determined. (Carlino \& Mills, 1987).

A similar approach is also followed by Deller, et al., (2001) to investigate the nature and extent of economic structural change in the United States with a particular focus on the role of non-market amenity attributes. Based on free migration assumptions they identify the effects of amenity-based attributes on regional economic growth.

Following a similar modeling technique, Duffy-Deno, (1997) employed the regional growth model to analyze the economic effects of the Endangered Species Act through the estimation of the relationship between the number of listed species in a county and county employment growth during the 1980s. In this disequilibrium model of regional growth, where households and firms are assumed to be geographically mobile, a loglinear distributed adjustment lag model is introduced for population and employment interactions.

Following the spirit of the Carlino-Mills model, this research work employs the regional growth model to investigate the simultaneous interaction of employment, population, and agricultural lands to capture the impact of growth on agricultural land conversion in West Virginia. 


\subsection{EMPIRICAL MODEL}

Regional growth models are one approach to capture the effects of growth factors on the conversion of agricultural lands. As specified in the previous section, employment and population growth changes can explain the pressure on resources. Capturing the simultaneous interaction of population, employment, agricultural land and other relevant variables of interest would provide a picture of land conversion processes in the study area.

The empirical model is specified following the Carlino-Mills general equilibrium model where firms and households adjust to disequilibrium by distributed-lag adjustment equations.

It is assumed that consumers maximize utility by the consumption of a vector of goods and services. Consumers consume goods and services as well as location and nonmarket amenities to maximize their utility. Consumers are mobile over locations that maximize utility. The consumption of the vector of consumer choices is limited by income (budget). Households migrate until utilities are equalized at different alternative locations.

Producers are assumed to maximize profit from the production of goods and services. Firms select locations to capture locational cost and revenue advantages, minimize the cost of transportation, benefit from agglomeration, and regional labor supply differences. Firms enter and leave regions until competitive profits are equalized across regions.

It is also assumed that firms and households adjust to disequilibrium by distributed-lag adjustment equations. In a general equilibrium framework, population and employment are affected not only by each other, but also by a variety of other variables that affect numbers of jobs consistent with competitive profit rates and number of people consistent with equalized utility levels among places. In principle, many such variables might be simultaneously determined in such a general equilibrium model, along with population and employment (Carlino \& Mills, 1987). 
Thus, following the assumptions and simultaneous determination process, the general model can be specified as:

$$
\begin{aligned}
& \mathrm{E}^{*}=\Psi_{\mathrm{E}} \mathrm{P}+\Phi_{\mathrm{E}} \Omega^{\mathrm{E}} \\
& \mathrm{P}^{*}=\Psi_{\mathrm{P}} \mathrm{E}+\Phi_{\mathrm{P}} \Omega^{\mathrm{P}}
\end{aligned}
$$

Where $\mathrm{E}$ is total employment, $\mathrm{P}$ is total population, $\Omega^{\mathrm{E}}$ and $\Omega^{\mathrm{P}}$ are vectors of exogenous variables that affect employment $(\mathrm{E})$ and population $(\mathrm{P})$, and * indicates equilibrium levels of $\mathrm{E}$ and $\mathrm{P}$. Hence, equilibrium levels of employment and population depend on the actual level of employment and population and on a vector of other factors belonging to the sets $\Omega^{\mathrm{E}}$ and $\Omega^{\mathrm{P}}$.

Population and employment are likely to adjust to equilibrium values with substantial lags (Mills \& Price, 1984). Thus a distributed lag adjustment equation can be introduced as:

$$
\begin{aligned}
& \mathrm{E}=\mathrm{E}_{\mathrm{t}-1}+\lambda_{\mathrm{E}}\left(\mathrm{E}^{*}-\mathrm{E}_{\mathrm{t}-1}\right) \\
& \mathrm{P}=\mathrm{P}_{\mathrm{t}-1}+\lambda_{\mathrm{P}}\left(\mathrm{P}^{*}-\mathrm{P}_{\mathrm{t}-1}\right)
\end{aligned}
$$

Where $\lambda_{E}$ and $\lambda_{P}$ are speed-of-adjustment coefficients with $0 \leq \lambda_{E}, \lambda_{P} \leq 1$, and t-1 is a one period lag. This indicates that current employment and population are dependent on one period lagged levels of population and employment and on the change between equilibrium values and one lagged period values adjusted at speed-of-adjustment values of $\lambda_{E}$ and $\lambda_{P}$. Substituting $E^{*}$ and $P *$ in equations 3 and 4 gives:

$$
\begin{aligned}
& \mathrm{E}=\mathrm{E}_{\mathrm{t}-1}+\lambda_{\mathrm{E}}\left(\Psi_{\mathrm{E}} \mathrm{P}+\Phi_{\mathrm{E}} \Omega^{\mathrm{E}}-\mathrm{E}_{\mathrm{t}-1}\right) \\
& \mathrm{P}=\mathrm{P}_{\mathrm{t}-1}+\lambda_{\mathrm{P}}\left(\Psi_{\mathrm{P}} \mathrm{E}+\Phi_{\mathrm{P}} \Omega^{\mathrm{P}}-\mathrm{P}_{\mathrm{t}-1}\right)
\end{aligned}
$$

Rearranging terms gives:

$$
\begin{aligned}
& \mathrm{E}=\lambda_{\mathrm{E}} \Psi_{\mathrm{E}} \mathrm{P}+\lambda_{\mathrm{E}} \Phi_{\mathrm{E}} \Omega^{\mathrm{E}}+\left(1-\lambda_{\mathrm{E}}\right) \mathrm{E}_{\mathrm{t}-1} \\
& \mathrm{P}=\lambda_{\mathrm{P}} \Psi_{\mathrm{P}} \mathrm{E}+\lambda_{\mathrm{P}} \Phi_{\mathrm{P}} \Omega^{\mathrm{P}}+\left(1-\lambda_{\mathrm{P}}\right) \mathrm{P}_{\mathrm{t}-1}
\end{aligned}
$$


Equations 5 and 6 are simultaneous equations with observable endogenous variables $\mathrm{E}$ and P. Each endogenous variable depends on the other endogenous variable, on a set of exogenous variables, and on its lagged values. This specification reduces the simultaneity and direction of causation problems, as end period dependent variables cannot affect beginning period independent variables.

Following a similar modeling procedure, the empirical model can be specified and modified to incorporate into the system the simultaneous determination of land use variables. Maintaining similar behavioral assumptions of economic agents and distributed-lag adjustment specification procedures, the simultaneous interaction of equilibrium employment and population can be stated as:

$$
\begin{aligned}
& \mathrm{P}^{*}=f\left(\mathrm{E}^{*} \mid \Omega^{\mathrm{P}}\right) \\
& \mathrm{E}^{*}=f\left(\mathrm{P}^{*} \mid \Omega^{\mathrm{E}}\right) \\
& \mathrm{A}_{\mathrm{g}} \mathrm{L}^{*}=f\left(\mathrm{P}^{*}, \mathrm{E}^{*} \mid \Omega^{\mathrm{AgL}}\right)
\end{aligned}
$$

Where $\mathrm{P}^{*}$ and $\mathrm{E}^{*}$ refer to equilibrium values of population and employment respectively, $\mathrm{A}_{\mathrm{g}} \mathrm{L}^{*}$ refers to equilibrium agricultural land level, $\Omega^{\mathrm{P}}, \Omega^{\mathrm{E}}$, and $\Omega^{\mathrm{AgL}}$ refer to a vector of exogenous variables having a direct or indirect relationship with population, employment and agricultural land respectively.

Following Deller, et al.'s (2001) linearized expression of the equilibrium conditions, equations (7), (8) and (9) can linearly be represented as:

$$
\begin{aligned}
& \mathrm{P}^{*}=\alpha_{0 \mathrm{P}}+\beta_{1 \mathrm{P}} \mathrm{E}^{*}+\sum \delta_{1 \mathrm{P}} \Omega^{\mathrm{P}} \\
& \mathrm{E}^{*}=\alpha_{0 \mathrm{E}}+\beta_{1 \mathrm{E}} \mathrm{P}^{*}+\sum \delta_{1 \mathrm{E}} \Omega^{\mathrm{E}} \\
& \mathrm{A}_{\mathrm{g}} \mathrm{L}^{*}=\alpha_{0 \mathrm{AgL}}+\beta_{1 \mathrm{AgL}} \mathrm{P}^{*}+\beta_{2 \mathrm{AgL}} \mathrm{E}^{*}+\sum \delta_{1 \mathrm{AgL}} \Omega^{\mathrm{AgL}}
\end{aligned}
$$

Population and employment are likely to adjust with substantial lags to their equilibrium levels. Partial adjustment equations can be given as:

$$
\begin{aligned}
& \mathrm{P}_{\mathrm{t}}=\mathrm{P}_{\mathrm{t}-1}+\lambda_{\mathrm{P}}\left(\mathrm{P}^{*}-\mathrm{P}_{\mathrm{t}-1}\right) \\
& \mathrm{E}_{\mathrm{t}}=\mathrm{E}_{\mathrm{t}-1}+\lambda_{\mathrm{E}}\left(\mathrm{E}^{*}-\mathrm{E}_{\mathrm{t}-1}\right)
\end{aligned}
$$


where $\lambda_{P}$ and $\lambda_{E}$ are speed-of-adjustment coefficients for population and employment, $\mathrm{P}_{\mathrm{t}-1}$ and $\mathrm{E}_{\mathrm{t}-1}$ are initial conditions of population and employment.

\section{Rearranging terms:}

$$
\begin{aligned}
& \Delta \mathrm{P}=\mathrm{P}_{\mathrm{t}}-\mathrm{P}_{\mathrm{t}-1}=\lambda_{\mathrm{P}}\left(\mathrm{P}^{*}-\mathrm{P}_{\mathrm{t}-1}\right) \\
& \Delta \mathrm{E}=\mathrm{E}_{\mathrm{t}}-\mathrm{E}_{\mathrm{t}-1}=\lambda_{\mathrm{E}}\left(\mathrm{E}^{*}-\mathrm{E}_{\mathrm{t}-1}\right)
\end{aligned}
$$

where $\Delta \mathrm{P}$ and $\Delta \mathrm{E}$ are change in county level population and employment levels respectively.

Substituting the linear expressions of $\mathrm{P}^{*}$ and $\mathrm{E}^{*}$ (equations 10 and 11) into equations (15) and (16) results in:

$$
\begin{aligned}
& \Delta \mathrm{P}=\mathrm{P}_{\mathrm{t}}-\mathrm{P}_{\mathrm{t}-1}=\lambda_{\mathrm{P}}\left(\alpha_{0 \mathrm{P}}+\beta_{1 \mathrm{P}} \mathrm{E}^{*}+\sum \delta_{1 \mathrm{P}} \Omega^{\mathrm{P}}-\mathrm{P}_{\mathrm{t}-1}\right) \\
& \Delta \mathrm{E}=\mathrm{E}_{\mathrm{t}}-\mathrm{E}_{\mathrm{t}-1}=\lambda_{\mathrm{E}}\left(\alpha_{0 \mathrm{E}}+\beta_{1 \mathrm{E}} \mathrm{P}^{*}+\sum \delta_{1 \mathrm{E}} \Omega^{\mathrm{E}}-\mathrm{E}_{\mathrm{t}-1}\right)
\end{aligned}
$$

Rearranging and substituting the expressions we have:

$$
\begin{aligned}
& \Delta \mathrm{P}=\alpha_{0 \mathrm{P}}+\beta_{1 \mathrm{P}} \mathrm{P}_{\mathrm{t}-1}+\beta_{2 \mathrm{P}} \mathrm{E}_{\mathrm{t}-1}+\beta_{3 \mathrm{P}} \Delta \mathrm{E}+\sum \delta_{1 \mathrm{P}} \Omega^{\mathrm{P}} \\
& \Delta \mathrm{E}=\alpha_{0 \mathrm{E}}+\beta_{1 \mathrm{E}} \mathrm{P}_{\mathrm{t}-1}+\beta_{2 \mathrm{E}} \mathrm{E}_{\mathrm{t}-1}+\beta_{3 \mathrm{E}} \Delta \mathrm{P}+\sum \delta_{1 \mathrm{E}} \Omega^{\mathrm{E}}
\end{aligned}
$$

Note that the speed-of-adjustment coefficient $(\lambda)$ is embedded in the linear coefficient parameters $\alpha, \beta$, and $\delta$. (Deller, et al., 2001).

Incorporating the change in agricultural land in combination with population and employment changes, the system of equations growth model can be specified as:

$$
\begin{aligned}
& \Delta \mathrm{P}=\alpha_{0 \mathrm{P}}+\beta_{1 \mathrm{P}} \mathrm{P}_{\mathrm{t}-1}+\beta_{2 \mathrm{P}} \mathrm{E}_{\mathrm{t}-1}+\beta_{3 \mathrm{P}} \Delta \mathrm{E}+\sum \delta_{1 \mathrm{P}} \Omega^{\mathrm{P}} \\
& \Delta \mathrm{E}=\alpha_{0 \mathrm{E}}+\beta_{1 \mathrm{E}} \mathrm{P}_{\mathrm{t}-1}+\beta_{2 \mathrm{E}} \mathrm{E}_{\mathrm{t}-1}+\beta_{3 \mathrm{E}} \Delta \mathrm{P}+\sum \delta_{1 \mathrm{E}} \Omega^{\mathrm{E}} \\
& \Delta \mathrm{A}_{\mathrm{g}} \mathrm{L}=\alpha_{0 \mathrm{AgL}}+\beta_{1 \mathrm{AgL}} \mathrm{P}_{\mathrm{t}-1}+\beta_{2 \mathrm{AgL}} \mathrm{E}_{\mathrm{t}-1}+\beta_{3 \mathrm{AgL}} \Delta \mathrm{P}+\beta_{3 \mathrm{AgL}} \Delta \mathrm{E}+\sum \delta_{1 \mathrm{AgL}} \Omega_{\mathrm{AgL}}
\end{aligned}
$$


Equations (21), (22), and (23) indicate that population and employment changes are dependent on initial levels and change of population and employment interchangeably as well as a vector of factors affecting the change of population and employment in a county. The change in agricultural land is affected by the initial levels of employment and population, their change from one period to the other and by a vector of other exogenous variables. In such a system, the simultaneous interaction and influence of each dependent variable can be identified.

Substituting relevant variables of interest and specifying the vector of exogenous variables, the model can be re-expressed for estimation purposes as:

$$
\begin{aligned}
& \Delta \mathrm{P}=\alpha_{0 \mathrm{p}}+\beta_{1 \mathrm{P}} \mathrm{P}_{\mathrm{t}-1}+\beta_{2 \mathrm{P}} \mathrm{E}_{\mathrm{t}-1}+\beta_{3 \mathrm{P}} \Delta \mathrm{E}+\delta_{1 \mathrm{P}} \mathrm{HWYDEN}_{99}+\delta_{2 \mathrm{P}} \mathrm{UNERT}_{\mathrm{t}-1}+
\end{aligned}
$$

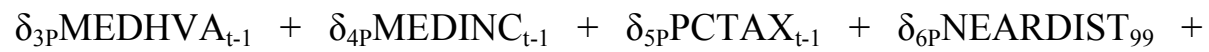

$$
\begin{aligned}
& \delta_{7 \mathrm{P}} \mathrm{OWNOCC}_{\mathrm{t}-1}+\delta_{8 \mathrm{P}} \mathrm{P}_{20 \mathrm{KADJ}_{1993}}+\delta_{9 \mathrm{P}} \mathrm{PFEDL}_{92}+\delta_{10 \mathrm{P}} \mathrm{PWATERAC}_{92}+ \\
& \delta_{11 \mathrm{P}} \mathrm{PFORESTL}_{92}+\delta_{12 \mathrm{P}} \mathrm{DAG}_{\mathrm{t}-1}+\delta_{13 \mathrm{P}} \mathrm{PINMIGRT}+\delta_{14 \mathrm{P}} \mathrm{POUTWORK}
\end{aligned}
$$

$$
\begin{aligned}
& \Delta \mathrm{E}=\alpha_{0 \mathrm{E}}+\beta_{1 \mathrm{E}} \mathrm{P}_{\mathrm{t}-1}+\beta_{2 \mathrm{E}} \mathrm{E}_{\mathrm{t}-1}+\beta_{3 \mathrm{E}} \Delta \mathrm{P}+\delta_{1 \mathrm{E}} \mathrm{HWYDEN}_{99}+\delta_{2 \mathrm{E}} \mathrm{UNERT}_{\mathrm{t}-1}+\delta_{3 \mathrm{E}} \mathrm{PAGEMP}_{\mathrm{t}-} \\
& { }_{1}+\delta_{4 \mathrm{E}} \mathrm{PMIEMP}_{\mathrm{t}-1}+\delta_{5 \mathrm{E}} \mathrm{PCNEMP}_{\mathrm{t}-1}+\delta_{6 \mathrm{E}} \mathrm{PSVEMP}_{\mathrm{t}-1}+\delta_{7 \mathrm{E}} \mathrm{PCTAX}_{\mathrm{t}-1}+ \\
& \delta_{8 \mathrm{E}} \mathrm{NEARDIST}_{99}+\delta_{9 \mathrm{E}} \mathrm{DAG}_{\mathrm{t}-1}+\delta_{10 \mathrm{E}} \mathrm{P}_{20 \mathrm{KADJ}_{1993}}+\delta_{11 \mathrm{E}} \mathrm{AGSLAC}_{\mathrm{t}-1}+ \\
& \delta_{12 \mathrm{E}} \mathrm{INCFM}_{\mathrm{t}-1}+\delta_{13 \mathrm{E}} \mathrm{PCOUNTY}+\delta_{14 \mathrm{E}} \mathrm{PINMIGRT}+\delta_{15 \mathrm{E}} \mathrm{POUTWORK}
\end{aligned}
$$

$$
\begin{aligned}
& \Delta \mathrm{A}_{\mathrm{g}} \mathrm{L}=\alpha_{0 \mathrm{AgL}}+\beta_{1 \mathrm{AgL}} \mathrm{P}_{\mathrm{t}-1}+\beta_{2 \mathrm{AgL}} \mathrm{E}_{\mathrm{t}-1}+\beta_{3 \mathrm{AgL}} \Delta \mathrm{P}+\beta_{4 \mathrm{AgL}} \Delta \mathrm{E}+\delta_{1 \mathrm{AgL}} \mathrm{HWYDEN}_{99}+ \\
& \delta_{2 \mathrm{AgL}} \text { PAGEMP }_{\mathrm{t}-1}+\delta_{3 \mathrm{AgL}} \text { INCFM }_{\mathrm{t}-1}+\delta_{4 \mathrm{AgL}} \mathrm{PCROP}_{\mathrm{t}-1}+\delta_{5 \mathrm{AgL}} \mathrm{PPAST}_{\mathrm{t}-1}+ \\
& \delta_{6 \mathrm{AgL}} \mathrm{NEARDIST}_{99}+\delta_{7 \mathrm{AgL}} \mathrm{DAG}_{\mathrm{t}-1}+\delta_{8 \mathrm{AgL}} \mathrm{P}_{20 \mathrm{KADJ}_{1993}}+\delta_{9 \mathrm{AgL}} \mathrm{AGSLAC}_{90}+ \\
& \delta_{10 \mathrm{AgL}} \mathrm{DCONSERV}+\delta_{11 \mathrm{AgL}} \text { POUTWORK }
\end{aligned}
$$

where the specified variables are defined as indicated in Table 1. 
Table 1. Definition of Specified Variables.

\begin{tabular}{|c|c|}
\hline VARIABLE & DEFINITION \\
\hline $\mathrm{DPOPDIFF}=\Delta \mathrm{P}$ & $\Delta$ Population density 1990-1999 \\
\hline $\mathrm{DEMPDIFF}=\Delta \mathrm{E}$ & $\Delta$ Employment density 1990-1999 \\
\hline $\mathrm{DAGDIFF}=\triangle \mathrm{A}_{\mathrm{g}} \mathrm{L}$ & $\Delta$ Agricultural land density 1990-1999 \\
\hline $\mathrm{DPOP}_{\mathrm{t}-1}$ & Population density (people per square mile) 1990 \\
\hline $\mathrm{DEMP}_{\mathrm{t}-1}$ & Employment density (jobs per square mile) 1990 \\
\hline $\mathrm{DAG}_{\mathrm{t}-1}$ & $\begin{array}{l}\text { Agricultural land density (agr. acres per total acres) } \\
1990\end{array}$ \\
\hline HWYDEN $_{99}$ & Interstate highway density 1999 \\
\hline PCTAX $_{t-1}$ & Per capital local tax 1990 \\
\hline $\mathrm{MEDHVA}_{t-1}$ & Median housing value 1990 \\
\hline OWNOCC $_{t-1}$ & Owner occupancy rate for housing 1990 \\
\hline $\mathrm{UNEMRT}_{\mathrm{t}-1}$ & Unemployment rate 1990 \\
\hline $\mathrm{P}_{20 \mathrm{KADJ}_{93}}$ & $\begin{array}{l}\text { Non-metro counties adjacent to metro counties (1993 Beale } \\
\text { codes) }\end{array}$ \\
\hline PFEDL $_{92}$ & Proportion of county in federal lands \\
\hline PWATERAC & Proportion of county in water \\
\hline PFORESTL & Proportion of county in forested land \\
\hline NEARDIST & $\begin{array}{l}\text { Distance to nearest metro area [Washington D.C., } \\
\text { Pittsburgh } \mathrm{PA} \text {, or Charleston WV] }\end{array}$ \\
\hline PAGEMP $_{\mathrm{t}-1}$ & Proportion of total employment in agriculture 1990 \\
\hline PMIEMP $_{t-1}$ & Proportion of total employment in mining 1990 \\
\hline PCNEMP $_{\mathrm{t}-1}$ & Proportion of total employment in construction 1990 \\
\hline PSVEMP $_{\mathrm{t}-1}$ & Proportion of total employment in services 1990 \\
\hline AGSLAC $_{t-1}$ & Total agricultural sales per acre 1990 \\
\hline $\mathrm{PCROP}_{\mathrm{t}-1}$ & Proportion of total agr. land in cropland 1990 \\
\hline $\mathrm{PPAST}_{\mathrm{t}-1}$ & Proportion of total agr. land in pasture 1990 \\
\hline $\mathrm{INCFM}_{\mathrm{t}-1}$ & Average farm income 1990 \\
\hline $\mathrm{MEDINC}_{\mathrm{t}-1}$ & Average median income 1990 \\
\hline DCONSERVE & Density of non-governmental land conserved \\
\hline POUTWORK & $\begin{array}{l}\text { Proportion of employed residents working outside county } \\
\text { of residence (bedroom communities) }\end{array}$ \\
\hline P INMIGRT & Proportion of resident jobs held by people outside county \\
\hline
\end{tabular}


The model specification identifies direct and indirect relationships of different variables of interest on the change in the endogenous variables. The change in population density is simultaneously determined by changes in employment and initial population conditions as generated from the interaction growth model. The change in employment density, however, is also affected by a vector of other variables as specified in equation (24).

Highway density, nearest distance, and adjacency to urbanized areas variables try to capture the direct effect of accessibility on population changes. It is expected that the more accessible a county is, the more (higher) the population density change is in the location.

Median housing value, percentage of houses that are owner occupied, and median household income in the sample counties can also be thought of as directly influencing demographic changes. These variables try to capture population changes derived from housing and property values in spatial location decisions. It can be argued that an increase in median household income and a reduction in property values expand the utility maximizing goods bundle, including housing and recreational site choices. This tends to positively influence population growth.

Per capita tax rates and unemployment are also specified to capture their direct influence on population. Labor mobility attributes in terms of in-migrating and out-migrating labor is also introduced. Generally, a higher unemployment rate can reduce population in two ways; indirectly through reducing people coming to a specific location in search of job (employment effect) captured by $=\Delta E$ in the population equation and directly through its effect on crime rates and safety affecting individual location decisions for housing and other purposes in that specific location. Generally, the effect of per capita tax on population could be viewed as negatively related. Those counties with higher per capita taxes might see people out-migrating to other locations of light fiscal burden or vice versa. However, it can also be argued that people can also prefer high per capita tax rates if the area is less populated and has the natural amenities intact than places with high 
population and congestion and less fiscal burdens. The sign has to be empirically determined to conclude on both possibilities.

Finally, the listed agricultural variables are related with population changes through the provision of natural amenities, federal land preservation, and intensity of the agricultural activity that have a direct bearing on property values and employment opportunities that directly and indirectly affect population changes.

Similarly, employment density changes are affected by initial employment conditions as well as change in population for the study period as determined in the simultaneous equation system. A vector of other relevant variables also directly interacts with employment growth.

Again, highway densities, distance from metropolitan or urban areas and adjacency to urbanized areas capture the effects of accessibility on employment changes. Generally, the more accessible or exposed a county or specific region is, increasing employment growth can be expected. Extension of highway infrastructure makes the temporary inmigration of labor and effort supply decisions of distant labor easier. These have a direct bearing on employment changes.

The decomposition of employment into different sectors identifies the influence of each employment sector on the overall employment change in West Virginia. Interrelationship of sectors should carefully be noted to capture the impact of employment change of one on the overall employment. For instance, a growing service industry can attract employment from other relatively less paying sectors. This can lead to employment cuts by other employers to raise the wage and salary. Similarly, the effects of these different sectors are in part reflected in their overall mobility. For example, the services sector may be much more mobile than the other sectors. The construction sector typically expands and contracts based on the demand for their products. Resource-dependent sectors (agriculture, mining) have limited mobility, as they require location-specific inputs (land, minerals) in their production processes. Though the actual impact can separately be 
studied in an impact analysis framework, the interrelationship of different employment sectors and their influence on overall employment is recognized.

The direct relationship between per capita taxes and unemployment rate with employment growth is analogous with the effect on population. Higher tax structures can discourage new businesses and can motivate relocation of businesses and employees to reduce tax burdens. Analogously, counties with tax incentives can attract more new businesses. Hence, the level of imposed tax is generally inversely related with employment creation. However, consideration of other factors of positive importance to businesses and households can offset the negative impact of higher taxes and induce them to move to areas of high fiscal burden if savings from other attributes of the area are greater. Higher unemployment rates can also directly affect employment growth trends. High unemployment regions attract lesser in-migrating laborers as compared to regions with boosting employment opportunities and high employment growth. This regional unemployment rate differential can affect and explain some portion of the change in total employment variations.

Another source of change in employment densities arises from the agricultural sector. Agricultural sales volume, average farm income (agricultural sales plus all transfer payments), and agricultural land density measures are specified to capture the competitive ability of agriculture in retaining its land use as measured by its profitability and use of land. Not only is the agricultural sector important for farm employment opportunities and off-farm employment opportunities through agricultural sector's backward and forward linkages with other sectors, a decline in agricultural land density and the shrinking of the agricultural sector will result in a direct cut of farm employment opportunities as well as related off-farm employment. This directly and indirectly affects the change in employment density.

Finally, much research focus is placed on the change in agricultural land densities. From the model specification, it is clear that all those factors simultaneously affecting employment and population densities will indirectly influence the change (conversion) of 
agricultural lands. From the specification, it is clear that initial employment and population states and their density changes over the study period will determine the agricultural land converted to other uses.

Highway density, distance measures, and adjacency to urbanized areas are specified to capture accessibility influences on agricultural lands. Though these variables have an indirect bearing on agricultural land conversion through their interaction with population and employment densities, they also have a direct effect on the change in agricultural lands through access and resulting pressures. It is expected that the more the agricultural sites are accessible or have improved communication and transportation facilities, the higher will be the conversion rate of agricultural lands to other uses.

Decomposing total agricultural lands into selected crop and pasturelands in the model tries to isolate the relative impact of those agricultural uses on total agricultural land densities in each county. It is expected that these changes will significantly explain some portion of the changes in agricultural land densities. That is, farmers tend to allocate prime land for crop production. This breakout may enable the identification whether prime farmland is being lost at a greater rate than marginal farmland. The model further specifies that initial agricultural densities will have a bearing for the end of period densities. Some studies indicate that farmers' decisions to sell land not only depend on their farm situation but also on the decision of other farmers (speculation effects) in the previous years. Hence, initial period land densities will capture some inherent consequent conversion decisions.

The change in agricultural land densities is also expected to be partially explained by initial period agricultural employment and average farm incomes. Changes in farm employment not only affect the agricultural land density through its effect on employment changes (simultaneously determined in the model) but it is also positively related with agricultural land. Increasing agricultural employment share might indicate feasibility of the sector in a region given certain circumstances. Hence, rapid changes in agricultural employment could be linked with the size and dominance of the sector. 
However, it should also be noted that increased mechanization could reduce employment while improving competitiveness of the sector. The final relationship between the two could be blurred. Thus, agricultural sales per acre are included to capture the total value of agricultural production per acre in a region.

Finally, to determine the influence or significance of conservation practices on the conversion of agricultural lands, a conservation variable is introduced to measure the marginal effect of private land conversion efforts on agricultural land densities.

\subsection{SOURCES OF DATA AND STATISTICAL SUMMARY OF VARIABLES}

The study of land use involves the interaction of different economic sectors encompassing different sources of pressure on current and past land use practices. Any attempt to reasonably capture the effect of the changes of exogenous variables on land use practices, therefore, demands extensive data gathering and organization.

For the purpose of this study, generally five broad categories of data were required for analytical purposes covering the study decade from 1990 to 1999/2000. The first category of data gathered is in relation to employment (and unemployment) and population statistics. The empirical model follows a growth model with a simultaneous interaction between employment and population. As such, it requires a bulk of employment and population data for estimation completeness. The data are obtained from the REIS 1969-1999 CD time series database provided by the US Bureau of Economic Analysis.

A second set of data gathered was focused on agricultural land, agricultural production, and agricultural income statistics. This particular information is required to capture the relative strength of the agricultural sector vis-à-vis other economic activities in West Virginia and to enable the estimation of agricultural land conversion equation in the simultaneous equation systems. Significant amounts of data of this type were gathered from the US Agricultural Census (US-AgCen.) and partially from the REIS database. 
A third set of data on distance and accessibility information is measured and compiled to identify the influences of spatial attributes on agricultural lands. It is quite evident that the accessibility and nearness impacts on agricultural land are exerted, among other things, through new changes in employment and residential location decisions. The identification and representation of such effects in the model requires the selection of proxy variables and collection of accessibility and distance measure data. Accessibility and distance measure data were generated in the Natural Resource Analysis Center GIS Lab (NRAC-GISLab) (WVU - Division of Resource Management).

The data gathering process also included the collection of data relating to per capita income, housing values, housing ownership proportions, and taxes information. This set of data could help identify the impact of income changes, housing demand and fiscal factors on the agricultural land conversion process. The County and City Data Books (Cty. \& Cit. DB) statistical publications provided by the US Census Bureau are primary sources of the required data.

Finally, a detailed breakdown of agricultural land in to different agricultural uses like farming, pasture, and forestry as well as open water resources are identified to capture detailed information on what particular land use in agriculture is influenced by the conversion pressure in West Virginia. US Agricultural Census and USDA publications provided these data.

In all the categories, the nature of the collected data is secondary. Data is gathered from secondary sources - government publications, census information, institutional reports, as well as other public information service publications (see Table 2 for list of data sources). Relevant information dealing with spatial physical distance of county seats from selected metropolitan areas and infrastructure density measures for 55 West Virginia counties is generated in the Natural Resource Analysis Center, at West Virginia University.

The specified growth model requires a set of initial period conditions that need to be compared with an end of study period to capture changes in the specified variables of 
interest in the model. For the present study, the decade 1990-1999/2000 is selected for growth comparison and analysis. Thus, the data set is a cross-sectional two time period data collected for the initial condition information for 1990 and end of period, 1999/2000, condition.

Table 2. Data Type and Source Summary.

\begin{tabular}{|c|c|}
\hline Data type & Source \\
\hline Population by county & REIS \\
\hline Employment by county & REIS \\
\hline Total farm employment & REIS \\
\hline Total non-farm employment & REIS \\
\hline Proportion of total employment in services & REIS \\
\hline Proportion of total employment in agriculture & REIS \\
\hline Proportion of total employment in mining & REIS \\
\hline Proportion of total employment in construction & REIS \\
\hline Median housing value & Cty. \& Cit. DB \\
\hline Owner occupancy rate for housing & Cty. \& Cit. DB \\
\hline Median housing income & Cty. \& Cit. DB \\
\hline Per capital local tax & Cty. \& Cit. DB \\
\hline Unemployment rate & Cty. \& Cit. DB \\
\hline Agricultural land & US-AgCen \\
\hline Forested land & US-AgCen \\
\hline Total agr. land in cropland & US-AgCen \\
\hline Proportion of total agr. land in pasture & US-AgCen \\
\hline Proportion of county in water & US-AgCen \\
\hline Federal lands & US-AgCen \\
\hline Total agricultural sales per acre & US-AgCen./REIS \\
\hline Total farm income & US-AgCen./REIS \\
\hline Non-metro counties adjacent to metro counties (1993 Beale codes) & USDA-ERS \\
\hline Interstate highway density & NRAC-GISLab \\
\hline Distance to nearest metro area & NRAC-GISLab \\
\hline
\end{tabular}

For econometric estimation purposes, the data set is transformed into density and per acre, per square mile, per capita, and other transformed measures. This standardizes the data for different sized counties. For instance, a small population change in a county with 
an initial small population can result in high percentage changes. Replacement by population density can reduce the size of related biases.

A general feature of the collected data is given in Table 3. It provides mean, standard deviation, range and other summary statistics describing the general characteristics of the collected data. The descriptive statistical summary provides pre-estimation general pictures of the growth momentum in West Virginia in general; though the pictures are average and aggregated.

First, population density changes indicate a small overall change in population growth in West Virginia. However, county level observation shows that there are fast population growth counties (like in the Eastern Panhandle) with growth rates more than $10 \%$ per annum. There are other counties showing negative population growth rates due to out migration to other counties and states. However, overall the change in population for the study period is small.

Employment measures are decomposed into different employment source sectors. Overall, there is relative employment growth in the construction, agricultural and mining sectors. In some counties, mining and service employment opportunities account for a maximum of $40 \%$ and $36 \%$ of the labor force respectively. However, a growing proportion of the labor force is getting employment opportunities in the service sector. Basically, service sectors are located in areas of growing population. Hence, service sectors are sources of potential land competition with the agricultural sector.

It can also be noted that there is a significant regional difference in farm income, per capita taxes, median income, median house value, and unemployment rates. For instance, housing value ranges across counties from a minimum average value of $\$ 15,800$ to a maximum of $\$ 84,100$. These spatial property values, income divergence, tax burden skewed distribution, and spatial job opportunity differences can provide incentives to move regionally to take advantage their differing regional patterns. Though the regions with high housing values and taxes could also be regions of high employment growth due 
to population concentrations, they could simultaneously also act as regions of fiscal burdens and high property values. The interaction of these facts determines location decisions in a complex manner.

Table 3. Descriptive Statistics Summary.

\begin{tabular}{|c|c|c|c|c|c|}
\hline VARIABLE & MEAN & STD.DEV. & MINIMUM & MAXIMUM & CASES \\
\hline SQMI & 437.938182 & 210.976202 & 83.0000000 & 1039.80000 & 55 \\
\hline DPOP 90 & 94.4027576 & 102.885929 & 9.54163565 & 478.107345 & 55 \\
\hline DPOP 99 & 94.8291925 & 100.055310 & 9.64054025 & 449.331450 & 55 \\
\hline DEMP 90 & 42.6650532 & 59.9165901 & 4.87142600 & 294.030132 & 55 \\
\hline DEMP 99 & 47.0563274 & 64.9026674 & 5.58532638 & 327.382298 & 55 \\
\hline PAGEMP 90 & 6.41665915 & 5.79358527 & .000000000 & 23.6085466 & 55 \\
\hline PMIEMP 90 & 7.54832662 & 8.50551502 & .0243902439 & 40.5964763 & 55 \\
\hline PCNEMP 90 & 5.63545214 & 2.59362898 & 1.21816168 & 15.4994925 & 55 \\
\hline PSVEMP 90 & 20.9485112 & 5.47152502 & 10.5118167 & 36.2870685 & 55 \\
\hline INCFM90 & 19.8700195 & 20.2110563 & .000000000 & 110.703704 & 55 \\
\hline PCTAX90 & 315.109091 & 126.388975 & 90.0000000 & 881.000000 & 55 \\
\hline MEDINC90 & 19557.4727 & 3829.39479 & 12855.0000 & 30941.0000 & 55 \\
\hline MEDHVA90 & 44614.5455 & 10725.6601 & 15800.0000 & 84100.0000 & 55 \\
\hline OWNOCC90 & 76.8090909 & 4.54586799 & 62.1000000 & 84.3000000 & 55 \\
\hline UNEMRT 90 & 11.1109091 & 3.97956227 & 4.60000000 & 22.0000000 & 55 \\
\hline NUMF AR90 & 309.454545 & 191.776569 & 9.00000000 & 799.000000 & 55 \\
\hline PCROP 90 & 39.6417178 & 11.2313300 & 8.54481208 & 75.6449615 & 55 \\
\hline PPAST90 & 52.9475403 & 13.7772745 & 26.0751157 & 111.386139 & 55 \\
\hline PWOOD 90 & 42.6156020 & 11.3394297 & 8.27139549 & 74.2789411 & 55 \\
\hline AGSLAC 90 & 83.2182608 & 70.2368806 & .000000000 & 354.362151 & 55 \\
\hline HWYDEN99 & .0227272727 & .0364871639 & .000000000 & .170000000 & 55 \\
\hline PFEDL & 4.96747732 & 10.2238671 & .000000000 & 51.6926651 & 55 \\
\hline PWATERAC & 1.36024057 & 1.23787414 & .290603810 & 5.38720539 & 55 \\
\hline PFORESTL & 67.3496292 & 15.1707480 & 22.8212703 & 93.7207944 & 55 \\
\hline NEARD IST & 62.4085866 & 25.4404087 & .000000000 & 126.141517 & 55 \\
\hline LINFAR90 & 59403.4182 & 45445.4879 & 258.000000 & 179736.000 & 55 \\
\hline LINFAR99 & 59668.0727 & 45197.5176 & 150.000000 & 184359.000 & 55 \\
\hline POPDIFF & .426434886 & 9.72424259 & -28.7758945 & 40.5853051 & 55 \\
\hline EMPDIFF & 4.39127422 & 9.02990465 & -22.5662651 & 33.3521657 & 55 \\
\hline DAG90 & .224806543 & .131307675 & $.953916233 \mathrm{E}-03$ & .553643845 & 55 \\
\hline DAG99 & .231872868 & .139350835 & $.554602461 \mathrm{E}-03$ & .544027314 & 55 \\
\hline DAGDIFF & .00706632547 & .0604841383 & -.397497314 & .0698747964 & 55 \\
\hline P20KADJ & .254545455 & .439620283 & .000000000 & 1.00000000 & 55 \\
\hline
\end{tabular}


Decomposition of total agricultural land into different agricultural uses also indicates that on average a greater proportion of agricultural land is allocated to forest, pasture, and crop uses respectively. A slight change in agricultural land density is observed overall for the study period.

The accessibility measure in terms of distance from metropolitan areas indicates that on average counties are 62 miles from major metropolitan areas. This provides information on the possible urbanization influence of counties in West Virginia. Similarly, the dummy coding of counties adjacent to selected urbanized counties indicates that 75 per cent of the rural counties are adjacent to selected urbanized areas.

A final note should be made at this point that the above general pictures are aggregated and potentially vary across individual sample counties. The whole interaction and county level movement is captured by the specified growth model, which is estimated and analyzed in the next chapter. 


\section{CHAPTER IV}

\section{EMPIRICAL RESULTS AND ANALYSIS}

\subsection{EMPIRICAL RESULTS PRESENTATION}

In the last chapter, the modeling procedure of the agricultural land conversion process based on a system of equations growth model was discussed in depth. Following the model specification, expected signs of theoretically consistent variables were briefly discussed. This section primarily presents the estimated empirical results of the model.

The system of equations model is estimated using two econometric techniques. The simultaneous equations system of employment and population is separately estimated, as the change in agricultural land is not endogenized in the population-employment system. It is argued that changes in agricultural lands may not be a reasonable predictor of changes in population and employment across space; though they may have a degree of influence on such variables. However, the changes in population and employment growth have a significant direct bearing on agricultural land conversion. Hence, agricultural land density changes are estimated using an Ordinary-Least-Squares (OLS) estimation technique while the simultaneous interaction of employment and population are captured through a Two-Stages-Least-Square (2SLS) econometric technique.

The simultaneous determination of employment and population equilibrium levels makes the estimation of the equation system with OLS biased and inconsistent. This is particularly due to the fact that some of the regressors are endogenous and could be correlated with the error terms. To adjust for simultaneity bias, a 2SLS method is employed. The simultaneity test undertaken, using Hausman's Specification Test, showed significant simultaneity between changes in employment and population, but not with changes in agricultural land. Hence, the 2SLS is used to overcome estimated coefficient bias and inconsistency and address the simultaneity introduced in the structural model. 
A two-stages-least-square method works in a way to possibly reverse the correlation of the endogenous explanatory variables, in the structural model, and the error terms by substituting the explanatory endogenous variables with closely related (correlated) proxy variables. 2SLS systematically creates such proxy variables (instrumental variables) by estimating a regression for the endogenous explanatory variables and using the estimated values as instrumental variables in the model (Studenmund, 2001).

As a cross-sectional one period lagged model, existence of autocorrelation in the model is not likely. In the three estimated models, this is evident with Durbin-Watson statistics being closer to 2 . However, the existence of multicollinearity and heteroskedasticity is likely. Generally, multicollinearity results in inefficient estimates that tend to increase standard errors of the estimated coefficients. Unexpected signs of the specified variables could also be potentially encountered. Multicollinearity is addressed by re-specifying suspected variables and dropping highly correlated variables from the model.

It will be noted that the estimated models exclude certain theoretically specified variables. The initial estimation involved high correlation in some of the specified variables. For instance, farm income and farm sales as well as median housing value and median income are highly correlated. Selective exclusion of one of two highly correlated variables is undertaken since they predict more or less the same behavior or closely vary in a predictable fashion. Existence of heteroskedasticity, autocorrelation, and simultaneity are tested and corrected using appropriate econometric approaches. The results reflect the growth model after the necessary econometric diagnoses are made.

It is also potentially arguable that cross-sectional panels involve high variance in observations due to size and other unevenly distributed factors of the sample area leading to heteroskedastic results. Such results plague data with a wide disparity in the observed values of the variables. In fact, "the larger the disparity between the size of observations in a sample, the larger the likelihood that the error term observations associated with them will have different values and therefore be heteroskedastic." (Ibid, 2001, pp. 347 $348)$. 
The statistical summary (Table 3) indicates that there is variation in the aggregated minimum and maximum values of certain observed variables arising from differences in the nature of the 55 counties in West Virginia. This raises potential heteroskedastic estimates arising from the nature of observation in the sample counties. Hence, "heteroskedasticity is hard to avoid if economic topics are going to be studied cross sectionally." (Ibid, 2001, p. 348).

There are different econometric techniques available to test for the existence of heteroskedasticity. One technique of diagnosis is the Park Test. This test identifies possible heteroskedasticity in the model in a three step process: first, from the OLS estimated regression equation residuals are obtained, then, the natural log of the squared residuals is regressed as a dependent with the natural $\log$ of the proportionality factor (a variable believed to vary in some proportion with the error terms) as an explanatory variable, finally, the coefficient of the proportionality factor is tested, using t-test, for statistical significance in explaining the variance of the error terms. Significance indicates that there is possible heteroskedasticity problem in the model. The White test, on the other hand, diagnosis the simultaneous existence of a number of proportionality factors in the model. By first obtaining the squared of the residuals from the OLS estimated model, it is regressed as a dependent variable against all independent variables, the square of each independent variables, and the cross products of all the explanatory variable. The resulting regression is tested for overall statistical significance using the Chi-Square test. (Ibid, 2001).

There are numerous ways of correcting heteroskedasticity in a model. For the purpose of this research, the heteroskedasticity-corrected standard errors method will be used. This techniques adjusts the standard errors of the possibly heteroskedastic model without altering the estimated coefficients (since heteroskedasticity affects the standard error without biasing the estimated coefficients in the model). It provides more accurate standard errors and enables to undertake inference with better degree of accuracy (Ibid 2001). 
However, the implication of multicollinearity and heteroskedasticity in the estimates is the increase in the standard errors of the estimated coefficient and affected t-scores while leaving the estimated coefficients still centered around their true mean. In such circumstances, though statistical inference is bound to have a certain degree of error, the estimates can represent their true mean values and could be used for analytical purposes.

The empirical estimation of the population density equation is provided in Table 4. The results indicate that the included variables in the model explain about $71.47 \%$ of the variation in population density changes. Most of the estimated variables have expected signs as stipulated in Chapter Three. However, some parameter estimates have large standard errors resulting in statistical insignificance in the equation.

High standard errors in some variables are also observed in structural models applied in other studies. Results of Carlino and Mills, (1987), Deller et.al. (2001), and Duffy-Deno $(1997,2001)$ specified structural models reveal higher standard errors for some of the specified variables. A higher level of variance in standard errors might indicate the existence of econometric problems.

The Durbin-Watson test for autocorrelation indicates that the estimates are not significantly affected by serial correlation problems. A value of 4 would indicate strong negative autocorrelation, 0 would indicate extreme positive serial correlation, and 2 would indicate possibly no serial correlation. For a one period lagged estimation process autocorrelation is not expected to be a problem.

The result is corrected for heteroskedasticity using White's consistent covariance estimators, and variable specification is adjusted to overcome associated multicollinearity problems.

Aside from the diagnostic econometric considerations, most of the estimated coefficients have theoretically logical and consistent coefficients. Thus, results using West Virginia data substantiates similar arguments in other studies in different sample regions. 
Table 4. Empirical Result for the Population Density Structural Model (1990-1999).

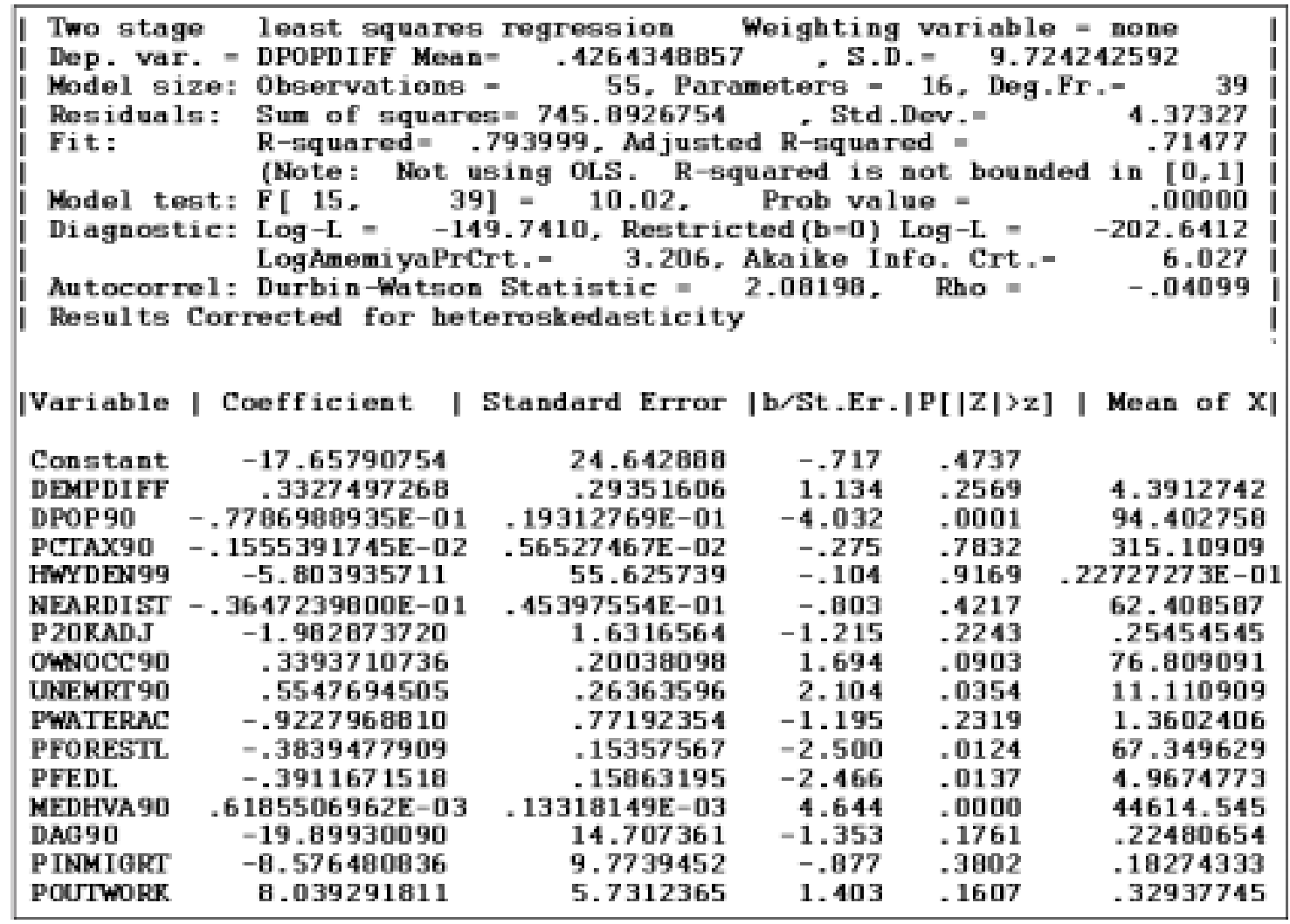

Table 5 summarizes the empirical estimation of the employment density equation in the system. The specified variables capture $65.85 \%$ of the variation in employment density. As in the population density case, most of the variables have expected signs though the standard error for most of the estimates is large relative to the parameter estimates.

As is true with many one lag period models, autocorrelation is almost non-existent, as indicated by the Durbin-Watson statistic of 2.3. The signs of the estimated employment density model for significant number of the specified variables is theoretically consistent. 
Table 5. Empirical Result for the Employment Density Structural Model (1990-1999).

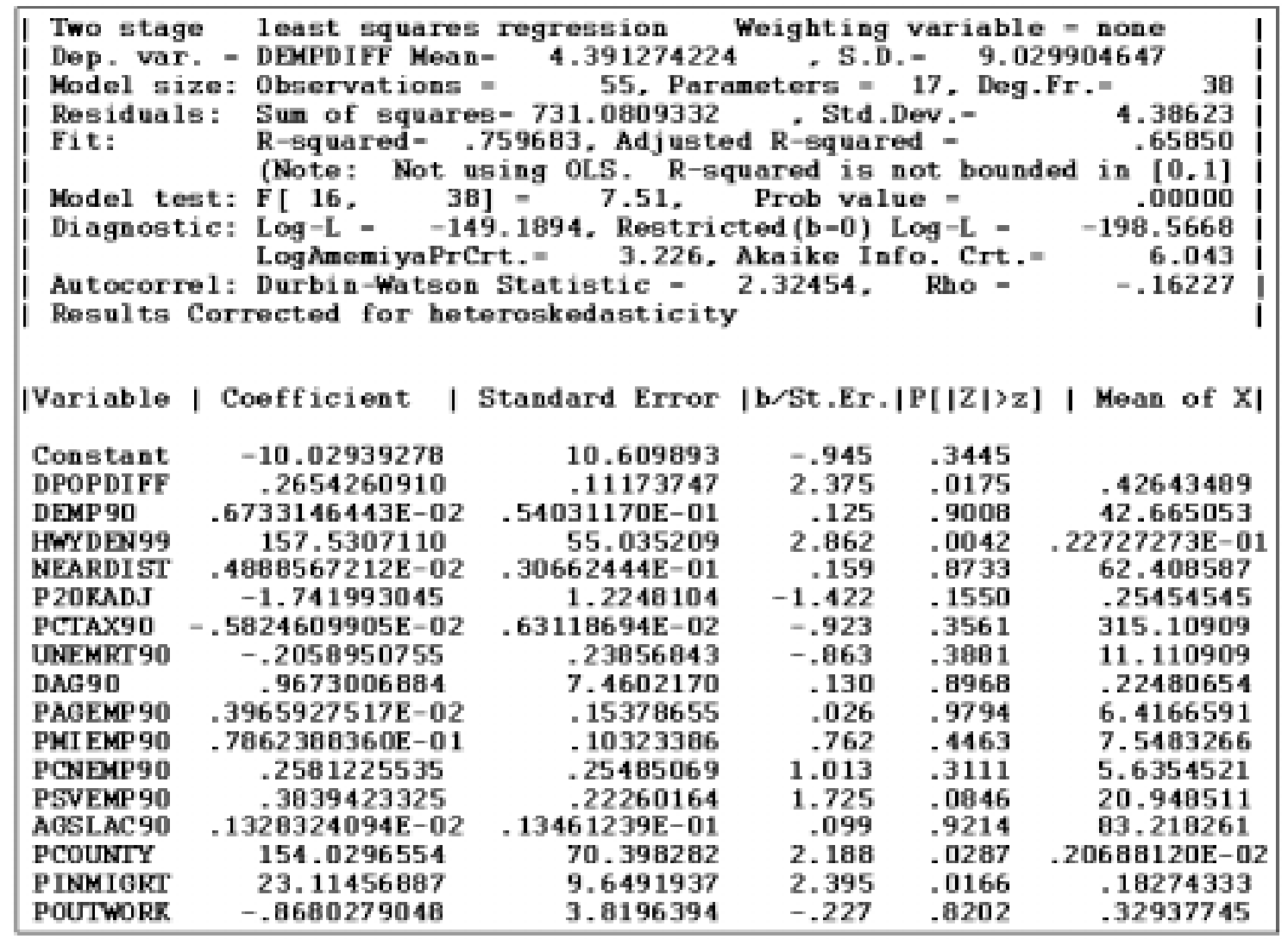

Table 6 provides the empirical estimation of the agricultural land density equation in the system. In theory, both employment and population changes should have a bearing on agricultural land conversion. Tables 4 and 5 provide separate estimates for changes in population and employment densities as influenced by specified variables. In the last model, all indirect influences of the variables in the population and employment model are captured as affecting agricultural land conversion through changes in population and employment densities. Direct effects are introduced in to the system to recognize immediate effects of spatial variables on agricultural land densities.

The model captures about $54.15 \%$ of the variation in agricultural land density. The estimates are corrected for heteroskedasticity. Autocorrelation is not present in the model as indicated by the Durbin-Watson statistic of 2.16. Similar with the populationemployment models, the agricultural land model shows expected signs in the specified variables and have expected comparative static features. 
Table 6. Empirical Result for the Agricultural Land Density Change Model (1990-1999).

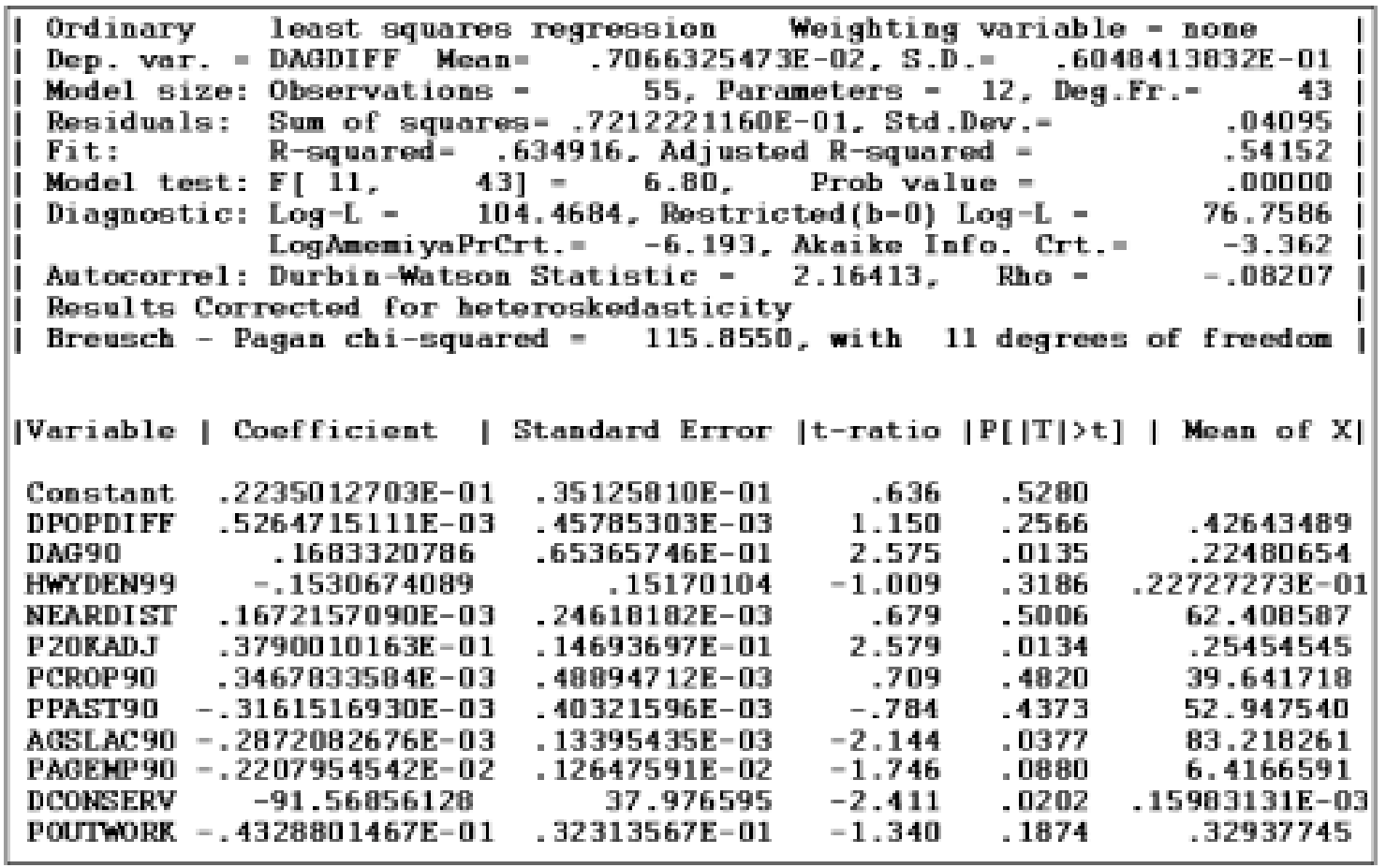

Generally, the empirical results provide important information about the land conversion processes in West Virginia. The results are consistent with expectations and other empirical results in the literature.

\subsection{ANALYSIS OF RESULTS}

The system of equations model results are generated from the two stages least squares and ordinary least squares estimates. The employment and population density changes, generated from the simultaneous interaction models are depicted in tables 4 and 5; similarly output for agricultural land density is provided in table 6 . This analysis focuses on the interpretation of the econometric results, interaction of the three models and comparative reference of the generated results with USDA's Natural Resource Conservation Service GIS maps dealing with land conversion indicators. The analysis for the three models is given in the following separate sections. 


\subsubsection{Analysis of the Population Density Model}

In the model specification, change in population (population in 1999 minus population in 1990) is specified as one of the significant factors explaining the conversion of agricultural lands. Population, though directly and indirectly interacting with changes in agricultural lands, is by itself affected by a number of other explanatory factors. These variables have an indirect bearing on agricultural lands through their direct effects on population density changes.

Population changes are explained in the literature by a number of reasons. One of them is the spatial difference in fiscal burdens. The population density model indicates that per capita tax in the base period (PCTAX90) is negatively related with changes in population density, though the standard error of the variable is high. Following the result, it can be expected that an increase in tax burdens in some areas may cause a decline in the population growth in that area as tax burdens are minimized through relocation decisions. Due to high tax burdens, for instance, a large number of people reside in adjacent nonmetropolitan and lower per capita tax areas while traveling to work in the metropolitan areas. Such kinds of spatial features are expected to be observed in the Eastern Panhandle, Charleston, and other urbanized locations of influence. Hence, fiscal attributes of locations can influence to a degree the location decision of households responding to their cost and income constraints.

This result may be better explained if the sample included neighboring metropolitan places and urbanized sites as tax burdens are typically higher and movement to regions of low tax burdens (like West Virginia) may be evident. The West Virginia model, however, still captures tax differential playing a role in influencing trends of population density changes as evidenced by sign on PCTAX90 in Table 4.

Access, as a predictor of population density changes is well argued in the literature. Comparative static results of the argument are provided in chapter three. Though there are different ways of capturing access as a variable, interstate highway density 
(HWYDEN99) in each county and physical nearness to metropolitan areas (NEARDIST) are selected as proxies to predict changes in population density.

According to population growth theories, it can be expected that nearness to metropolitan areas and urbanized locations would affect population growth positively. However, unexpected sign and high insignificance is found for the relationship between highways and changes in population density in West Virginia. The result may indicate that since interstate density in West Virginia is small and since the distribution of the interstate network is limited to a few counties in the state, interstate highways may be a poor predictor of changes in population density in the state. The results show an insignificant influence of interstate highway in predicting changes in population density.

Nearness to metropolitan and urbanized areas demonstrates a demographic tendency that as distance from these central locations increases, population density decays at some rate. The negative coefficient for NEARDIST captures such a decaying nature of population growth with distance. The result is intuitive in that as distance increases from central places (to possibly rural locations), the transportation and other public facilities decline in supply and economic cost of movement to distant areas (areas of job and frequently visited recreational site) increases. This is an important result as similar population patterns have a significant bearing on agricultural lands at the sub-urban and adjacent locations.

The result for the relationship between adjacency to urbanized areas (P20KADJ) and changes in population density indicates an insignificant negative relationship. This may indicate that counties that are adjacent to urbanized areas do not significantly show much difference in population change than the non-adjacent counties. This may imply that population changes are not limited to adjacent counties but has spread to non-adjacent rural counties.

The percentage of houses that are owner occupied (OWNOCC90) is significantly associated with population density changes. The result indicates that rates of owner 
occupancy positively affect density change in population. This makes sense in two ways. First, that a higher rate of owner occupancy indicates that people decide to stay in that location for an extended period of time, which positively affects the population density in the location of settlement. However, beyond this obvious physical relationship one can infer that higher rates of owner occupancy is normally observed, among many groups, with in-migrating high income families and retired (senior) citizens. Hence, relating the tax burden analysis and the wealth of natural amenities in West Virginia, gradual movement to West Virginia from surrounding high tax and less natural amenity supply areas is possible. The spread of new retirement houses and recreational and residential facilities in some parts of West Virginia is one justification for the result.

There is also a significant positive relationship between changes in population densities and unemployment rates (UNEMPRT90). Intuitively, regions of high unemployment attract fewer people through the employment and crime effects. The unexpected negative sign in the population density model, however, may mean that across the 55 sample counties in West Virginia, population density changes are higher in counties with higher rates of unemployment. Generally, rural counties face higher rates of unemployment.

Furthermore, the positive relationship between unemployment and population density changes might indicate that the change in population is little affected by unemployment considerations but rather by other factors. Again, the groups that are less averse to unemployment are affluent and retired people. Thus, an inference may be made that the change in population in West Virginia are affected by the natural growth rates as well as by the influx of affluent and senior citizens as also evidenced by the high rates of owner occupancy. 
Fig. 9. New Acres of Developed Land in Non-Metropolitan Areas, 1992-1997.

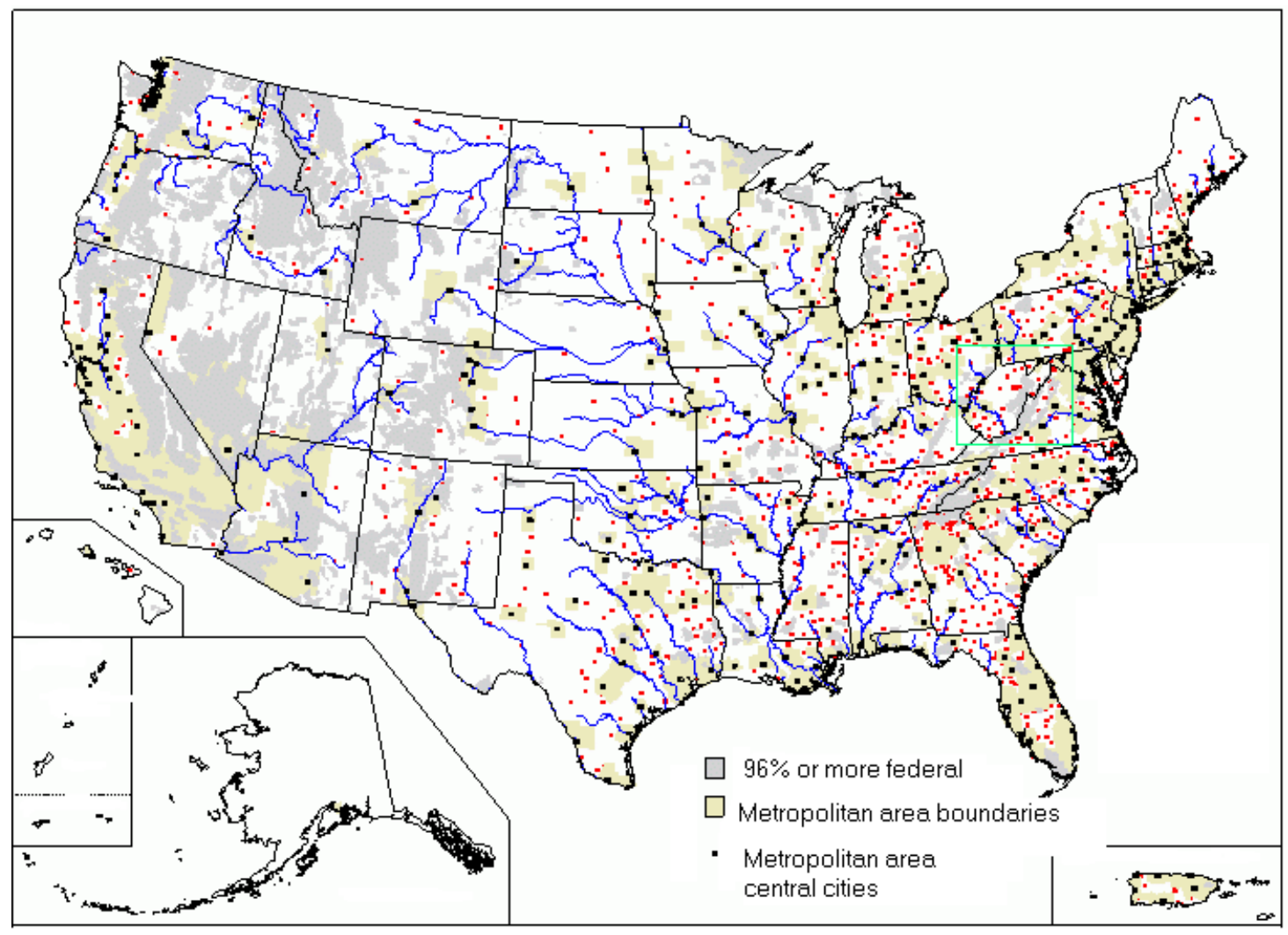

Source: USDA, Natural Resources Conservation Service, Resource Assessment Division, Washington,

D.C., 2001.

Studies associate positively the relationship between population growth and pressure on natural amenities. In a structural simultaneous equations model, for instance, Duffy-Deno (1997) measured the pressure exerted on endangered species due to changes in population and employment. A similar result is indicated between changes in population density and natural amenities - percentage of agricultural land in water (PWATERAC) and percentage of agricultural land in forest (PFORESTL) in this study. The model estimates indicate a significant negative relationship between population change and forested counties and a negative but insignificant relationship with density of surface water (lakes, rivers).

Consistent with the model specification and sign expectation, the result may indicate that high changes in population density is occurring in areas where there is decreasing 
proportions of forest and water acres, which might indicate influences of the population change on the stock of natural amenities.

Intuitively, inference can be made that if population change is influenced by nearness to urbanized areas, then access (nearness) indirectly affects agricultural land conversion through population pressures. (The result for agricultural land density and its relation to access reinforces this analysis). Hence, the result supports that regions with more exposure to urban influence attract higher rates of population and increase pressure on natural endowments and agricultural lands. Figure 7 supports this result. The map indicates new development spots that are highly spatially associated with nearness (accessibility) to urbanized areas of Charleston in the southwest, Morgantown in the north central and the Eastern Panhandle in the northeast parts of West Virginia. The spots are also regions of high population growth in West Virginia.

The relationship between population density changes and percentage of counties in federal ownership (PFEDL) is also indicated in table 4 . The result indicates a significant inverse relationship between federal preservation programs and population density changes. An increase in federal land will negatively affect population density changes, i.e., federal land preservation programs can slow population growth in some regions. This can happen in many ways. One possible way is that preservation programs, by limiting the encroachment of residential land to federal land reserves, physically limit the spread of population pressures. This is particularly evident in figure 7 where the shaded federal land region in the southeastern part of West Virginia is free from significant development pressures. Another way a federal land preservation program affects population growth is through the effect on the value of land. By physically limiting the economic supply of land to other uses, preservation programs can increase the market value of land hence reducing the incentive to buy land. This can push development and housing demands of land to neighboring counties where land reservations are not significant in affecting land and property values. The interaction of these processes within the context of a large land reservation program (like more than $65 \%$ for the southeastern region) hence negatively influences the spread and growth of population. 
The result also estimates a significant positive relationship between population density changes and median housing value (MEDHVA90). The model estimate result for the relationship between median housing value and change in population was not as intuitively expected. The positive relationship may imply that higher population density changes are occurring in areas of higher median housing value in West Virginia. This may be due to the fact that regions of high population experience high demand for properties. This can raise property values in the face of higher demands from increasing population through time. This can yield a positive relationship between housing value and population concentration.

However, it may also be argued that areas of growing housing and property value, ceteris paribus, attract less population in-migration and hence slowdown the density change in population. The data set does not account for the fact that though property values are increasing in population centers in West Virginia, it could be true that still they are relatively cheaper when compared to surrounding metropolitan and urbanized areas. For instance, the housing value in the Eastern Panhandle is increasing at a significant scale but still faces increasing demand. One reason for this could be the fact that though property values are increasing, they are cheaper when compared to the adjacent metropolitan D.C. area, making the Eastern Panhandle a substitute for the high property values in D.C. Since the study is concentrated in West Virginia, economic activities in the surrounding states are not included in the dataset. The result can thus be attributed to sampling limitations.

On the relationship between population density change and agricultural land density (DAG90), the population density model estimates a negative relationship, which is intuitive. This may imply that changes in population are associated with declining agricultural lands. A growth in population not only requires increased public facilities, it also requires housing, recreational, and other attendant land demanding necessities. This comes in direct competition over the use of land, especially in areas of significant agricultural activities. 
It is evident from the result in the case of West Virginia where agricultural land density is negatively related with population growth trends. Figure 8 depicts the spatial distribution of development growth rates rated from very high development to very small or almost neutral development activities for the period 1982-1997. It indicates that a very high development rate is observed in the Eastern Panhandle (similar rates with that of Washington, D.C., and major Suburbs), a significantly high development rates around Charleston, and north-central West Virginia. These spatial locations are also areas of very high population growth in the state. Significantly high rates are also depicted in the rest of West Virginia except the southeast.

Comparison of figure 8 with figure 9 confirms the estimated econometric result for the relationship between population and land conversion. The indicated spots of high population growth (counties in black cover) coincide with high development rates as predicted by the model.

Fig. 10. Annual Rate of Development, 1982-1997.

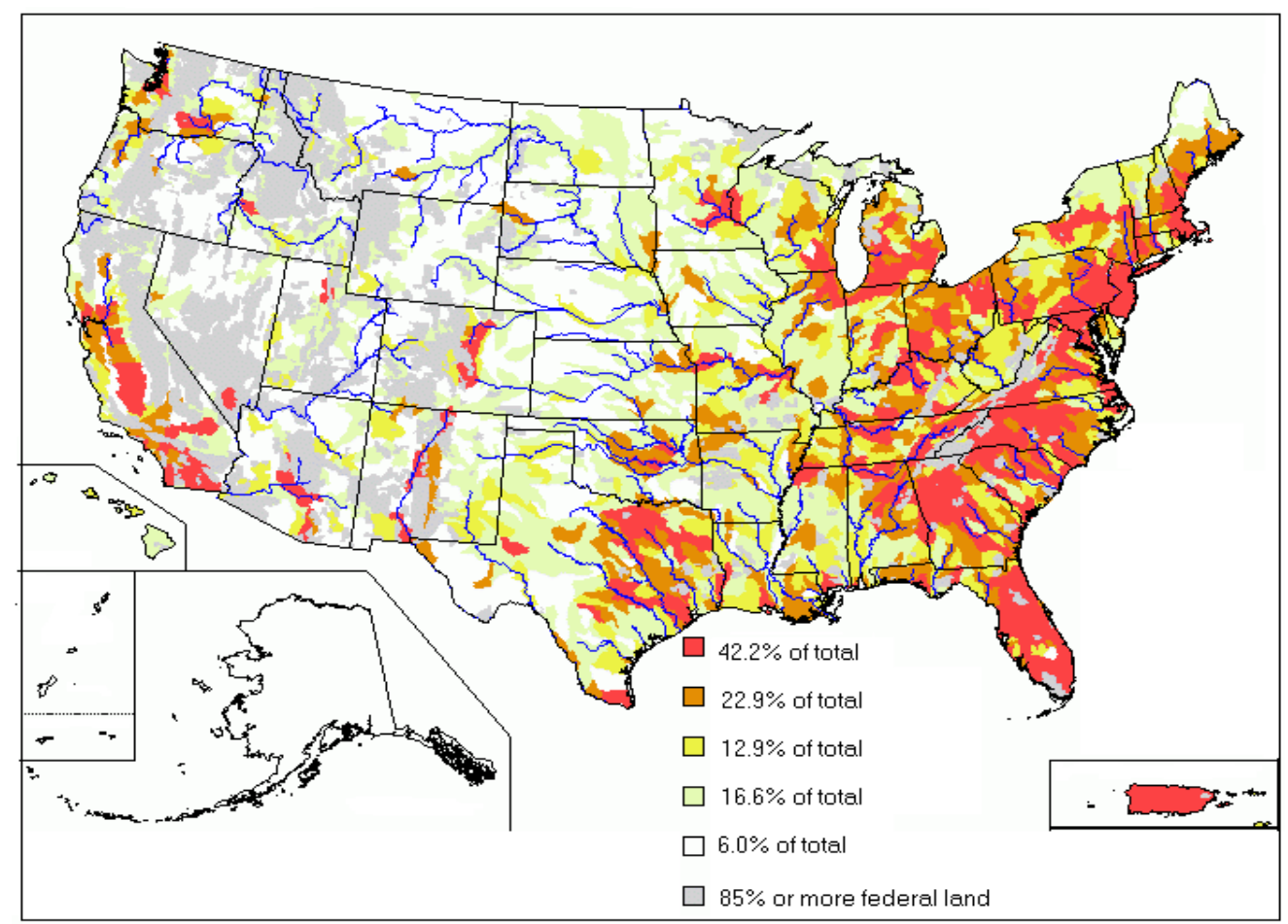

Source: USDA, Natural Resources Conservation Service, Resource Assessment Division, Washington, D.C., 2001. 
This further justifies the conclusion that population change (rather than employment driven changes) accounts for the major conversion situation in West Virginia. The growth of population in locations of high unemployment rates and high median housing values reinforces that population changes drive most of the population conversion than employment generation, though they are also significant factors in explaining the conversion of agricultural land to non-agricultural uses.

Fig. 11. Percentage Change in Population: 1990 - 1999.

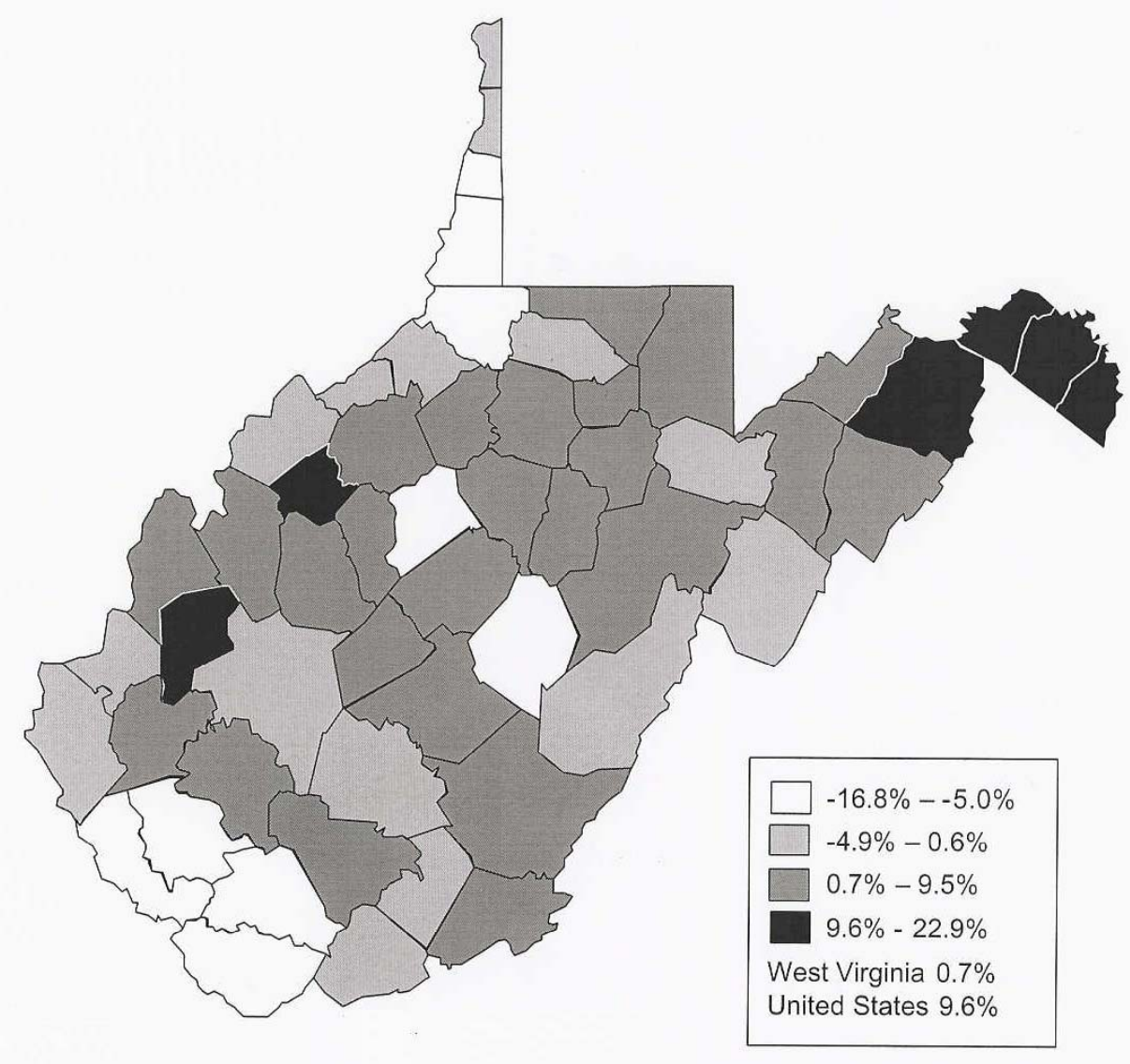

Source: Adopted from U.S. Bureau of Census by Condon, Childs, and Bogdan, Bureau of Business and Economic Research, West Virginia University, Sept. 2000.

The relationship between employment and population is addressed in some detail in the specification. The results for the association of proportion of county jobs held by outside county residents (PINMIGRT), proportion of residents employed outside the county (POUTWORK), and changes with total employment density (EMPDIFF) are provided in 
table 4. Generally, a positive relationship is found between changes in population density with total employment changes and proportion of residents employed in a different county while a negative relationship is found with proportion of county non-resident employment.

The result may imply that counties with high proportion of employed residents who work outside a county ('bedroom communities'), face high population density changes, and counties with high proportion of resident jobs held by people outside the county face low population changes. Joint consideration of the two results may indicate that changes in population density are high in counties with favorable access to locations of urban development. With considerations of urban negative externalities (congestion, crime and safety, tax burden, etc), people may prefer to stay in suburban counties and work in cities or urbanizing counties, as returns to efforts are higher. For example, high rates of population increases are recorded in the Eastern Panhandle where significant number of people work in Washington, D.C., metropolitan area and reside in the Eastern Panhandle counties. Similar behaviors are true around Charleston and major urbanizing locations in West Virginia. Thus, the result might imply that population changes, and thus increased competition for land, are high in the suburban counties.

The result also estimates a positive but insignificant relationship between population density changes and employment change. This coefficient estimate directly tests the relative influence of the simultaneous endogenous variable - employment difference (EMPDIFF) - on population density changes. Contributing to the debate on whether population attracts employment or vice-versa, the results indicate that employment creation has a positive, but statistically insignificant influence on population growth trends in West Virginia as compared to the influence of population on employment growth. This might contribute to the on going argument as to whether employment follows jobs or jobs follow employment. From the result, it may be inferred that in the case of West Virginia the argument that employment changes drive population density changes is rather weak. 
To summarize the population density model, the following comparative static results for West Virginia are confirmed by the results of the study:

$\partial($ DPOPDIFF $) / \partial($ NEARDIST $)<0, \quad \partial($ DPOPDIFF $) / \partial($ P20KAD $)<0, \partial($ DPOPDIFF $) / \partial($ OWNOCC90 $)>0$, $\partial($ DPOPDIFF $) / \partial($ UNEMPRT 90$)>0, \partial($ DPOPDIFF $) / \partial($ PWATERAC $)<0, \partial($ DPOPDIFF $) / \partial($ PFORESTL $)$ $<0, \partial($ DPOPDIFF $) / \partial($ PFEDL $)<0, \partial($ DPOPDIFF $) / \partial($ MEDHVA90 $)>0, \partial($ DPOPDIFF $) / \partial($ DAG90 $)<0$, $\partial($ DPOPDIFF $) / \partial($ PINMIGRT $)<0, \partial($ DPOPDIFF $) / \partial($ POUTWORK $)>0, \partial($ DPOPDIFF $) / \partial($ DEMPDIFF $)>0$.

\subsubsection{Analysis of the Employment Density Model}

The employment model captures significant information concerning employment density changes and their relationship to key variables of research interest. Table 5 summarizes the output for the econometric estimation.

On the influence of access to employment density changes, the result indicates a significant positive relationship between employment changes and improved access. Specifically, a significant positive relationship is observed between employment growth and highway density (HWYDEN99) while a weak positive relationship is estimated for the relationship with the distance from nearest metropolitan county (NEARDIST) measure.

Consistent with logical expectations, the significant positive relationship between employment and improved access implies that locations endowed with better access (for example, interstate highways) attract more employment opportunities as access reduces the costs of transportation and exposes new markets separated by transportation barriers. Figure10 indicates regions of high population growth labeled at different growth rates. Interestingly, such spatial clusters of employment growth are associated with access. Employment growth centers are centered significantly across regions of high access of infrastructure amenities. This result can be compared with figures 10 and 11 that shows that employment densities and location of interstate highways are spatially correlated. 
In the theoretical model, it is specified that employment directly and indirectly affects the conversion of land from agriculture to other uses. Therefore, since infrastructural and access convenience facilitates job creation, regions with better access face more pressure on their agricultural land than regions with less access to those public amenities.

Fig. 12. Job Growth: 1990-1998.

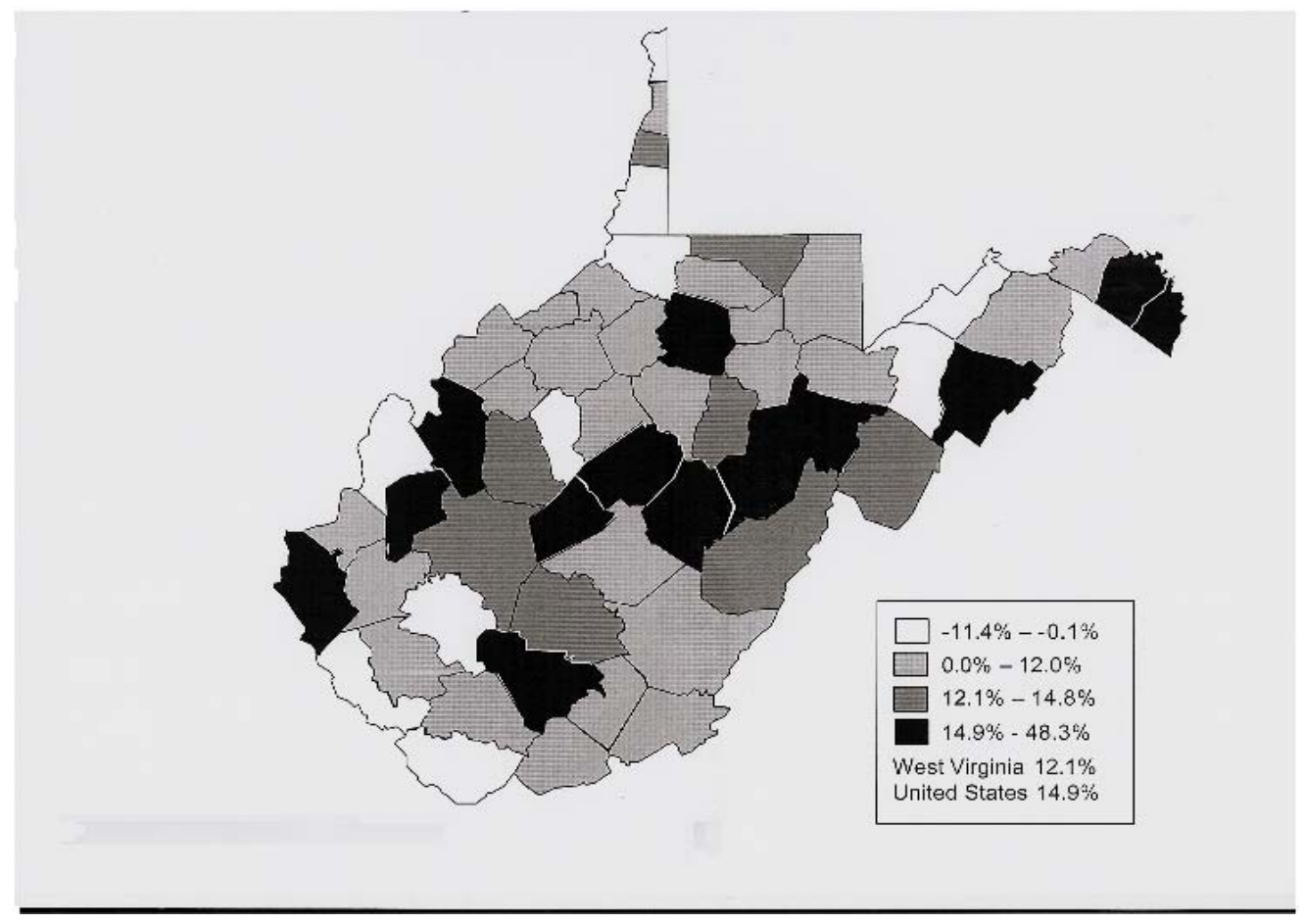

Source: Adopted from Regional Economic System, BEA, by Condon, Childs, and Bogdan, Bureau of Business and Economic Research, West Virginia University, Sept. 2000

Previous analysis similarly indicates that closeness to urbanized areas increases population density changes. The final effect on the agricultural sector comes from both employment and population related land needs and consequent competition and pressures.

The positive relationship between employment and distance from metropolitan centers implies that employment growth increases with increasing distance from metro areas. Since the estimate is highly insignificant, it may imply that nearness to urbanized centers is a weak predictor of changes in employment densities in West Virginia. This may 
further indicate that changes in employment densities are occurring in locations that are not close to urbanized locations. In addition, the employment growth occurring in West Virginia may be heterogeneously distributed beyond the speculated urban expansion effects.

Fig. 13. Interstate Road Map: West Virginia.

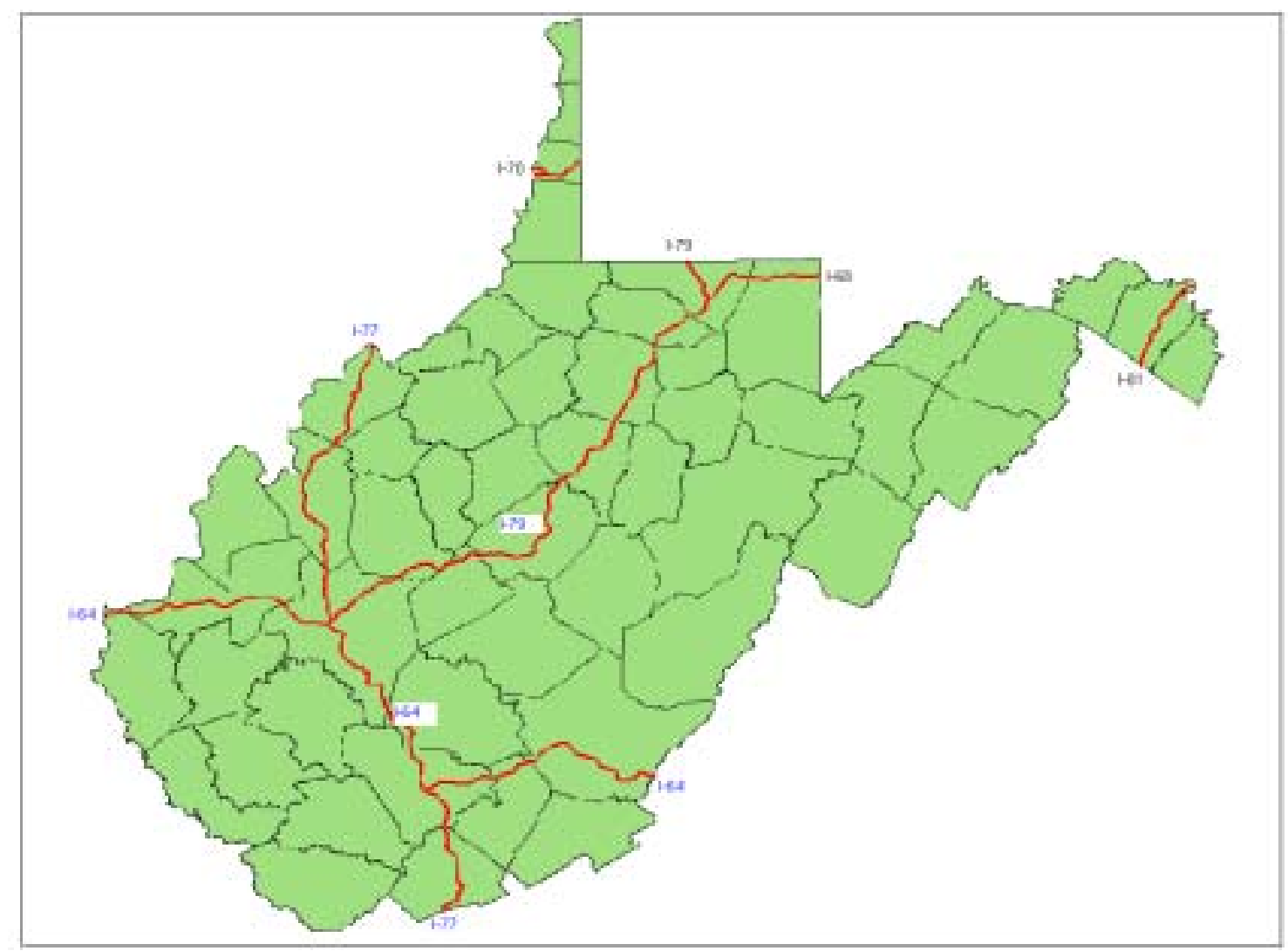

Source: Adapted from Natural Resource Analysis Center GIS resources, West Virginia University.

The model result for the relationship between adjacency to urbanized areas and changes in employment densities indicates an insignificant and negative relationship. This may imply that counties that are adjacent to urbanized areas showed no significant difference in employment than those that are not adjacent. This may further imply that employment growth is not significantly limited to adjacent counties, but rather is dispersed in nonadjacent counties as well. 
The employment density model estimates a negative relationship between per capita taxes and employment density changes. Theoretically, firms choose locations that minimize the total costs of the operation. If costs vary across space, then mobility of firms across space to capture cost advantages is expected. Similarly, the result indicates that employment growth is negatively associated with high tax locations as firms may relocate to take advantage of tax structures that vary across space. This result is consistent with theoretical expectation that firms will be less attracted to regions of high tax burdens.

A negative relationship between employment density growth and unemployment rates (UNEMPRT90) is observed in the result indicated in table 5. Though it may be argued that regions of high unemployment have lower labor costs that could attract employment growth, it is not justified in the case of West Virginia. Given the nature of employment growth, a high proportion of growth is observed in the service sector. Such services (like fast food, malls, recreational facilities...) are spread across areas of high population growth (demand factor) and areas of better purchasing power capacity (fast growing counties). Hence, it could be possible that the lower income of high unemployment areas and high poverty counties could have adverse negative implications on employment growth opportunity.

The change in employment, in the model specification, is decomposed into different sectors of interest to capture the sources of employment density changes through employment changes in different sectors. The relevant sectors of analytical interest are the percentage of employment in the agricultural (PAGEMP90), mining (PMIEMP90), construction (PCNEMP90), and service (PSVEMP90) sectors. The results from the model indicate that construction, mining, and agricultural sector employment have a positive but highly insignificant relationship with changes in total employment. The agricultural sector in particular poorly explains total changes in employment density in West Virginia. This may imply that these sectors account for insignificant variation in employment density changes in the state. However, a change in employment density is significantly and directly related with counties dominated by the service sector. 
Figure 10 indicates higher rates of employment growth, which are basically concentrated in areas of high population density. The growing percentage of employment in the service and construction industry might infer the spread of service based new industries and emerging construction activities in the state. Growth in the service sector may generate new employment opportunities. This can negatively influence employment in the agricultural sector.

From this result, it can indirectly be inferred that pressure on agricultural employment and hence, on the viability of the agricultural sector across regions is influenced by the growing new economy. The implication on agricultural land conversion thus becomes evident.

Interestingly, the model estimates a positive relationship between agricultural sales (AGSLAC90) and employment density changes. Intuitively, it could be expected on the contrary that changes in non-agricultural employment may exert pressure on the agricultural sector affecting the income and feasibility of the agricultural sector. However, the result opens room for many possible educated guesses. Ambiguously, the increase in employment and population in the suburban and other high employment growth areas can be thought of as a source of growing agricultural output market for local farmers. This may mean that not only do negative externalities caused by development exist, but also there are positive externalities associated with market creation for farm products. Nonetheless, a critical argument can also be raised that since employment competes for land and labor with the agricultural sector, negative effects on the agricultural sector may be encountered. This ambiguity leads to the direction of marginal effects - with increasing employment and purchasing power growth, does the positive effect of market creation exceed the negative effect of resource conversion to other sectors? This by itself could be an area of separate research. For the purpose of current analysis though, it would be enough to recognize the possible external benefits of employment growth to agricultural market extension as evidenced by the result of the model. It is expected that specialty markets for agricultural products would result in higher agricultural sales per acre as production switches to high valued crops. In a way, 
the result is recognizing the fact that employment growth need not necessarily have only negative effects on the agricultural sector, but could possibly support some market creation.

Unlike federal land preservation programs, the result indicates a positive and significant relationship between proportion of land owned by a county and changes in employment density. With the federal land preservation program, it was indicated that it slows changes in population density and might push development pressures to counties with significantly less federal land preservation. However, the result for the relationship when a county owns proportionate land is significantly positive which may imply that counties with significant land ownership saw significant changes in employment. This may be due to the fact that such counties might provide incentives on their county land to encourage employment opportunity growth and development to overcome poverty and development bottlenecks in the state. Through the model set up, this will have an indirect effect on the conversion of agricultural lands to such development uses.

Incorporating labor mobility aspects into the employment density model, a significant positive relationship is estimated between total employment changes and the proportion of resident county jobs held by people outside a county. This indicates that a high change in employment density is associated with counties that draw workers from neighboring areas. Generally, labor migrates to areas of better probability of employment and areas of high return per supply of labor effort. However, in this case, people are commuting from adjacent counties for employment, potentially due to the shortage of a labor force in the county with jobs.

Figure 10 depicts counties in West Virginia experiencing different rates of job growth. Associating the result with previous discovery on the association of access and employment issues, it can further be linked that counties with better employment growth and access can experience changes in in-migrating labor that may significantly affect changes in total employment densities. Since the employment density model predicted an insignificant relationship between changes in agricultural employment and changes in 
total employment densities and a significant positive association with service sector growth, this labor in-migration result might imply some degree of pressure on agricultural lands excreted by non-agricultural sector pressures.

On the other hand, counties with bedroom communities (proportion of resident labor employed outside the county) experienced negative changes in employment density. Though intuitive, the result is highly insignificant. Intuitively, counties with high proportion of resident labor force working outside the county face lower changes in employment density. Better compensation and incentives can attract county labor to supply their effort outside the county. With increasing significance of bedroom communities, a slower growth in employment in a county could be experienced.

A positive relationship is also found in the result on the relationship between changes in employment density and population changes. The significant positive relationship between population changes (POPDIFF) and employment density change provides further information to the previous result on whether people follow jobs or jobs follow people argument presented in the previous section. The conclusion that jobs follow people is also reinforced in the employment model. A change in population significantly influences employment growth. One inference that can be generated from this result is that combining the results from the two models, population pressures account for higher land conversion influences than employment growth in West Virginia.

Figure 12 reinforces the conclusion from the model by indicating that for the northeastern region in general, residential (household) demand accounts for a significantly higher rate of agricultural land conversion ( $72 \%$ of the converted crop land, while for business purposes it stands at 14\%) to non-agricultural uses for the $1982-1992$ period. Though employment also significantly interacts in the conversion process, its effect is relatively less that population pressures. This result also holds for the case of West Virginia for the considered period of $1990-1999 / 2000$. 
Fig. 14. Crop Land Converted to Developed Land by NRCS Region, $1982-1992$.

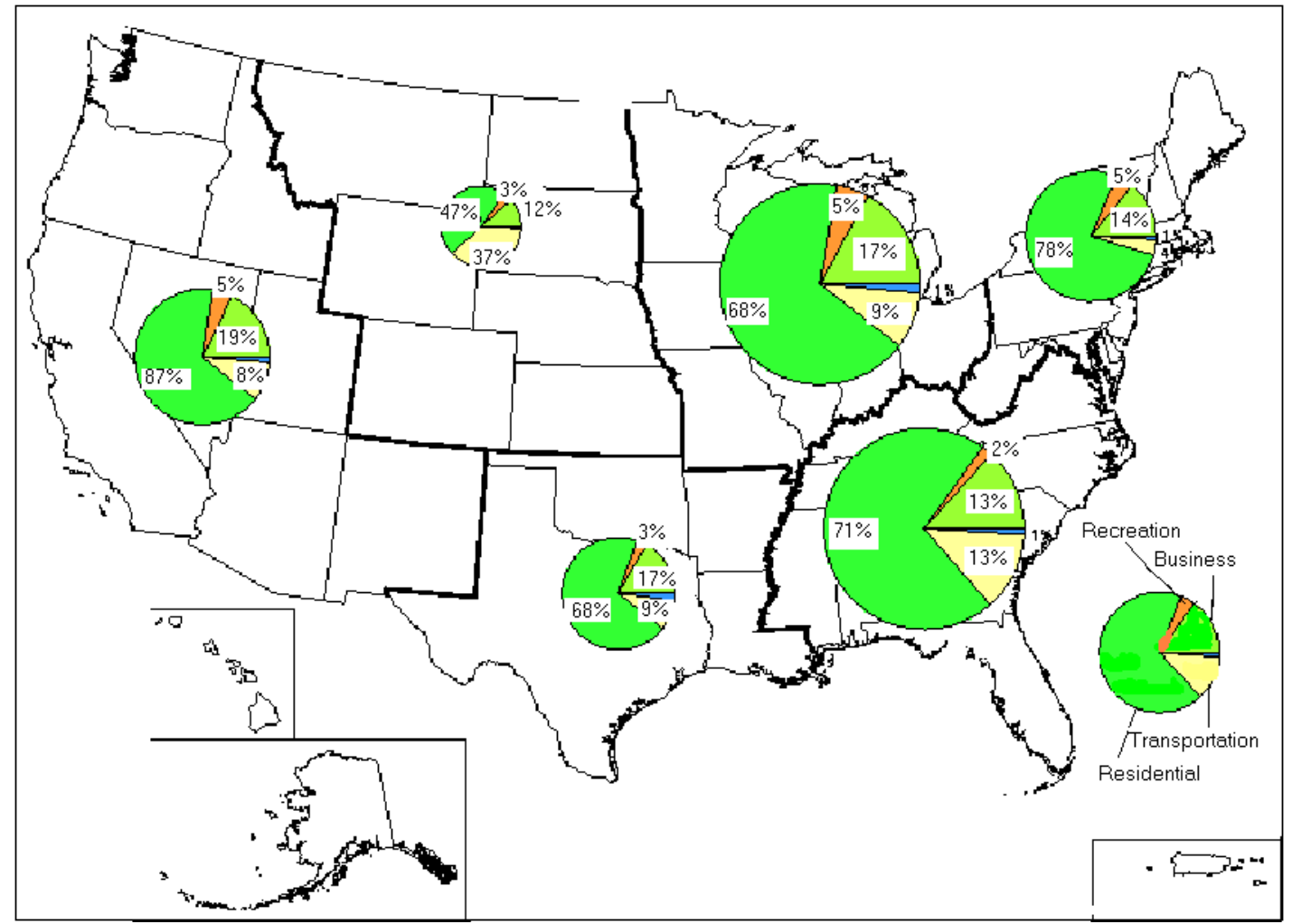

Source: Adapted from USDA, Natural Resources Conservation Service, Resource Assessment Division, Washington, D.C., 1997.

To summarize, the model confirms the following comparative static results:

$\partial($ DEMPDIFF $) / \partial($ HWYDEN $)>0, \partial($ DEMPDIFF $) / \partial($ P20KADJ $)<0, \partial($ DEMPDIFF $) / \partial($ PCTAX 90$)<0$, $\partial($ DEMPDIFF $) / \partial($ UNEMRT 90$)<0, \partial($ DEMPDIFF $) / \partial($ PMIEMP90 $)>0, \partial($ DEMPDIFF $) / \partial($ PCNEMP90 $)>$ $0, \partial($ DEMPDIFF $) / \partial($ PSVEMP90 $)>0, \partial($ DEMPDIFF $) / \partial($ DPOPDIFF $)>0, \partial($ DEMPDIFF $) / \partial($ DAG90 $)>0$, $\partial($ DEMPDIFF $) / \partial($ PCOUNTY $)>0, \partial($ DEMPDIFF $) / \partial($ PINMIGRT $)>0$.

\subsubsection{Analysis of the Agricultural Land Density Model}

In the previous two sections, the simultaneous interactions of employment and population models are analyzed, including characteristics of agriculture as an explanatory variable. In this section, the direct influence of employment and population density changes in agricultural land will be discussed.

The agricultural density model estimates a negative relationship with agricultural land density and access. The result indicates that agricultural land density is negatively related with highway densities (HWYDEN). It is evident that access improves the growth of 
employment in a region, as confirmed by the employment model in the last sections. At the same time, it also tends to diminish agricultural land densities due to increased pressure. The result is confirmed by the negative comparative static result for the agricultural land - access relationship. Expansion of highways has facilitated the increase in population and employment concentrations directly impacting land holdings for different agricultural activities.

Fig. 15. Acres of Non-Federal Developed Land, 1997.

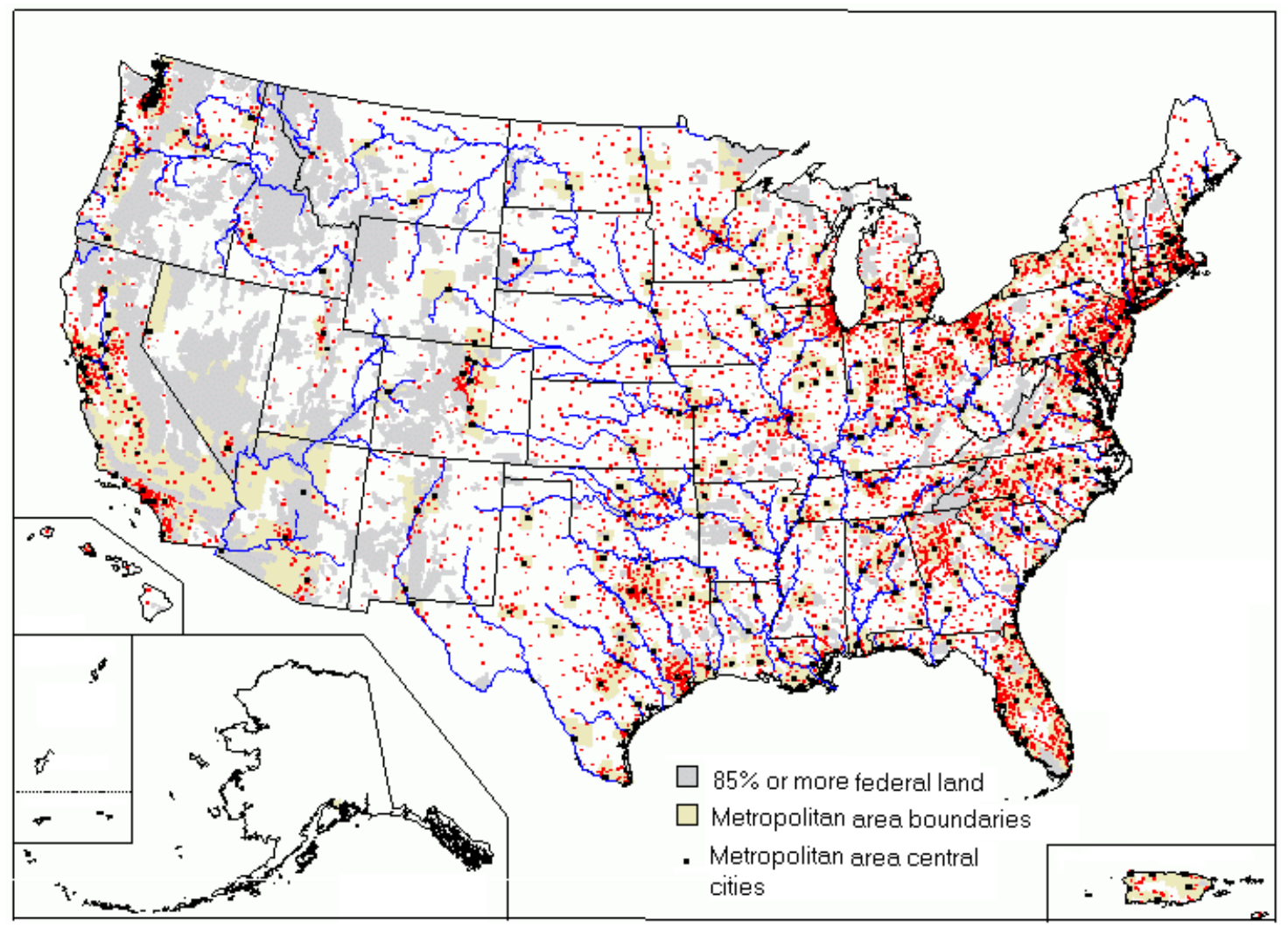

Source: Adapted from USDA, Natural Resources Conservation Service, Resource Assessment Division, Washington, D.C., 2000.

As indicated in figure 13, development pressures are highly associated with road infrastructure developments in West Virginia. This can be inferred by comparing the distribution of development spots with interstate road developments (figure 11). This result is consistent with the conclusions that agricultural land conversion intensifies near transportation facility developments and decays as distance from accessed areas increases. 
The positive result describing the relationship between changes in agricultural land and nearness (NEARDIST) to urbanized centers was not theoretically expected. The direct effect of distance on agricultural land conversion was expected to decay as distance increased from the urbanized centers. However, the estimated relationship is highly insignificant and could be a poor proxy to capture locational variation through physical distance.

A more appropriate measure of the influence of location on agricultural land conversion may be the adjacency dummy proxy (P20KADJ) that measures the influence on rural communities of being adjacent to urbanized areas as compared to not being adjacent to urbanized locations. The result, at a 2 percent significance level, indicates that those counties that are adjacent to urbanized areas experienced $37.9 \%$ more changes (variations) in their agricultural land density as compared with those counties that are not adjacent to urbanized locations. This result can be related with the finding in the population density model that agricultural lands density is negatively related with changes in population density. Generally, higher population pressure is expected in urbanized and suburbanized locations that have more pressure on land for growing nonagricultural purposes. From this perspective, it can be inferred that counties that are adjacent to urbanized locations experiencing $37.9 \%$ more variation in their agricultural land density have more pressure on land use and allocation that may negatively affect agricultural land densities.

Figure 14 indicates population growth concentration in West Virginia. Significant clusters of population growth can be observed adjacent to urbanized and sub-urbanized areas.

On the relationship between changes in population density (DPOPDIFF) and agricultural land density (DAGDIFF), the relationship estimate shows (in table 6) a positive relationship between the two endogenous variables. This result indicates that high changes in agricultural land density occur in areas where there are high changes in population density. This result is logically consistent with the theoretical expectation that 
the more population changes in locations, the more would be the expected variation or change in agricultural lands.

Fig. 14. Population Changes: 1990-2000, West Virginia.

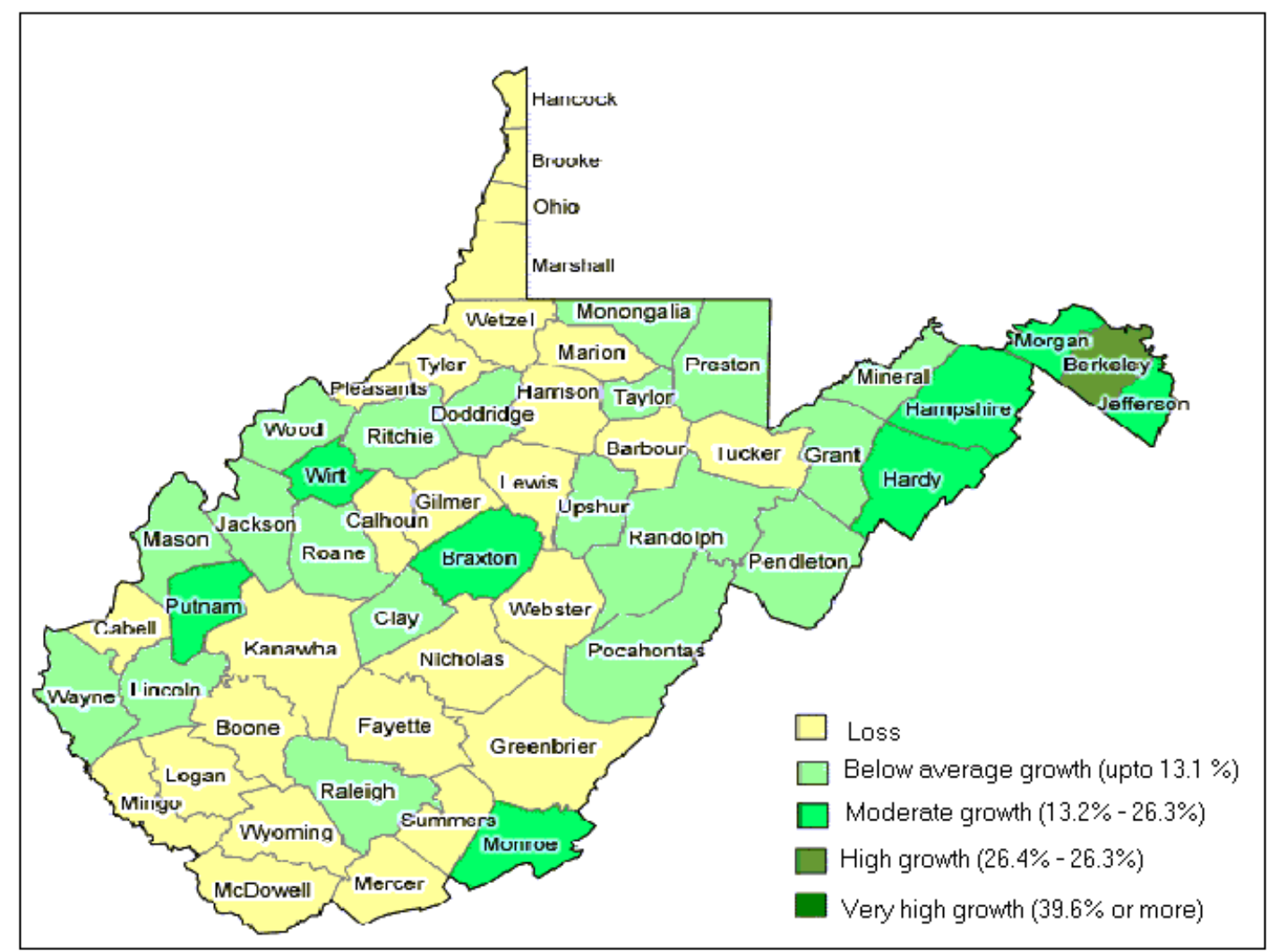

Source: ERS, U.S. Department of Agriculture, http://www.ers.usda.gov/Data/Population/PopList.asp?ST= WV\&LongName $=$ West $\% 20$ Virginia.

Similar to the result of a regional conversion study reported in figure 12 , a significantly large impact of population density variations facilitates the conversion of agricultural land. The result is consistent with growth theories in relation to the effect on the agricultural sector. As specified in Chapters One and Two, one of the basic arguments for the conversion of land is increase in the population pressure. This result confirms that population pressure is a valid argument in explaining associated agricultural land changes or conversion possibly for household and recreational demands. An increase in population in an emerging region not only increases the demand for land for residential purposes, it also increases the demand for recreational, public services, basic community developments, administrative and transportation installments and other attendant land demands. Since the physical supply of land is basically fixed, the pressure has to be met 
by changing the economic supply of land through reallocation from other sectors. In suburban fringes and rural areas, where the dominant economic activity could be agriculture, this sector faces growing challenges of economic, legal, and administrative pressures making sustained farming practices difficult. Ultimately, this results in conversion of agricultural lands to meet growing population needs. The result for West Virginia indicates similar tendencies.

However, a specific argument can be raised about what particular agricultural land use is typically affected by the conversion pressures. Modeling agricultural lands classified into two major uses - cropland (PCROP90) and pastureland (PPAST90) - the result in the agricultural density model indicates that croplands are positively related with changes in agricultural land density while pastureland is negatively related with the total agricultural land density changes. The proportion of cropland is modeled as a proxy for prime farmland establishing a rational expectation that farmers will allocate their land according to the priority that best lands are put into crops and relatively marginal lands are set aside for pasture land and other relevant agricultural activities. Thus, the relationship with cropland indirectly captures changes in prime farmland.

From the result, it may be inferred that the loss of farmland coincides with areas having more cropland. In addition, areas with a greater proportion of farmland in pasture saw smaller changes in farmland. This may indicate that in those counties or areas where farmland conversion is intensified, croplands and consequently prime farmlands are primarily affected. The negative effect on croplands could be due to the features of such lands. In many instances, croplands are flatter and more convenient to development than are pasturelands, woodlands, or other agricultural land uses making cropland even more sensitive to development pressures. The conversion of other agricultural land uses is relatively more costly than the conversion of croplands for development purposes. 
This can be better understood with the visualization of the structure of the agricultural sector in West Virginia. Baniecki and Dabaan (1998) report:

\begin{abstract}
Poultry, meat animals, and dairy dominate the farm economy in the Mountain State. Commercial broiler production has shown a dramatic increase over the last ten years with the value of production increasing from \$29.4 million in 1985, to \$52.2 million in 1990 to $\$ 139.0$ million in 1997. The relatively small field crop acreages are mainly devoted to livestock feeds. Of the 637,000 acres harvested from principal field crops in 1997, 88 percent are hay, 10 percent corn, 1 percent wheat, and 1 percent oats. Based on 1997 cash receipts of over $\$ 393$ million, the top ten commodities are: broilers, 35 percent; cattle and calves, 18 percent; dairy products, 9 percent; eggs, 6 percent; greenhouse and nursery, 4 percent; hay, 3 percent; apples, 3 percent; corn, 2 percent; and peaches, 1 percent. ... Other livestock related commodities important to West Virginia's economy are sheep and lambs and hogs. Apple and peach orchards cover about 9,000 acres in the State. Burley tobacco harvested, although only 1,800 acres, ranks fifteenth in production. ${ }^{10}$
\end{abstract}

The agricultural land density model provides interesting information about the nature of the agricultural sector and related tendency to conversion. The relationship between agricultural sales (AGSLAC90), agricultural employment levels (PAGEMP90), and agricultural land density change is estimated in table 6 . Interestingly, the result indicates that agricultural sales and agricultural employment are significantly negatively related with changes in agricultural land density.

The result indicates that the less profitable and competitive agriculture is, the more conversion of agricultural lands to other uses would be expected. This result is clearly intuitive and logically consistent with the theoretical setup that economic agents that can provide a higher bid rent for a given land at a particular distance and location will dominate that location. Conversely, a rise in agricultural sales and employment opportunities should lead to lower agricultural land density declines. From this interesting comparative static result, it can be inferred that the conversion of agricultural lands to other uses observed in this study can partly be justified by the relatively lower sales performances and declining shares of employment creation in the agricultural sector.

The protection of agricultural land can be addressed from two directions: government reservation programs and increasing the profitability of the agricultural sector. Without

${ }^{10}$ See report at http://www.wvu.edu/ agexten/ipm/pestprog/NAPIAP/agricult.htm\#Agriculture. 
government intervention, farms with relatively lower incomes definitely face growth threats and ultimate conversion. This argument can be justified by a fairly significant result derived from the model.

The attempt to partially link labor mobility with changes in agricultural land density is made through estimating the direct relationship between bedroom communities and changes in agricultural land densities. The estimated result indicates a negative relationship between proportion of employed residents who work outside their county of residence (bedroom communities) (POUTWORK) and changes in agricultural land densities. This may mean that those counties that are bedroom communities generally face lower changes in agricultural land density. However, this estimate is insignificant. Particular regional considerations might alter the result in that in some counties with high bedroom communities (like the Eastern Panhandle region), high changes in population and employment are also occurring. This may create pressure on agricultural lands. However, at the state level, less agricultural land changes are observed in those counties with bedroom communities.

Finally, the relationship between non-governmental organizations operation in land preservation and its relationship to agricultural land conversion is established. Local land trusts, The Nature Conservancy and other non-governmental organizations actively involved in the preservation of agricultural lands and rural lands of significant importance to the preservation of nature. The agricultural land density model estimates the relationship with non-governmental land preservation programs and their influence on the change of agricultural lands. The result indicates a significant negative association. This implies that increased effort to preserve land in the face of pressure significantly contributes to the reduction of changes (decline) in agricultural lands.

To conclude the analysis, the following comparative static results of the agricultural density model are summarized:

$\partial($ DAGDIFF $) / \partial($ HWYDEN $)<0, \partial($ DAGDIFF $) / \partial($ P20KADJ $)>0, \partial($ DAGDIFF $) / \partial($ DPOPDIFF $)>0$, $\partial($ DAGDIFF $) / \partial($ PCROP90 $)>0, \partial($ DAGDIFF $) / \partial($ PPAST90 $)<0, \partial($ DAGDIFF $) / \partial($ AGSLAC90 $)<0$, $\partial($ DAGDIFF $) / \partial($ PAGEMP90 $)<0, \partial($ DAGDIFF $) / \partial($ POUTWORK $)<0, \partial($ DAGDIFF $) / \partial($ DCONSERVE $)<0$. 


\section{CHAPTER V}

\section{SUMMARY AND CONCLUSION}

\subsection{SUMMARY}

The relationship between mankind and the environment and resources is an intricate one. With ever growing population and social needs, the resulting strain on natural resources is increasing. One of the natural resources of particular importance is land. As the economy grows, there is increased pressure over the use of land.

The objective of this study is the investigation of factors associated with spatially varying land use changes; in particular, agricultural land changes. The loss of agricultural land is evident in the United States as the growth of other non-agricultural sectors demand more land, creating direct and indirect pressure on agricultural land conversion nationwide. This study particularly focuses on the case of West Virginia where development pressures along urbanized and semi-urban locations are believed to compete most strongly with agricultural uses of land.

Land value and land use changes are areas of study in economic history since Adam Smith. Treating land as any other economic good, it is demanded by consumers to maximize their utility attached to locations and by producers to maximize profits that vary across locations. The interaction of these forces and the resulting location bid rent determines the land use feature of different locations. That is, land will be put to its highest and best (most valuable) use.

Different studies substantiate that with ever growing cities and expanding urban boundaries, a significant conversion of agricultural land to other uses has occurred. The implications of this growing trend in the conversion of agricultural land to other uses have been a focus of much concern and research. The concern over the loss of agricultural land includes losses of rural character and environmental and other natural amenities associated with farming practices. 
Generally, spatial land use changes through time are associated with regional economic patterns that can fairly be captured by decision behaviors of households and firms. The spatial preference of people emanates from their desire to maximize utility that varies depending on what location is preferred for residential or recreational purposes. With growing congestion, urban pollution, crime, and a number of urban attendant externalities, the preference of people has shifted to sub-urban and accessible rural locations where the urban-associated externalities are minimal and offer additional natural amenities and other rural attendant external benefits. This has attracted a change in the population and structural composition of rural lands directly interfering with rural economic practices - typically agricultural activities.

Similarly, business enterprises (firms) adjust their locations to minimize costs across different locations. With growing population along the suburban and urban fringes, different service based industries and other business activities have intensified in order to capture the newly emerging markets and labor cost advantages.

The interaction of these business and household decisions to maximize gains across locations results in a re-allocation of land in those locations. The implication of these trends on the agricultural sector is the main focus for this study.

To systematically capture the interaction of different growth factors and agricultural sector attributes, a system of equations model is specified. The model follows from the work of Carlino and Mills with relevant adjustments to address the research objective. The model captures the influence of population and employment density changes on agricultural land. A separate equation in the system focuses on agricultural land density changes as a function of employment and population changes as well as a vector of other factors. The model captures regional economic changes, in terms of population and employment distribution across space, and translates the impacts to the rate of land conversion. 
Results indicate that population density changes are negatively associated with natural amenities, federal lands, density of agricultural lands, per capita taxes, and distance from urbanized and suburbanized places, while highways, employment growth, and owner occupied housing positively influence the change in population density.

The employment density model results indicate that access, population growth, construction and service sector employment dominance, and agricultural sales are positively related with employment density expansions. Unemployment rate, agricultural employment and distance are found to be negatively associated with employment density changes.

The agricultural land density model reinforces the argument that agricultural land conversion is motivated by population pressure, highway expansion, nearness of metropolitan and urbanized centers, and weak agricultural sectors. The model consequently captures the sources of pressure on agricultural land conversion and isolates particular activities of agricultural land use affected by the conversion process. The result is believed to provide relevant information for the ongoing land use issues in West Virginia.

\subsection{CONCLUSION}

Modeling the interaction of intricate economic phenomena occurring in spatial dimensions is a very challenging task. In light of this challenge theories assist in focusing on specific relationships among variables of economic interest without making any attempt to make them exhaustive or overly detailed.

This study relied on established structural growth modeling techniques to derive relevant conclusions about agricultural land conversion in West Virginia. Following the structure of the model and the behavior of the state's economy, relevant results have been identified leading to the derivation of necessary implications. 
The study focused on factors that are directly and/or indirectly associated with changes in agricultural land density from 1990 to 1999 . Following is a summary of the research results.

\section{A. The population Density Model}

- Population density is expected to vary inversely with distance from identified metropolitan, urbanized, and semi-urbanized areas, as transportation cost will increase offsetting savings from lower property values and high natural amenities.

- Population density is estimated to vary inversely with per capita tax burden, which is unevenly distributed across different locations.

- The density of highway systems is insignificant and negatively related to population density changes across the state.

- Population density change is negatively related with agricultural land density.

- Federal land ownership reduces the expansion of population densities by the physical protection on the conversion of land for development uses.

- The rate of owner occupied housing in regions is positively related population density changes.

- Population density is negatively related with the stock of natural amenities. A negative relationship is isolated between population densities and the percentage of land covered by forest and water resources.

- Population density changes are positively linked with unemployment rates.

- A change in employment density will positively influence population density changes.

- Change in population density is negatively related with proportion of resident jobs held by people outside the county and positively related with proportion of employed residents who work outside their county of residence 
B. The Employment Density Model

- Change in employment density is positively affected by population changes. Population growth is found to be significantly attracting employment changes in West Virginia.

- Changes in employment density are inversely related with per capita taxes.

- Employment density changes are positively related with access endowments. Highway density is found to affect employment growth.

- The change in employment density is insignificantly related to employment in the mining, agricultural, and construction sectors, but significantly and positively related with service sector employment.

- An inverse relationship is captured between unemployment rate and employment density changes.

- Employment densities are found to be positively related with agricultural sales. This result possibly recognizes that employment growth need not necessarily have only negative effects on agricultural sector, but could possibly support some market creation.

- Counties with high county land ownership have a significant positive relationship with changes in employment density.

- Change in employment density is positively and significantly related with proportion of resident jobs held by people outside the county and negatively related with proportion of employed residents who work outside county of residence.

\section{The Agricultural Land Density Model}

- High agricultural land density changes are associated with high population density changes. Thus population growth is the driving force behind farmland conversion in West Virginia.

- Transportation access is negatively associated with agricultural land densities. By directly claiming land and by intensifying other economic activities concentrated around the accessed locations, the expansion of highways facilitates the conversion of agricultural lands. 
- Decomposition of agricultural land uses into different specific use types indicates that the density of agricultural land is positively related with croplands and negatively related with pasturelands. This indicates that West Virginia may be losing its prime farmland, as proxied by cropland.

- The decline in both agricultural sales and agricultural employment will facilitate the conversion of agricultural lands. This means that less competitive and profitable agriculture is most at risk to alternative demands for land.

- A negative relationship is found between bedroom communities and changes in agricultural land densities.

- Non-governmental land conservation initiatives reduce the change in (conversion of) agricultural lands.

It is believed that the results and conclusions derived from this study will shed some light on the ongoing issue of land conversion in West Virginia and could provide a steppingstone for further studies, inquiries, and improvements.

\subsection{POLICY RECOMMENDATIONS}

The study addresses the intricate relationship between population, employment, and agricultural lands. Analysis of the three separate models of population, employment and agricultural land densities provided extensive information on the nature and interaction of the three forces of interest. From the results, summarized in section 5.2, it can be noted that growth over time in population and employment has to be compromised with the agricultural sector on the use and allocation of land.

Particularly, the agricultural density model estimated that the poor performance of the agricultural sector in terms of farm sales and employment generation will negatively affect agricultural lands as they face more pressure from non-agricultural sectors through time.

Though markets allocate resources efficiently under conditions of perfect competition, assumptions of zero externalities of the perfect competition model is violated in the case of agricultural lands. In many cases, agricultural lands not only provide agricultural 
products to society or land to non-agricultural uses, it is also a source of non-market values in terms of preservation of the farming tradition, landscape preservation, scenic values, and other positive externalities to society that may not be represented in land values.

On the other hand, West Virginia has a lower economic standard and economic growth as compared to the rest of the United States. Economic development objectives may in this case emphasize the encouragement of new developments in the hope of generating more employment and growth opportunities to the state. Recent highway extension programs and other development packages are indications of this maintained desire.

From a policy perspective, the encouragement of development per se may not be objected from the perspective of the state's economic development agenda. However, the proper management of growth and its implication to the established local and rural economic activities need to be properly evaluated and considered and tallied with the marginal benefits of new development undertakings.

In this study, the effects of tax structures, housing values and ownership, employment and population expansion on agricultural lands are established and discussed. Policies focusing or affecting such important areas need to take proper judgment as to the possible implications on the agricultural communities.

Conservation (public and private) is found to significantly affect the conversion of agricultural land to other uses. Policies oriented towards agricultural land management and protection need to properly consider the role and participation of federal and nongovernmental agencies in the effective management of the agricultural landscape.

Finally, to efficiently manage regionally varying developments and agricultural lands, a proper land use policy should be introduced in the state of West Virginia to address both development targets and agricultural land preservation. To overcome regional variability of land use structure, county level land use management practices may be introduced to flexibly address the growing patterns of land use problems in the state. 


\subsection{LIMITATIONS OF THE STUDY AND AREAS OF FURTHER RESEARCH}

The study of land use changes and identification and modeling of forces explaining the land allocation process is a challenging task. Consideration of the issue at the broader state level complicates the study and proper investigation of land use changes through time.

This study provides relevant information and analysis about the land use trend in West Virginia. A proper relationship between land use and relevant sources of influence affecting the land use system is introduced and analyzed. A growth equilibrium model is introduced to study the land use issue in West Virginia and relevant conclusions are made based on the findings.

However, the study faces its own limitations that can be summarized as follows:

- Scope: the study focuses on West Virginia and systematically isolates the effects of regional changes of important variables as constant. However, with the new economy, the interaction of regions is highly correlated. Today, there is growing interdependence among states and regions in terms of policy, trade, and many other areas of interaction. Hence, modeling land conversion with a state level frame has its own shortcoming.

- Policy: the influence of policy measure directly and indirectly related with agricultural land have a bearing on land use. West Virginia does not have an explicit policy to address land use and growth management. However, such policies are adopted and implemented in the Northeastern Region and their implication in terms of growth dispersion and other attendant implications are not captured. With a broader regional scope, a proper integration of policy variables will help explain the land conversion processes and their marginal effects on limiting or directing growth, and conserving agricultural land.

- Spatial measures: it is evident that the location of an activity will have a significant effect on land. Establishing the proper proxy and/or variable to 
represent the effect of spatial location on land use is vital. Physical distances, adjacency to urbanized areas, and interstate highway proxies are taken to represent spatial locations. However, such measures can be improved by integrating applied GIS spatial measures to properly establish the influence of location on land use changes.

- Modeling: this study models the change in land uses using a static system of equations growth model, applied to a single decade. Initial conditions are compared with values at the end of the decade. However, approaching the problem from a dynamic model may provide a better understanding of how different forces interact in land use changes.

Thus, further research in this area can effectively be pursued by incorporating a dynamic analysis of land use changes, that includes policy and effective spatial measures, in a regional growth modeling framework. 


\section{BIBLIOGRAPHY}

1. Alonso, William. Location and Land: Toward a General Theory of Land Rent. Harvard University Press. 1964.

2. Anderson, W. D., G. C. Gustafson and R. F. Boxley. Perspectives on Agricultural Land Policy. Journal of Soil and Water Conservation, 30(1): 1975.

3. Barkley, Paul W. and Gene Wunderlich. Rural Land Transfers in the United States. USDA/ERS, Agricultural Information Bulletin No. 574, October 1989.

4. Barlowe, Baleigh. Land Resource Economics: The Political Economy of Rural and Urban Land Resources Use. Prentice-Hall, Inc., Engelwood Cliffs, NJ. 1958,

5. Berry, David. Effects of Urbanization on Agricultural Activities. Growth and Change, 9(3): 1978.

6. Berry, David. Idling of Farmland in the Philadelphia Region, 1930-1970. Regional Science Research Institute. Discussion Paper Series No. 88. University of Massachusetts, Amherst, 1976.

7. Bevan, Wilson Lloyd. Sir William Petty: A Study in English Economic Literature. Publications of the American Economic Association, Vol. IX, No. 4. 1894.

8. Brewer, M. F. and R. F. Boxley. Agricultural Land: Adequacy of Acres, Concepts and Information. American Journal of Agricultural Economics, 63(5): 1981.

9. Brooks, Douglas H. Land Use in Economic Theory: Principles and Prospects. USDA-ERS Staff Report Number Age870806. Washington, D.C., September 1987.

10. Brueckner, Jan K. and David A. Fansler. The Economics of Urban Sprawl: Theory and Evidence on the Spatial Sizes of Cities. The Review of Economics and Statistics. 65(3): August 1983.

11. Brueckner, Jan K.. The Structure of Urban Equilibria: A Unified Treatment of the Muth-Mills Model," 1982, in Mills, Edwin S., ed., Handbook of Regional and Urban Economics, Vol 2, Amsterdam: North Holland-Elsevier Publishers. 1987.

12. Cantillon, Richard. Essai sur la nature du commerce en general, 1755.(English Translation).[Online] available from http://socserv2.socsci.mcmaster.ca/ econ/ ugcm/ 3113/cantillon/essay1.txt; accessed 14 September 2002; Internet. 
13. Carlino, Gerald A. and Edwin S. Mills. The Determinants of County Growth. Journal Of Regional Science. 27(1): 1987.

14. Daniels, Thomas L. Hobby Farming in America: Rural Development or Threat to Commercial Agriculture? Journal of Rural Studies 2(1): 1986.

15. Daniels, Thomas L., and Arthur C. Nelson. Is Oregon's Farmland Preservation Program Working? Journal of the American Planning Association, 52(1): 1986.

16. Deller, Steven C., Tsung-Hsiu (Sue) Tsai, David W. Marcouiller, and Donald B. K. The Role of Amenities and Quality of Life in Rural Economic Growth. English. American Journal of Agricultural Economics. 83(2): May 2001.

17. Department of Agriculture, National Agricultural Land Study. Where Have the Farmlands Gone?, Department of Agriculture, Washington, D.C., May 1980.

18. Duffy-Deno, Kevin T. Economic Effect of Endangered Species Preservation in the Non-Metropolitan West. Growth and Change. Vol. 28: September 1997.

19. Fisher, Joseph L. Discussion. The American Economic Review. 46(2): May 1956.

20. Gardner, B. D. The Economics of Agricultural Land Preservation. American Journal of Agricultural Economic, (59) 1977.

21. Haig, Robert Murray. Toward an Understanding of the Metropolis. The Quarterly Journal of Economics, 40(3): May 1926.

22. Heimlich, R. E. and Robert C. Reining. The Economic Research Service in Urbanization Research. In Land Use Transition in Urbanizing Areas. (Research and Information Needs). Ralph E. Heimlich (editor). Proceedings of a workshop sponsored by USDA/ERS and Farm Foundation, Washington, D.C., 1989.

23. Henry L. Diamond and Patrick F. Noone, Foreword by Rockefeller, Laurence S. Land Use in America: The Report of the Sustainable Use of Land Project. Island Press, Washington, D.C., USA, 1996.

24. Irwin, Elena G. and Nancy E. Bockstael. The Problem of Identifying Land Use Spillovers: Measuring the Effects of Open Space on Residential Property Values. American Journal of Agricultural Economics. 83(3): August 2001. 
25. Jevons, William Stanley. Brief Account of a General Mathematical Theory of Political Economy. The Journal of the Royal Statistical Society, London, XXIX (June): 1866. [Online] available from Archive for the History of Economic Thought, McMaster University, Canada, http://www.marxists.org/reference/subject/economics /jevons/mathem.htm; accessed 14 September 2002, Internet.

26. Johnson, James H. Geographical Process at the Edge of the City, 1974, In Suburban Growth: Geographical Processes at the Edge of the Western City, Edited By James H. Johnson, John Siley \& Sons, Ltd, Aberdeen, Uk. 1974.

27. Joseph S. Keiper, Ernest Kurnow, Clifford D. Clark and Harvey H. Segal. Rent: Doctrines, Measurement, and Public Policies. Chilton Company, Philadelphia, 1961.

28. Krupta, Kenneth S. and Marlow Vesterby. How Urban Pressure Affected Sales of Agricultural Products: 1950-1977. USDA-Economic Research Service (ERS), Washington, D.C., 2001

29. Lapping, Mark B., and J. F. FitzSimmons. Beyond the Land Issue: Farm Viability Strategies. Geo Journal 6(519): 1982.

30. Lopez, Rigoberto A., Adesoj O. Adelaja, and Margaret S. Andrews. The Effects of Sub-urbanization on Agriculture. American Journal of Agricultural Economics, May 1988.

31. Losch, August. The Economics of Location. Translated from the Second revised edition by William H. Woglom with the assistance of Wolfang F. Stolper. Yale University Press, 1954.

32. Marshall, Alfred. Principles of Economics. London: Macmillan and Co., Ltd, 1920. [Online] available from http://www.econlib.org/library/Marshall/marP1.html; accessed 16 November 2002; Internet.

33. Menger, Carl. Principles of Economics.1871. [Online] available from ITU Support Center, http://mason.gmu.edu/ tlidderd/menger/; accessed 16 September 2002; Internet.

34. Mieszkowski, Peter, Edwin S. Mills. The causes of Metropolitan Suburbanization. The Journal of Economic Perspectives. 7(3): 1993. 
35. Mill, John Stuart. Principles of Political Economy. London: Longmans, Green and Co., ed. William James Ashley, 1909. [Online] available from http://www.econlib.org library/Mill/mlP1.html; accessed 14 September 2002; Internet.

36. Mills, David E. Competition and the Residential Land Allocation Process. The Quarterly Journal of Economics. 92(2): May 1978.

37. Miyao, Takahiro. Some Dynamic and Comparative Static Properties of a Spatial Model of Production. The Review of Economic Studies, 44(2): June 1977.

38. Muth, Richard F. Economics Change and Rural-Urban Land Conversions. Econometrica. 29(1): January 1961.

39. Pimentel, David and Mario Giampietro. A U.S. Population Growth Threatens Irreplaceable Farmland. In Food, Land, Population and the US Economy. Carrying Capacity Network. Clearinghouse Bulletin, December 1994.

40. Plantinga, Andrew J. and Douglas J. Miller. Agricultural Land Values and the Value of Rights to Future Land Development. Land Economics. 77(1): February 2001.

41. Platt, R. H. The Farmland Conversion Debate: NALS and Beyond. Professional Geographer, 37(4): 1985.

42. Plaut, Thomas R. Urban Expansion and the Loss of Farmland in the United States: Implications in the Future. American Journal of Agricultural Economics, August 1980.

43. Ramsey, A. Frank and Floyd L. Corty. Prime Agricultural Lands of Louisiana: Location and Losses to Non-Agricultural uses. D.A.E. Research Report No. 569, Louisiana State University, Baton Rouge, April 1982.

44. Smith, Adam. An Inquiry into the Nature and Causes of the Wealth of Nations. London: Methuen and Co., Ltd., ed. Edwin Cannan, 1904. [Online] available from http://www.econlib.org/library/Smith/smWN1.html; accessed 14 September 2002; Internet.

45. State Land Use Committee, Mountaineers for Rural Progress. Major Land Use Changes. Part I, for West Virginia, 1970-74, A Summary Report. Coope. Ext. Service, Center for Extension and Continuing Education, West Virginia University. January 1976. 
46. Steinnes, Donald N. and Walter D. Fisher. An Econometric Model of Intraurban Location. Journal of Regional Science. Vol. 14: 1974.

47. Studenmund, A. H. Using Econometrics: A Practical Guide. Addison Wesley Longman, Inc, USA. 2001.

48. Tall, Madani M. and Dale Colyer. Economic Assessment of Agricultural Land-Use Values in West Virginia. Paper presented at the Northeastern Agricultural and Resource Economics Association annual meeting, University Park, Pennsylvania, June 1989.

49. The Institute for Memetic Research, FuturesEdge.org site, 2001. Historical World Population Data. [Online] available from http://futuresedge.org/ World_Population_Issues/Historical_World_Population.html; accessed 15 August 2002; Internet.

50. The Northeast Regional Center for Rural Development. Land Use Problems and Conflicts in the U.S., A Comprehensive Research for the $21^{\text {st }}$ Century. Rural Development Paper No. 10, 2002.

51. Thomas, David. The Urban Fringe: Approaches and Attitudes, 1974, In Suburban Growth: Geographical Processes at the Edge of the Western City, Edited by James H. Johnson, John Siley \& Sons, Ltd, Aberdeen, Uk. 1974.

52. Turgot, Anne Robert Jacques. Reflections on the Formation and Distribution of Wealth. London: J. Good, 1793. [Online] available from http://www.econlib.org/ library/Essays/trgRfl1.html; accessed 14 September 2002; Internet.

53. U.S. Department of Agriculture. The second RCA appraisal, Number USDA Miscellaneous Publication 1482. U.S. Department of Agriculture, Washington. D.C., 1990.

54. United Nations, 2000. The Role of the United Nations in the $21^{\text {st }}$ Century. 'We the People' Executive Summary. [Online] available from http://www.un.org/ millennium/ sg/report/summ.htm; accessed 8 September 2002; Internet.

55. University of St. Thomas, Minnesota. Quotations on Land. [Online] available from http://www.stthomas.edu/recycle/land.htm; accessed 12 September 2002; Internet.

56. USDA. Census of Agriculture 1992. [Online] available from http://www.nass.usda. gov/census/census92/agrimenu.htm; accessed 14 June 2002; Internet. 
57. USDA, Natural Resource Conservation Service, 2001. National Resources Inventory: Highlights. [Online] available from http://www.nrcs.usda.gov/technical/land/pubs/97 highlights.pdf; accessed 2 December 2002; Internet.

58. Vesterby, Marlow, Ralph E. Heimlich and Kenneth S. Krupta. Urbanization of Rural Land in the United States. USDA/ERS, Agricultural Economic Report No. 673, Washington, DC., March 1994.

59. World Resources Institute. World Resources 1996-97, A Guide to the Global Environment: the Urban Environment. [Online] available from http://www.wri.org/ wri/wr-96-97/ee txt2.html; accessed 8 September 2002; Internet. 